\title{
ANTITRUST AND COMPETITION IN HEALTH CARE MARKETS
}

\author{
Martin Gaynor \\ William B. Vogt
}

Working Paper 7112

http://www.nber.org/papers/w7112

\author{
NATIONAL BUREAU OF ECONOMIC RESEARCH \\ 1050 Massachusetts Avenue \\ Cambridge, MA 02138 \\ May 1999
}

Prepared for the Handbook of Health Economics, Anthony J. Culyer and Joseph P. Newhouse, Editors, Amsterdam: North-Holland. We gratefully acknowledge support from the Robert Wood Johnson Foundation and from the National Bureau of Economic Research. We wish to acknowledge Deborah Haas-Wilson for many extensive conversations and discussions that were instrumental in helping to frame much of the material in this chapter. Thanks also go to Bob Berenson, Bob Bloch, David Dranove, Winand Emons, Roger Feldman, Ted Frech, Mark Pauly, Joe Newhouse, Tom Philipson, Carol Propper, Bill Sage, Mark Satterthwaite, Mike Scherer, and Dennis Yao. The usual caveat applies. Antitrust and Competition in Health Care Markets. The views expressed herein are those of the authors and do not necessarily reflect the views of the National Bureau of Economic Research.

(1) 1999 by Martin Gaynor and William B. Vogt. All rights reserved. Short sections of text, not to exceed two paragraphs, may be quoted without explicit permission provided that full credit, including ${ }^{(0)}$ notice, is given to the source. 
Antitrust and Competition in Health Care Markets

Martin Gaynor and William B. Vogt

NBER Working Paper No. 7112

May 1999

JEL No. I11, L40, L44, L12, L13, L31, D21

\section{ABSTRACT}

In this paper we review issues relating to antitrust and competition in health care markets. The paper begins with a brief review of antitrust legislation. We then discuss whether and how health care is different from other industries in ways that might affect the optimality of competition. The paper then focuses on the main areas in which antitrust has been applied to health care: hospital mergers, monopsony, and foreclosure. In each of these sections we review the relevant antitrust cases, discuss the issues that have arisen in those cases, and then review the relevant economics literature and suggest some new methods for analyzing these issues.

Martin Gaynor

Heinz School of Policy \& Management Carnegie Mellon University Pittsburgh, PA 15213-3890 and NBER mgaynor@andrew.cmu.edu
William B. Vogt

Heinz School of Policy \& Management Carnegie Mellon University Pittsburgh, PA 15213-3890 wilibear@andrew.cmu.edu 


\section{Introduction}

The U.S. health care system is organized around markets. ${ }^{1}$ There has, however, been ongoing concern about the functioning of these markets, so much so that some have despaired of these markets working at all. The policy response to this concern has been disjointed. Health care markets are subject to many regulations and interventions. Some of these policies have attempted to substitute regulation for competition, regulating entry and investment (certificate of need laws, health planning) or price (all-payer regulation). At the same time, health care markets have been subject to antitrust enforcement. Recent years have seen a shift away from regulatory policies and toward competition. Antitrust policy towards health care markets has become much more vigorous since the early 1970s. Antitrust is intended to ensure the efficient functioning of these markets. As a consequence, competition and antitrust policy have become prominent issues in U.S. health policy.

Economic research is vital to addressing issues of competition and antitrust in health care. This includes issues of market definition and detecting anti-competitive conduct. In rule of reason cases, where benefits are weighed against costs, it includes measuring the loss of consumer welfare resulting from a particular practice against any gains in consumer welfare resulting from it.

In this chapter we consider research issues in the analysis of competition and the application of antitrust to health care markets. ${ }^{2}$ We outline our views on the analytical issues and review the relevant literatures both from health economics and industrial organization and antitrust generally. Our focus is mainly on hospitals and interactions between hospitals and insurers. This is due, in part, to where there has been antitrust activity. Physician markets have been for the most part very unconcentrated, and as such have not lent themselves to the kinds of anti-competitive conduct the antitrust laws prohibit. ${ }^{3}$ Although issues of competition and antitrust in pharmaceutical markets are fascinating and important, they differ in some fundamental ways from markets for health care services, and as such, we exclude them from this chapter. ${ }^{4}$

In what follows we first provide some background on antitrust and health care. We then discuss distinctive features of the health care industry, then proceed to horizontal and vertical issues in antitrust. Finally, we present a set of recommendations for future research.

\section{Background}

The major antitrust statutes of the United States are the Sherman Act (1890), the Clayton Act (1914), and the Federal Trade Commission Act (1914). ${ }^{5}$ The Sherman Act prohibits attempts to restrain trade and attempts to monopolize. Sections 2 and 3 of the Clayton Act prohibit price discrimination, tying, or exclusive dealing that substantially lessen competition or create a monopoly. Section 7 prohibits mergers or other combinations that could reasonably be expected to reduce competition or create a monopoly. The Federal Trade Commission Act created the Federal Trade Commission and prohibits unfair methods of competition which affect interstate commerce. An important law directly relevant to health care is the McCarran-Ferguson Act 
(1948), which exempts the business of insurance from the antitrust laws if regulated by the state (excepting actions such as boycott, intimidation, or coercion).

Antitrust issues in health care have only been an issue where markets are relied upon to a large degree to determine prices and quantities (and other characteristics) of health care services. Thus antitrust enforcement has been relevant only in the United States for the most part, since most other countries have relied mainly on the public sector for price or quantity determination. ${ }^{6}$ Active application of the antitrust laws to the health care sector in the U.S., however, can only be dated to the late 1970 s and early 1980s.

Up until 1975 the courts fluctuated on the application of antitrust to the professions. ${ }^{7}$ The debate was whether the "learned professions," such as law and medicine, were subject to the antitrust laws. For example, in FTC v. Raladam Co., 283 U.S. 643 (1931) it was suggested that medical practitioners "follow a profession and not a trade." On the other hand, the Supreme Court ruled in 1943 that the American Medical Association had violated the antitrust laws by helping the District of Columbia Medical Society to deny staff privileges to physicians in the Group Health Association of Washington, D.C., an early HMO (American Medical Ass'n. $v$. United States, 317 U.S. 519 (1943)).

In a landmark case in 1975, the Supreme Court decided in Goldfarb v. Virginia State Bar (Goldfarb v. Virginia State Bar, 421 U.S. 773 (1975)) that there was no "learned professions" exemption from the antitrust laws. Since that time there has been extensive antitrust enforcement in health care. Sixteen health care cases have been decided by the Supreme Court in the period following Goldfarb. Many more cases have been decided by lower courts. A number of these have struck down activities by medical associations, such as parts of the ethical codes of the American Medical Association and other professional associations which ban advertising, ${ }^{8}$ associations setting fee schedules for their members, ${ }^{9}$ associations prohibiting members from certain practice forms (notably HMOs), ${ }^{10}$ and associations imposing restraints related to standards setting. ${ }^{11}$ The courts have also seen cases involving mergers, denial of staff privileges, exclusive dealing, most-favored-nations contracts, market allocation, and joint ventures (see Miles, 1998, Volume 2 for extensive detail).

In the rest of this chapter we focus on the types of behavior that have both been most relevant in health care antitrust and, in our judgment, are most amenable to economic analysis. We begin in the next section by discussing whether the health care industry is different with regard to implications for the optimality of competition. In section 4 we consider hospital

mergers. Section 5 covers monopsony power and foreclosure, and section 6 contains our conclusions.

\section{Is the health care industry different?}

The economic justification for antitrust enforcement is that competition maximizes social welfare. While in most industries the link between competition and social welfare is (or seems to be) direct, it is not obviously so in health care. Health care markets are usually thought to differ from textbook competitive markets in a number of important ways. Health care markets are 
characterized by multiple imperfections, in large part deriving from the uncertainty and asymmetry of information between buyers and sellers that are inherent in the nature of health and medical care [Arrow (1963), Pauly (1978), Gaynor (1994)]. As a consequence, questions of social welfare must be decided in the context of the second-best. This implies not only that competition may not be second-best, but that as a consequence, antitrust laws should not be enforced in health care markets, or possibly enforced differently in health care than in other markets. Indeed, a common claim has been that health care markets are so fundamentally different from other markets that meaningful competition is either an impossibility or counterproductive. As a consequence, adherents of such views have been in favor of extensive government regulation or production in health care and hostile to the application of antitrust to health care. ${ }^{12}$ It should, however, be pointed out that there are few real world markets that satisfy the requirements for a textbook perfectly competitive market. Most markets are characterized by some imperfections, and in many markets the deviations from the requirements for perfect competition are substantial. The antitrust view is that all markets are special, and that while competition in health care markets should be examined in light of its special character, so should competition in any other market.

In what follows we consider the differences between health care markets and other markets and discuss what is known about the implications of these differences for the optimality of competition in health care markets.

Health care markets differ from textbook markets in the following major ways: the product is differentiated, information is imperfect, there is extensive government regulation, and many firms are not-for-profit. We discuss the general issues associated with these differences and review the health economics literature on these specific imperfections and their implications for the desirability of competition in health care markets.

\subsection{Differentiated product}

Health care is a differentiated product. Health care is a service and all services are by their nature inherently heterogeneous and non-retradable. A haircut, an auto repair, a will preparation, are never the same thing twice. ${ }^{13}$ Further, these products can only be purchased by direct interchange with the seller, thus they cannot be retraded among consumers. This is even more true of made to order, or customized, services, e.g., a fashion makeover, music lessons, catering, investment advice, or representation in divorce proceedings. This certainly applies to health care services, from those which are routine, such as check-ups, to those which are specific to the patient (i.e., made to order, or "customized"). Further, preferences are heterogeneous. Some patients will prefer extensive explanation and discussion of their case, others would prefer the bare minimum. Some will prefer "Cadillac" or "gold-plated" treatment, whereas others will only wish to pay for only that which is adequate or necessary, the "Ford" or "Chevrolet" treatment. This may also be the case with immutable seller characteristics (or those which cannot be changed ex post, like "putty-clay" investment, e.g., a physician's board certification, medical school degree, or a hospital's religious affiliation or neighborhood location). Individuals may prefer physicians of a particular age, sex, race, or ethnic background, or with a particular appearance (tall, short, brown hair, blue eyes, conservatively dressed, fashionably dressed, hip, etc.). Some may prefer a general practitioner for 
their primary care, while others may favor a board certified internist. Similarly, some may prefer a Catholic or Jewish hospital, a hospital with extensive landscaping or modern architecture. Satterthwaite $(1979,1985)$ has stressed the idiosyncratic nature of preferences in the physician services market in particular.

It is this combination of a heterogeneous product with heterogeneous preferences which is key. ${ }^{14}$ As Satterthwaite has argued persuasively, this bestows the seller with market power. Patients choose sellers who produce the type of services and have characteristics which best match their preferences. The fact that patients choose sellers who give them the highest utility gives sellers market power, since switching to another seller will reduce a patient's utility. The less substitutable are sellers for one another, the greater the degree of market power, i.e., the lower is the elasticity of demand a seller faces. In the case of physicians, since the vast majority of physicians are located in urban markets with many other physicians, the market can be characterized as monopolistically competitive. ${ }^{15,16}$ In the case of hospitals, since most hospital markets are characterized by a relatively small number of hospitals interacting over a long period, this implies a differentiated product oligopoly. These are powerful paradigms which can help to explain observed patterns in these markets. In particular, this implies that we should expect sellers to possess power over price in these markets, even absent any form of anti-competitive behavior. Health care markets do not seem to be fundamentally different in this regard from other markets with substantial product differentiation.

Competition may or may not be optimal in markets with product differentiation. The theoretical literature on monopoly and product quality and monopoly and product variety does not provide strong guidance. In general, anything can happen. Competition (monopoly) can result in too little quality or variety, too much, or just the right amount [Spence (1976), Dixit and Stiglitz (1977), Salop (1979), Anderson et al. (1992)]. The intuition is as follows. Competition may underprovide product variety, since competitive firms cannot capture the consumer surplus from additional variety. It thus may not be profitable for competitive firms to offer a product which has positive social value. A monopolist, however, may do so, due to its ability to extract consumer surplus. On the other hand, competition may overprovide product variety. In a competitive market, part of the profit from offering a new variety will come from "stealing demand" from other firms. A firm deciding whether to offer a new variety will not take into account this external effect and thus too much product variety may be offered in a competitive equilibrium. Whether product variety/quality is optimal, insufficient, or excessive depends on whether and which of these two effects dominates. ${ }^{17,18}$

Further, if price is fixed by regulation, then competition can lead to excessive product differentiation, as in models of non-price competition in the (price) regulated airline industry [e.g., Douglas and Miller (1974), White (1972), Van der Weide and Zalkind (1981)]. Some have claimed that, due to insurance, hospitals do not (or did not) compete on price to attract patients, but rather compete solely on quality or facilities to attract patients (or doctors, who then bring patients with them). This has been called the "medical arms race" [Robinson and Luft (1985)]. ${ }^{19}$ This has some plausibility for hospitals prior to the 1980s (although the empirical evidence is weak), since most hospitals were reimbursed on the basis of costs and patients were both heavily insured and unrestricted in their choice of health care provider. This notion of competition 
leading to excessive product differentiation and higher prices through a medical arms race has been influential in at least one antitrust case, in which the judge declared " $[\mathrm{H}]$ ospital rates are lower, the fewer the number of hospitals in an area." 20

What all of this means is that economic theory does not give general guidance to appropriate antitrust policy in markets with significant product differentiation. In this regard health care is no different than many other markets. It is clear that price fixing reduces social welfare. There is little else in the domain of antitrust policy that is clear in general from economic theory. Mergers resulting in increased market power, price discrimination, attempts to deter entry, and attempts to reduce competition may either reduce or increase social welfare. While it may be possible to agree that attempts to reduce entry or eliminate competitors such as limit or predatory pricing $^{21}$ are "unfair" and should not be allowed, the welfare effects of such practices will depend on the specifics in each case.

It is worth pointing out, however, that the antitrust enforcement agencies only concern themselves with short-term anti-competitive impacts. The 1984 Merger Guidelines (U.S. Department of Justice, 1984) specifically state that anti-competitive impacts are of concern for only two years. If product characteristics are fixed for the short term, then the only competitive concern is price competition. Price competition is clearly optimal when product characteristics are fixed and no entry or exit occurs.

\subsection{Imperfect information}

It has long been understood that the structure of information is critical for understanding health care markets [Arrow (1963)]. What is critical is uncertainty and, more importantly for the issues here, asymmetries in information. The important asymmetries lead to moral hazard in health insurance, adverse selection in health insurance markets, and agency problems in health care markets. What is critical here is the extent to which these information problems either impair the workings of health care markets so that competition is ineffective, or are exacerbated by increases in competition. We review these issues as associated with each of these imperfections, in turn.

\subsubsection{Moral hazard in health insurance}

Consumer uncertainty about illness and its associated losses leads to a demand for health insurance. However, since it is difficult to verify the exact nature of the illness and the appropriate treatment, there is an asymmetry of information between the consumer and the insurer leading to moral hazard.

One of most important imperfections in health care markets is the moral hazard effect on consumption due to health insurance [Arrow (1963), Pauly (1968), Zeckhauser (1970)]. The vast bulk of health care bought and sold is covered by insurance. This means that the consumer of the service himself pays only a small fraction of the cost, while the majority is reimbursed by thirdparty payers. Insuring individuals against risk reduces the price they face for medical care, thereby inducing excessive consumption. Since moral hazard induces excessive consumption, it might seem that market power on the part of firms selling health care services could improve 
matters by restricting output [Crew (1969), Frech (1996), Pauly (1998)]. Indeed, for a fixed insurance policy for which there is excess consumption of health care goods and services at the competitive (marginal cost) price, raising the price of health care goods and services above the competitive level increases welfare. ${ }^{22}$

It turns out, however, that if the insurance market is competitive, then setting price at marginal cost in the health care product market is always second-best optimal [Gaynor et al. (1998)]. The insurance market will sell insurance policies that maximize consumer welfare conditional on prices in the health care product market.

Another form of moral hazard is the decreased incentive for consumers to search for the lowest price [Newhouse (1978)]. In general, however, insurance may lead consumers to search less, or more, in equilibrium [Dionne (1984)]. ${ }^{23}$ The presence of insurance will tend to lead to greater dispersion in prices. It is possible that consumers may search more because the increased dispersion in the price distribution means that there is a bigger potential payoff to search, since the expected gap between the current price and the lowest price is larger. On the other hand, since consumers pay only a small fraction of the expense, the payoff to search may still not exceed the costs. The emergence of highly price responsive buyers of health care in the form of managed care plans can be thought of as an institutional innovation in response to this problem.

Therefore in health care markets insurance may lead to quality being the salient competitive factor (as in the medical arms race story). In this case, search may focus entirely on quality. Dranove and Satterthwaite (1992) show that if there is imperfect information about both price and quality then in the case where only information about quality is improved (beyond the level required for first-best quality), both price and quality increase to supra-optimal levels. This result is suggestive of what might happen in health care markets, but not definite, since there is no insurance in the Dranove and Satterthwaite formulation.

Dranove and Satterthwaite (1992) also show that it is possible for increased price information to either decrease or increase welfare. If only information about price is improved (beyond the point necessary for first-best quality), it is possible that consumer welfare will decrease. Price will fall, benefiting consumers, but firms' margins fall enough that quality decreases, causing a net decrease in consumer welfare. It is also possible for the welfare effect of the price decrease to outweigh that of the quality decline, thus resulting in an increase in welfare.

This result occurs in a setting where consumers pay the full price for their purchases. It is not clear that improved information about price will lead to a significant price decrease in health care markets where consumers are heavily insured. Hibbard and Weeks (1989) provide evidence that increased information on prices has little effect on consumers' decisions, in large part due to insurance coverage. Nonetheless, the Dranove and Satterthwaite result may occur in the presence of highly price-responsive managed care plans. Indeed, much of the concern over managed care seems to be due to a perceived emphasis on price at the expense of quality.

\subsubsection{Adverse selection in health insurance markets}


Another form of information asymmetry between consumers and insurers is when consumers are of different risk types known to themselves but not to insurers, leading to adverse selection in health insurance markets. This is another well-known imperfection in health care markets. The classic paper by Rothschild and Stiglitz (1976) shows that competitive insurance markets may fail in the face of adverse selection. When individuals know their risk types but insurers don't, an equilibrium in which both types are pooled in a single insurance contract does not exist. A separating equilibrium may exist in which high risk individuals purchase complete insurance, while low risk individuals purchase incomplete insurance. This equilibrium will not exist if there are "sufficiently few" high risk types. Stiglitz (1977) analyzes the equilibrium insurance contracts offered by a monopolist in the face of adverse selection. He shows that a pooling equilibrium does not exist in the case of monopoly either. In the separating equilibrium the high risk individuals purchase complete insurance. Low risk individuals either purchase partial insurance or no insurance. The terms of low risk individuals' contracts are such that they are indifferent between purchasing insurance and having no insurance.

The welfare comparison between competition and monopoly in insurance markets based on the Rothschild-Stiglitz analysis is unclear. ${ }^{24}$ Competition is suboptimal, but monopoly may be no better. Further, there are other theoretical analyses in which competition does not pose a problem for existence [Spence (1978), Miyazaki (1977), Riley (1979), Wilson (1977), Cave (1986)]. Another issue is that it is possible that the Rothschild-Stiglitz assumption of an immutable risk type known to the individual is not plausible. Some recent evidence indicates that, while there is some persistence among individuals in their health expenditures, this only lasts at most for 4 or 5 years [Eichner et al.(1997)]. In consequence, the normative implications for competition in real world health insurance markets is unclear.

The empirical evidence on the functioning of health insurance markets is mixed. First, it appears that insurers do not price differentially by risk, either because of transactions costs or regulations banning such practices. As a consequence, most analysts are more concerned with favorable selection by insurers (this is often referred to as "cream skimming" or "cherry picking") seeking out good risks and avoiding bad risks, than with adverse selection by individuals [Pauly (1986), Newhouse (1996)]. Second, while it appears there is risk selection in terms of enrollment in HMOs versus conventional insurance plans [Hellinger (1996), Newhouse (1996)], there is also evidence pointing to consumer persistence in their choice of insurance plans [Neipp and Zeckhauser (1986), Madrian (1994), Royalty and Solomon (1997)].

\subsubsection{Agency problems in health care markets}

The product in this market is not a typical service in that sellers (physicians) do not provide only medical care, or treatment, but also diagnosis and advice. The physician is hired to make a diagnosis and provide advice on the appropriate course(s) of action. This, in and of itself, is not unique to health care markets. Repair services generally have this characteristic. An auto mechanic diagnoses a car problem and provides a recommendation for action. ${ }^{25}$ Appliance repairmen operate in the same way. Stockbrokers or financial advisers diagnose an individual's financial situation and advise them on investment strategies and on particular investments. Taxi drivers are told the destination of the passenger and allowed/requested to choose the route. The 
purchase of such services has been analyzed under the literature known as "games of persuasion."26

Such games have the following information structure. The consumer observes a symptom (engine knocking, pain in the side). The consumer observes only the symptom, but does not know the nature of the problem. There is some probability, known to all, that the problem is a serious problem, with an expensive treatment/repair and some probability it is minor (inexpensive treatment). The expert can observe (let's say with certainty) whether the problem is serious or minor, and can perform both the expensive and the inexpensive treatments. ${ }^{27}$ The consumer prefers the appropriate treatment/repair, but cannot observe the problem. Thus, the consumer's choice can only be based on a report that has been sent strategically by the doctor. There is an asymmetry of information between the buyer and seller, and thus an agency relationship. This creates the possibility for the seller to misrepresent the nature of the consumer's problem to him. An incentive to do so exists when the more expensive repair is also more profitable.

This problem has been referred to in the health economics literature as "induced demand" and is another frequently mentioned imperfection in health care markets. While deductively it is plausible that physicians exploit their role as agents to induce some demand from their patients, it is not clear whether this is an empirically significant phenomenon. ${ }^{28}$ The empirical literature on this topic suffers from such severe methodological flaws that it does not provide useful evidence on either the existence or magnitude of this effect [see the chapter by McGuire in this Handbook or Gaynor (1994) or Frech (1995, Chapter 5) for discussion].

The relevant issue here is whether competition leads to more or less inducement. One of the most common attempts to test for demand inducement by physicians takes the form of regressing price against the number of physicians per capita (and controls). The notion is that if the market is competitive, the presence of more physicians implies a greater supply and hence a lower price. Demand inducement, by contrast, is hypothesized to occur in the following way. Entry of more physicians implies a reduction in demand per physician on average. Physicians will thus induce demand to increase their incomes. While this "model" and its empirical testing suffer from severe flaws, what concerns us here is the relationship of inducement to competition.

A number of models with profit maximizing physician firms produce the result that competition reduces or eliminates inducement. Stano (1987) constructs a model in which profit maximizing physician firms choose prices and inducement levels. Stano shows that, so long as entry increases the price elasticity of demand facing the physician firm and marginal inducement costs are constant, entry reduces inducement. ${ }^{29}$ Stano's model does not allow physician firms to leave the local market and move to another one in response to entry. Since exit from a local market does not imply (necessarily) exit from the industry, the only losses from relocation to a new market are the sunk costs of entering a local market, which for physicians are the costs of building a practice. If exit from the local market is a viable strategic choice, exit may further reduce the attractiveness of inducement as a response to entry.

Consider also the following simple competitive model. Physician firms maximize profits. They have constant marginal costs and fixed capacities. The firms have different marginal costs. 
They enter a market when their variable profits exceed the (common) fixed cost of entry. Price is set at the intersection of supply and demand schedules, keeping in mind that supply becomes vertical at industry capacity. Then as demand in a market grows firms will enter in (inverse) order of their marginal costs. Even if firms price at marginal cost, then markets with more physicians will have higher prices. This leads to a positive correlation in equilibrium between price and entry, but implies nothing about demand inducement.

If physician firms are not profit maximizers, but utility maximizers, then it may be possible that income effects can lead to increased inducement in response to entry. However, to our knowledge there are no papers that have analyzed precisely this situation. McGuire and Pauly (1991) find that a monopolist only engages in inducement in response to a (regulated) price decrease if income effects outweigh substitution effects. There is some weak evidence for the existence of income effects in physician labor supply [see Sloan (1975), Hurdle and Pope (1989), Lee and Mroz (1991), Rizzo and Blumenthal (1994)]; however, the results of Rizzo and Blumenthal (1994) show that the substitution effects of a wage change outweigh the income effects by a wide margin. Thus, even if physicians maximize utility (rather than profit) the available evidence is not consistent with an increase in inducement in response to entry and price decreases. While it seems likely that some inducement exists due to asymmetric information and agency problems [Darby and Karni (1973)], neither theory nor current evidence indicate that competition is likely to increase distortions from this market imperfection, but rather just the opposite.

\subsection{Government regulation ${ }^{30}$}

Health care markets are characterized by extensive regulation. Regulations cover market entry (physician licensure, hospital certificate-of-need regulation), pricing (hospital all-payer regulation, insurance premium regulation), product offerings (insurance mandates), and the activities of not-for profit firms (community benefit requirements). Some regulations are not intended to replace competition, but rather to augment it. Regulations like physician licensure or requirements for full information disclosure on insurance coverage are intended to protect consumers who may be poorly informed. Regulations such as these do not affect the desirability of competition.

Other regulations, such as all-payer regulation, are intended to replace market determination of price. Whether competition is beneficial in the presence of such regulations may depend on what particular constellation of regulations are present. For example, when hospitals' prices are controlled by regulation (e.g., all-payer regulation), then competition may occur over services and well could result in supra-optimal levels of service adoption. Certificateof-need regulation may be an optimal response to this situation (the evidence, however, is that certificate-of-need regulation has not been effective). Another example is mandated community rating of premiums for insurance firms, i.e., insurers must charge a single premium to all consumers based on expected losses in the community. It is certainly possible that in this case competition among insurers may take the form of competing for the good risks, i.e., favorable selection, as discussed previously. Such competition is inimical to welfare. The solution may be regulations designed to combat this phenomenon, or removal of the original price regulation. 
Situations like these, however, rarely become the concern of antitrust enforcement. Usually state government does such extensive regulation and this usually supercedes the antitrust laws under a doctrine known as "state action immunity."

\subsection{Not-for-profit firms}

A distinctive institutional characteristic of the health care sector in the United States is the presence of not-for-profit firms. In particular, the hospital sector is dominated by not-for-profit firms. This has led to two issues about the desirability of competition in hospital markets. One question is whether not-for-profit hospitals exercise market power. The alternative that has been advanced is that not-for-profit hospitals seek to maximize the welfare of the community in which they are located, and thus do not exercise market power if given the opportunity. This argument was very influential in a recent court decision to allow the merger of the two largest hospitals in Grand Rapids, Michigan. ${ }^{31}$ The second issue is the impact of increased competition on charity care provided by hospitals. Hospitals, particularly not-for-profit hospitals, provide a lot of charity care to indigent patients. To the extent that such care is financed out of profits, increased competition may reduce charity care. While it is true that financing charity care via monopoly profits is inefficient, charity care which is lost due to increased competition may not be replaced, due to the vagaries of politics. We take these issues up in the next section.

\section{Hospital mergers}

We now turn to a discussion of hospital mergers. Hospital mergers are both one of the most prominent areas of antitrust enforcement in health care and an area where economic analysis plays a critical role. We first provide an overview of the enforcement process and outcomes in section 4.1. In section 4.2 we discuss market definition. Sections 4.3 through 4.5 contain a discussion of merger analysis, focusing in particular on the effect of not-for-profit status. In section 4.6 we review the empirical evidence relevant to hospital mergers.

\subsection{Enforcement}

\subsubsection{Process}

Hospital mergers are covered by the same antitrust laws as are mergers in other industries. In particular, Section 1 of the Sherman Act and Section 7 of the Clayton Act forbid mergers which, in the words of the Clayton Act, "may be substantially to lessen competition, or to tend to create a monopoly". Typically enforcement of the antitrust laws with respect to hospitals works as follows. Section 7A of the Clayton Act requires, in the case of large acquisitions (and hospital mergers are normally large for these purposes), that the merging parties inform the Department of Justice (DOJ) and the Federal Trade Commission (FTC) of their intent to merge. The firms must then wait thirty days, during which time the DOJ and FTC investigate the proposed merger.

During this thirty day period, the agencies may issue a request for additional information to the merging firms, requiring the firms to produce information relevant to the competitive impact of the proposed merger. At this time also, the agencies decide which of them is to pursue 
the matter. The merging firms are then required to wait twenty days after they have complied with the request for additional information before they may consummate the merger.

During this time, the relevant agency may seek a preliminary injunction in federal court to prevent the merger. If the agency is the DOJ, it will seek a preliminary and permanent injunction, typically; whereas, if the agency is the FTC, it will seek a preliminary injunction, pending a trial-like administrative proceeding within the FTC before an administrative law judge. If the agencies fail to obtain a preliminary injunction, the merger can proceed. If the agencies fail to obtain a preliminary injunction, they may still pursue a trial in federal court (DOJ) or the administrative procedure (FTC) in order to force the firms to divest; however, this is not typically done. A decision at the district court stage may be appealed to the circuit court and to the Supreme Court. A decision in the administrative proceeding may be appealed to the full Federal Trade Commission and then to circuit court and to the Supreme Court.

This process may end in a number of ways. Most commonly, the relevant agency takes no action. The agency may also offer to allow the merger, provided that the merging firms agree to some conditions, (for example divestiture of some assets). If the merging firms agree, a consent decree or consent order is the outcome. If the agency decides to try to stop the merger, it must go either to court or to an administrative proceeding, to obtain an order either to enjoin the merger or to force the merged firms to divest. We review (briefly) the decisions in the eleven cases that we know of in which the process has run all the way to a decision in this last stage.

\subsubsection{Framework for analysis}

In deciding whether or not a merger is illegal under the Clayton or Sherman Acts, the courts and the enforcement agencies go through a fairly routinized sequence of steps. We follow Miles (1998) in describing the sequence as a six-step process. ${ }^{32}$ The steps are:

1. Definition of the relevant product market.

2. Definition of the relevant geographic market.

3. Identification of the competitors in the relevant product/geographic market.

4. Calculation of market shares of the competitors and Herfindahl index of concentration.

5. Calculation of merging firms' post-merger market share and the post-merger Herfindahl, and determination of the likely competitive effect of the merger.

6. Consideration of any factors which mitigate or exacerbate anticompetitive effects. $^{33}$

In the definition of the relevant market, both product and geographic, the idea is to find the smallest group of products for which there are not close substitutes. A product is to be 
included in the relevant market if buyers could easily substitute to it in response to a price increase of the merging firms. In addition, a supplier is to be included in the relevant market either if it does produce the same product, or does not produce the relevant product currently, but could easily come to produce it. The Merger Guidelines articulate a test of market definition which, at least in principle, can be implemented. The Guidelines say that the relevant market, both product and geographic, is the smallest market in which the sellers, acting as a cartel, could profitably implement a "small but significant and nontransitory price increase." They later go on to say that, most often, this means a $5 \%$ increase for the period of at least one year.

Once market definition is completed, market shares and concentration indices are straightforward to calculate. There is ambiguity in the hospital industry regarding the proper variable for calculating market shares. Proposals include total revenues, inpatient revenues, beds, admissions, and patient-days. Choosing among these alternatives does not seem to make a substantial difference in the outcome of the calculations. Once the various indices have been calculated, the analyst looks at the post-merger market share, the pre and post merger HerfindahlHirschmann Index (HHI), ${ }^{34}$ and the change in the HHI, as well as other evidence (testimony of competitors and third party payers, for example) in order to determine the likely competitive impact of the merger. No firm standard appears to exist for a concentration index threshold. However, there are guidelines. The Supreme Court (U.S. v. Philadelphia National Bank et al. (1963, 374 U.S. 321)) has found that a post-merger market share of 30\% is high enough to make a merger presumptively illegal. The Merger Guidelines say that a merger which increases the HHI by 50 or more points and results in an HHI of more than 1800 is likely to be anticompetitive and that a merger which increases HHI by 100 or more points and results in an HHI of more than 1000 is also likely to be anticompetitive.

If this evidence and the testimony of competitors and third party payers is strong enough, the merger is presumptively illegal, and the merging firms must present evidence that there are other (non-concentration related) reasons that the merger will have pro-competitive effects. The most common such defense is the efficiency defense. Merging firms argue that they will achieve cost savings by the merger, which will be passed along to consumers in the form of lower prices. Another defense is the failing firm defense, in which the merging firms argue that, without the merger, one of the firms will fail, so that the merger itself will not result in fewer firms (that there will be fewer firms anyway). To make this defense the firms must establish not just that one firm is failing but that there are no other potential buyers for the failing firm. In addition, firms may argue that entry into the market is fast and easy, so that an attempt at supra-competitive pricing will be defeated by entry of new firms.

In hospital merger cases, other defenses have been attempted. Hospitals have argued that they are in a closely regulated industry, and that the government will not permit them to behave in an anti-competitive way. Hospitals have claimed that, since they are not-for-profit firms, they will not behave in an anti-competitive way. Hospitals have claimed that, since there is no price competition in the first place, there is no competition to be protected. Hospitals have also argued that competition in the hospital industry is a bad thing, and that getting rid of it is therefore beneficial to consumers. The analyst must then weight these considerations against the potential 
harms associated with less competition to decide whether the merger will benefit consumers or not.

\subsubsection{Outcomes to date}

Table 1 presents a list of cases. We denote the cases by the name of the city in which the merging hospitals were located. ${ }^{35}$ For the cases the government lost, we provide our reading of the primary reason for the decision. For the sake of brevity, in what follows we generically say "court" where we could mean court, or administrative law judge, or full Federal Trade Commission, since different cases are decided by different entities, depending on the circumstances, as discussed in the preceding section. When the government has prevailed, it has managed to convince the court on steps one through six above. ${ }^{36}$ As can be seen from the table, the government has prevailed in five of the eleven cases, but, before its 1998 victory in Poplar Bluff, had not prevailed in a case since 1991.

\section{[INSERT TABLE 1 HERE.]}

In order to gain some insight into the key questions in these cases, with an eye towards identifying where economic research can provide valuable input, we will proceed through the six steps outlined above, summarizing as we go the typical method that the court uses in its analysis.

In defining the product market in which hospitals compete, courts have typically used a "cluster market" approach. So, a typical product market definition is "general acute care hospital services." However, outpatient care was included in the product market in the Roanoke decision. Later, in the calculation of market shares, this product market definition means that inpatient revenue, beds, or inpatient days for all services are treated as a "single product" for the purpose of measuring market share.

As is discussed, for example, by Baker (1988), this cluster of services approach is likely to overstate the size of the relevant market if the component parts of the cluster are not easily substitutable in demand or supply and if the various hospitals in the relevant geographic market produce the various component services in differing proportions. For example, consider two hospitals, one of which specializes in cardiac care and another in oncology, and suppose that resources are not easily and quickly fungible between these two uses on the supply side. These two hospitals will appear to be competitors in "general acute care hospital services"; whereas they are really operating in totally separate product markets. This is acknowledged to some extent by the courts, as there are some variations in the product market definitions. Some courts have divided the product market into primary/secondary and tertiary inpatient care (Roanoke, Long Island, Poplar Bluff) or into primary and general inpatient care (Grand Rapids).

Geographic market definition has most often relied heavily upon the Elzinga-Hogarty (1973) technique of analyzing shipments data in order to infer the boundaries of geographic markets [Morrisey et al. (1988)]. Using this technique, a putative market is expanded until it encompasses a geographic area large enough so that sales from sellers outside the area to buyers inside the area are small and sales from sellers inside the area to buyers outside the area are also 
small. In other words, the geographic market is expanded until "imports" and "exports" are a small proportion of total sales. In hospital cases this is typically measured by flows of patients (inpatient discharges is the actual measure used) out of and into the area. There are no universally applied cutoffs for these criteria, although the courts follow Elzinga and Hogarty in calling a cutoff of 10 percent a "strong market" and a cutoff of 25 percent a "weak market." This exercise is regarded by the courts as a starting point in market definition. Additional evidence which the courts typically consider are the admitting and referral patterns of physicians, overlap in physician admitting privileges among hospitals, claims by executives of hospitals on whether they consider themselves to be competitors, planning documents of merging and non-merging hospitals, and claims by third party payers about their ability to defeat potential price increases by shifting their patients over geographic space.

Notwithstanding the similarity in the courts' approaches and what appear to be fairly similar facts, there is a great deal of heterogeneity in the outcomes of the market definition process. Geographic markets have been found to be as small as a single county, with a single city as a relevant submarket (San Luis Obispo) to as large as 19 counties (Roanoke) or to include hospitals as far away as 100 miles from the merging hospitals (Dubuque). Several issues come up repeatedly in the disputes over market definition.

First, it is typically found that patients flow from outlying areas into a central city. The hospitals then argue that this militates for including hospitals in rural areas in the relevant market. The government argues that these flows do not establish demand substitutability between rural and urban hospitals, since people flowing from rural to urban areas are seeking different care (are in a different product market, essentially) than are the people staying in the rural area. Alternatively and relatedly, the government argues that the hospitals in the urban area are differentiated from the rural hospitals by reputation, quality, breadth of services, etc. (again, essentially an argument that they are in a different product market). Sometimes the courts accept this argument (Rockford, San Luis Obispo, Grand Rapids, Poplar Bluff) and sometimes they do not (Joplin, Dubuque, Roanoke, Long Island, Ukiah).

Second, the relative importance of managed care and physician loyalty in steering patients to providers is frequently disputed. The government typically claims that since physicians admit to few hospitals (near their offices) and since patients are very loyal to their physicians, geographic product differentiation is extremely important and, therefore, it would be very difficult for managed care plans to channel demand away from local hospitals in response to price increases. The hospitals argue that managed care has great power to channel patients and would do so in response to a price increase. ${ }^{37}$ Again, sometimes the courts find that patients are tightly tied to their local doctor and hospital (San Luis Obispo, Chattanooga, Rockford, Poplar Bluff) and sometimes the courts find that they are easily directed to distant hospitals by financial incentives and selective contracting (Joplin, Dubuque, Ukiah, Long Island). ${ }^{38}$

The calculation of market shares and HHI proceeds once the relevant market has been decided. The shares are usually based upon such things as beds, admissions, revenue, or patientdays, and differing choices among these measures do not produce noticeably different results, at least in the decisions where more than one of them are presented. Table 2 presents values for 
post-merger share, post-merger HHI, and change in HHI for mergers in which these figures could be gleaned from the decision. In all cases the market definition settled upon by the court was used.

\section{[INSERT TABLE 2 ABOUT HERE.]}

With few exceptions these markets are very concentrated, the merging firms would command a large market share post-merger, and the HHI would increase a great deal as a result of the merger. ${ }^{39}$ For the most part, the government theorizes that anticompetitive effects will take two forms. First, transaction prices paid to managed care organizations will rise with the increase in market power caused by the merger. Second, quality of care will fall, as hospitals gain market power in their competition for patients whose payers pay a fixed, non-negotiable fee (Medicare and Medicaid). With the exception of Roanoke, it is reasonably clear that in all of the mergers in the table the government met its prima facie case for anticompetitive effects, using either the market share test or the standards in the merger guidelines. Of the cases in the table, the government lost in Grand Rapids, Joplin, and Roanoke.

Hospitals in merger cases argue that there will be efficiencies from the merger. These claimed efficiencies typically are to result from consolidated operations, savings on administrative expenses, improved management practices, elimination of duplicative facilities and equipment, and, sometimes, via the elimination of cost-increasing competition ("medical arms racing"). In hospital merger cases, as in antitrust cases in general, the efficiency defense is very hard to make successfully. Cost savings are usually speculative and disputed. Neither the realization of the cost savings nor the passing along of the savings to consumers is easily enforceable. Courts usually regard the efficiency defense with skepticism.

In hospital merger cases, courts have sometimes found the efficiency claims plausible. In the Grand Rapids case, the District Court's decision in Augusta, the Roanoke case, the Long Island case, and the Ukiah case, the courts found that the mergers would generate significant efficiencies. These courts found both that there would be operating efficiencies from the consolidation of laundry, administration, and similar functions and that there would be savings associated with reducing non-price competition. In the Roanoke case, the court found that "hospital rates are lower, the fewer the number of hospitals"; in the Grand Rapids case, the court found that the merger would serve to end the "medical arms race" which was previously occurring; in the Augusta case the court found that the merger would eliminate wasteful duplication of services caused by "a desire among those who administer hospitals to have expensive equipment because other hospitals have it." In the Ukiah case, the administrative law judge found that hospital costs were lower in one hospital than in two hospital towns and that this was indicative of wasteful non-price competition.

In cases involving the merger of not-for-profit hospitals, the merging parties often argue that their not-for-profit status makes it unlikely that they will exercise any market power which they gain. Again, there is heterogeneity in courts' willingness to accept this argument. The decisions range from the District Court in Augusta saying "The board of University Hospital is quite simply above collusion," to Judge Posner in HCA vs. FTC (1986, 807 F2d 1381) saying "no 
one has shown that [nonprofit status] makes the enterprise unwilling to cooperate in reducing competition ... which most enterprises dislike and which nonprofit enterprises may dislike on ideological as well as selfish grounds" and the court in Rockford which found that the two nonprofit hospitals in that case had, in fact, colluded in the past. The court in the Grand Rapids case found the not-for-profit defense quite persuasive. It referred repeatedly in its opinion to Lynk (1995a) and to an analysis done by Lynk on behalf of the defendants (see Lynk and Neumann, 1999 for similar analysis using the same data), which find that not-for-profit hospitals do not mark up their prices in concentrated markets, and remarked repeatedly on the unchallenged nature of the findings. It is worth noting as well that the government's only success in recent years has come in Poplar Bluff, where both hospitals in the proposed merger were forprofit, so that this defense did not arise.

We now turn to a discussion of what we see as the principle points on which economic scholarship would be useful in improving the analysis of merger cases. We will consider in turn, market definition, the effects of merger on competition, the effect of ownership status on competition, and the efficiency defense.

\subsection{Market definition}

\subsubsection{Background and issues}

In hospital merger cases, it seems apparent that market definition is the most important issue. When the government has succeeded in convincing courts to adopt its preferred product and geographic market, it has typically won (the leading exception being the Grand Rapids case). Market definition is always an important component of antitrust cases, with the party seeking to block a proposed merger, often the government, arguing for a narrow market and therefore fewer competitors and the merging parties arguing for a broad market with correspondingly many competitors. In the 1997 Horizontal Merger Guidelines (Department of Justice and Federal Trade Commission, 1997) the FTC and DOJ have articulated a test for market definition. ${ }^{40}$ The Guidelines are explicit that market definition considers only demand substitution and not supply substitution. A market is the smallest group of competing firms such that they could, acting in coordination (the guidelines say a "hypothetical monopolist"), raise their prices by more than 5\% profitably $^{41}$ for at least one year (DOJ and FTC, 1997). This market definition may, in principle, be implemented by an analyst in possession of the full demand system faced by the relevant universe of hospitals (Scheffman and Spiller, 1987; see also Froeb and Werden, 1992). ${ }^{42}$ Many methods for market definition have been proposed. Here we describe those that have been employed in analyzing hospital markets. ${ }^{43}$ In the next section we describe a proposed method for hospital market definition using commonly available data.

There are two important dimensions of market definition in hospital merger cases, product market and geographic market. As we discussed above, the product market is typically taken to be "general acute care inpatient hospital services" or some functional equivalent. Hospitals are thought to have little market power, in practice, in outpatient care, since there are a large number of actual competitors and since entry into this market is relatively easy. By definition, only hospitals are in the market for inpatient care. As was discussed previously, this 
definition is problematic. Economic product market definition depends on both demand and supply substitutability. There does appear to be some substitutability in demand between inpatient and outpatient care, as, for example, one effect of Medicare PPS is thought to have been the substitution of outpatient and home health for inpatient care (Eldenburg and Kakapur, 1997; Kenney, 1991; ProPAC, 1995). ${ }^{44}$ On the supply side, treating aggregate inpatient services as a product is not likely to be problematic if there is easy substitution on the supply side among different categories of inpatient care or if hospitals provide inpatient care of different types in relatively fixed proportions. ${ }^{45}$ Both theoretical and empirical research is needed in this area.

The determination of the geographic market has been subject to more research. A common method of market definition in antitrust cases has been the analysis of "shipments data." In many states, there are detailed discharge data detailing the residential location and hospital chosen by each hospital inpatient. It is possible, through the use of such data, to define markets using the method of Elzinga and Hogarty (1973). ${ }^{46}$ The market is defined by increasing the size of the potential market until some threshold for both exports (termed LOFI = "Little out from inside" $\equiv 1-\frac{\text { patient inflows }}{\text { patients treated in area }}$ ) and imports ( termed LIFO = "Little in from outside" $\equiv 1-\frac{\text { patient outflows }}{\text { patients from the area }}$ ) is crossed. No threshold is universally applied, but $75 \%$ and $90 \%$ are focal numbers in court decisions, since they appear in Elzinga and Hogarty $(1973,1978)$.

The Elzinga-Hogarty market definition method is attractive since it can be calculated in a fairly straightforward way with commonly available discharge data; however, this method suffers from theoretical shortcomings. As has been detailed by Werden (1990, 1981), an ElzingaHogarty market may overstate or understate the true size of the market. The producers in two markets may be very close substitutes for one another, though no product flows between them, if, for example, their products are very close substitutes and are priced similarly. In this case, no product will flow between the putative markets (since consumers economize on transport costs). As the putative markets are not truly distinct, were the producers in one putative market to increase their prices, product would flow between them. Conversely, producers in two different markets may be selling widely differentiated products, so that there are considerable flows between the markets caused by consumers seeking out their more preferred products. However, this does not imply that the producers are in the same market, since their products are widely differentiated and therefore the price of one product in one market does not effectively constrain the price of the other product in the other market. This issue arises often in hospital markets when a large "tertiary care" hospital providing a wide range of services draws patients from outlying areas, which are served by much smaller "primary care" hospitals. Though there is flow between the two markets, there may not be much in the way of substitution possibilities between the products produced in the two markets.

In the scholarly literature, a wide variety of market definition techniques have been employed, with considerable controversy concerning appropriate methodology. These market definitions have included the Elzinga-Hogarty method discussed above. Another method is the "fixed-radius" technique (Robinson and Luft , 1985; Gruber, 1994) in which a hospital's market is defined to be an area 5 or 10 or 15 miles in radius around the hospital. Still another type is the 
"variable radius" technique Melnick et al., 1992; Gruber, 1994) in which a hospital's market is, in essence, a weighted average of fixed radius markets, where the weights come from observed or predicted market shares in zip codes. The most common definitions are political or census divisions such as counties, Metropolitan Statistical Areas (MSA), Health Services Areas (HSA), urbanized areas, etc. (Romeo et al., 1984; Lynk, 1995a; Dranove et al., 1992).

There has been relatively little work in providing either theoretical or empirical justification for these choices. There are exceptions, however. Phibbs and Robinson (1993) attempt to validate fixed radius limits with variable radius measures. Makuc et al. (1991) validate their aggregates of political subdivisions with Elzinga-Hogarty measures. Dranove and Shanley (1989) criticize both fixed radius limits and political subdivisions, showing that even relatively carefully defined political division measures suffer from problems. All of these methods also are subject to Werden's critique, since they do not take account of price and substitution possibilities.

\subsubsection{A proposed method}

We now briefly outline what one would like to do in order to measure geographic hospital markets, and then discuss why this procedure has not been feasible to date.

Suppose there are three hospitals pricing, as the Guidelines suggest, Bertrand ${ }^{47}$ at $P_{1}, P_{2}, P_{3}$ and producing quantities, $Q_{1}, Q_{2}, Q_{3}$ at constant marginal costs, $c_{1}, c_{2}, c_{3}$. We wish to know if firms 1 and 2 are in the same market, as defined by the Guidelines. The firms price as:

$$
P_{i}=c_{i}-Q_{i} / \frac{\partial Q_{i}}{\partial P_{i}}
$$

Here, $\frac{\partial Q_{i}}{\partial P_{i}}$ is both demand and residual demand, by the Bertrand assumption. Now, following the Guidelines, imagine a hypothetical cartel of firms 1 and 2. Pricing by the cartelized firms is at:

$$
\begin{gathered}
P_{1}=c_{1}-Q_{1} / \frac{\partial Q_{1}}{\partial P_{1}}-\left(P_{2}-c_{2}\right) \frac{\partial Q_{2} / \partial P_{1}}{\partial Q_{1} / \partial P_{1}} \\
P_{2}=c_{2}-Q_{2} / \frac{\partial Q_{2}}{\partial P_{2}}-\left(P_{1}-c_{1}\right) \frac{\partial Q_{1} / \partial P_{2}}{\partial Q_{2} / \partial P_{2}}
\end{gathered}
$$


The above two equations, the structural demand equations $Q_{i}\left(P_{1}, P_{2}, P_{3}\right)$, and the assumption of constant $P_{3}$ suffice to solve for the new, cartelized $P_{1}^{c}, P_{2}^{c}$ and $Q_{1}^{c}, Q_{2}^{c}$. Also, the average price increase from the hypothetical cartelization can be calculated as:

$$
\frac{\frac{P_{1}^{c} Q_{1}^{c}+P_{2}^{c} Q_{2}^{c}}{Q_{1}^{c}+Q_{2}^{c}}-\frac{P_{1} Q_{1}+P_{2} Q_{2}}{Q_{1}+Q_{2}}}{\frac{P_{1} Q_{1}+P_{2} Q_{2}}{Q_{1}+Q_{2}}}
$$

The Guidelines suggest that if the price increase is at least $5 \%$, then the two firms are in the same market. ${ }^{48}$ If not, then a $3^{\text {rd }}$ firm is added, and so on. Notice that this method (the method of the guidelines) is subject to the "reverse cellophane fallacy" critique detailed by Froeb and Werden $(1992) .^{49}$

This method requires that the researcher be in possession of the full demand structure facing firms. This typically requires knowledge of a very large number of cross-price elasticities of demand, and absent some method for reducing this curse of dimensionality, market definition along these lines is likely to be problematic. As a simple example, consider the following constant elasticity market demand curve for product $j$,

$$
\ln \left(q_{j}\right)=\alpha_{j}+\sum_{k} \eta_{j k} \ln \left(p_{k}\right)+\varepsilon_{j}
$$

where $\eta_{j k}$ is the elasticity of good $j$ with respect to the price of good $k$. If there are $\mathrm{N}$ goods there will be $\mathrm{N}^{2}$ elasticity parameters to estimate. ${ }^{50}$ This can potentially be a very large number. There are, however, promising avenues for addressing this curse in hospital markets. In what follows we describe a method for estimating demand using data on individual patient choices that allows us to overcome this curse of dimensionality and use demand estimates to define markets.

Since the choice of which hospital to patronize is discrete, it is natural to structure the demand for hospital services using discrete choice models (McFadden, 1974, Berry, 1994, Berry et al., 1995). The utility to patient $i$ of consuming care at hospital $j$ is:

$$
U_{i j}=\delta_{j}-O p_{j}-\chi d_{i j}+\varepsilon_{i j}
$$

In this notation, $\delta_{j}$ is the mean utility ("quality") of hospital $j^{51}, p_{j}$ is the price of hospital $j$ 's services, $d_{i j}$ is the distance from patient $i$ 's residence to hospital $j$, and $\varepsilon_{i j}$ is the idiosyncratic part of consumer $i$ 's evaluation of hospital $j$. It is well documented that the physical distance from a patient's residence to a hospital is a major determinant of choice of hospital. In fact, there is a moderately large literature on the subject (see Burns and Wholey, 1992, Garnick et al., 1989, and references therein). 
A consumer chooses hospital $j$ if the utility derived from going there is higher than any other alternative (we ignore outside goods, although it would not be hard to include them). The parameters of the utility function in equation (4-6) can be estimated using data on individual consumer choice of hospital. Market share for hospital $j$ is the probability of an average consumer choosing hospital $j$. Market demand for product $j$ is the product of its market share and the number of consumers in the market. Cross-price elasticities can then be calculated from market demand. Note that if we assume that the $\varepsilon_{i j}$ are distributed Type I extreme value (logit) this requires estimating only a single parameter on price, and thus avoids the dimensionality problem. This approach to addressing the curse of dimensionality is discussed, for ex ample, by Berry et al. (1995).

In practice hospital choice is a complex combination of the consumer's choice of health plan, the health plan's choice of providers to contract with, the consumer's choice of physician, and the consumer-physician-health plan choice of whether and where to admit the consumer. The choice model above implicitly combines all of these. Modeling all of these choices simultaneously is probably too demanding, but it would be useful in practice to interact whatever health plan or physician variables are available with the above characteristics.

In additive random utility models such as the one above, in which $\varepsilon_{i j}$ is independent across consumers, implausible substitution patterns among products at the consumer level are generated. In particular, the slope of demand in both own and rival's price are dependent only upon choice probabilities. That is, two products with identical choice probabilities will have identical own-price slopes and identical cross-price slopes with all other products. In the case of logit demand, the slope of the demand for product $j$ in its own price is $-\alpha s_{j}\left(1-s_{j}\right)$, where $s_{j}$ is product $j$ 's choice probability. Furthermore, the slope of $j$ 's demand curve in the price of another product, $k$, is $\alpha s_{k} s_{j}$, where $s_{k}$ is product $k$ 's choice probability. Clearly if another product, $l$, has the same market share as $j$ then it will have identical own price and cross-price effects.

These undesirable properties of the individual level demand curves carry over to the market level demand curves faced by firms if consumers are identical (except for realizations of $\left.\varepsilon_{i j}\right)$. However, if there is consumer heterogeneity and there are interactions between consumer and firm characteristics, then the undesirable properties need not carry over to market demand curves. In this case, $d_{i j}$, the distance from the consumer to the firm, is such an interaction. It arises from the interaction of a consumer characteristic (location) and a firm characteristic (location). The consequence of this is that hospitals which are physically closer to one another will be better substitutes than are hospitals further apart. For more complete discussion of these issues, see Berry (1994) and Berry et al. (1995).

It is easy to see, in a simple example, that the tie between market shares and substitution patterns is broken by including the interaction. Suppose that there are three locations, 1, 2, 3. Hospital A is in location 1 as are a share $\lambda_{1}$ of consumers. Hospital B is in location 3 as are a share $\lambda_{3}$ of consumers. The remaining share $\lambda_{2}$ of consumers are located between the two 
hospitals at location 2. The locations are arranged on a line with one mile separating location 1 from location 2 and one mile separating location 2 from location 3:
A
B
$1 \quad 2 \quad 3$

If the $\varepsilon_{i j}$ are distributed type I extreme value, $\gamma=1$ and $\delta_{A}=\delta_{B}=0$ (so that choice only depends on distance and price), then the unconditional choice probabilities of hospitals $\mathrm{A}$ and $\mathrm{B}$ are:

$$
\begin{aligned}
& s_{A}=\lambda_{1} s_{1 A}+\lambda_{2} s_{2 A}+\lambda_{3} s_{3 A} \\
& s_{B}=\lambda_{1} s_{1 B}+\lambda_{2} s_{2 B}+\lambda_{3} s_{3 B}
\end{aligned}
$$

where $s_{1 A}$ is the conditional probability of A being chosen by consumers in location 1 , and so on for the other conditional probability terms.

The conditional probabilities $s_{1 A}, s_{2 A}, s_{3 A}$ have the usual multinomial logit form, so that the derivatives are:

$$
\begin{aligned}
& \frac{\partial s_{A}}{\partial p_{A}}=-\alpha\left(\lambda_{1} s_{1 A}\left(1-s_{1 A}\right)+\lambda_{2} s_{2 A}\left(1-s_{2 A}\right)+\lambda_{3} s_{3 A}\left(s_{3 A}\right)\right) \\
& \frac{\partial s_{A}}{\partial p_{B}}=\alpha\left(\lambda_{1} s_{1 A} s_{1 B}+\lambda_{2} s_{2 A} s_{2 B}+\lambda_{3} s_{3 A} s_{3 B}\right)
\end{aligned}
$$

These two expressions are equal in absolute value (only because there are only two hospital choices, however, i.e., $1-s_{1 A}=s_{1 B}$, and so on).

As discussed by Berry (1992) and Berry et al. (1995) the problems in the market level substitution patters arise in additive random utility models because all price effects are determined by a single price parameter, $\alpha$, and the vector of choice probabilities (or, equivalently, the product-specific mean utility levels, $\delta$ ). Our point is that the above slopes are not dependent only upon the choice probabilities, $s_{A}, s_{B}$. They are also dependent upon $\lambda$. Evaluating at $p_{A}=p_{B}, s_{2 A} s_{2 B}$ is greater than either $s_{1 A} s_{1 B}$ or $s_{3 A} s_{3 B}$, so that any re-allocation of consumers from location 2 to locations 1 and 3 would decrease the slope of hospital A's demand curve with respect to either $p_{A}$ or $p_{B}$. Thus, with geographically distributed consumers and hospitals, the particulars of the distribution of consumers and firms affects substitution elsticities directly (not only via market shares), so that the one to one correspondence between market shares and substitution elasticities is broken.

Since $d_{i j}$ is an interaction effect, the distribution of the $d_{i j}$ in the population is relevant to the slopes of the demand curves, especially since $d_{i j}$ will not be independent across choices. 
Obviously, with more hospitals and locations, one would see more interesting effects of the $d_{i j}$ as hospitals closer to one another in geographic space would be better substitutes than would hospitals further apart.

Assuming that a consistently estimated model of the above type is available, all of the relevant demand elasticities, including own and cross-price elasticities may be calculated. This will allow us to perform the test described above in order to establish the size of the market. Additionally, if we possess cost information and are willing to make assumptions about (or have measurements on) price-setting in the market, we can simulate the effects of merger. Indeed, there is a recent literature concerning the use of "unilateral" theories of market power in differentiated products industries (Werden and Froeb, 1994, Baker, 1997, Werden, 1997). To evaluate product market aspects of market definition (say primary vs. secondary vs. tertiary) additional interactions, either explicitly on consumer characteristics or implicitly via random coefficient modeling, would be needed.

These techniques, potentially at least, offer the ability to assist with product as well as geographic market definition. By including hospitals' characteristics, both measured and unmeasured, in interaction with consumer characteristics, both measured and unmeasured, in $U_{i j}$, it is possible to evaluate the "locations" in both geographic and product space of various hospitals. This would allow for substitution among providers to differ based upon (for example) "tertiary-ness" or "quality" and based upon the patient population under examination. Using such a model, it would be possible to evaluate whether or not patient flows from rural to urban areas truly represent substitution possibilities or just variation in the perceived product market location of hospitals.

The analysis described above requires that the demand system for the hospitals be estimated correctly. In particular, the parameter on price must be estimated correctly. Demand systems of roughly this type have been estimated in the hospital choice literature (see Burns and Wholey, 1992, and Garnick et al., 1989 and references therein). The chief difficulty with using the estimates from these studies for the purposes described above is that there are significant econometric problems with the estimation of the coefficient on price, leading most researchers to regard these coefficient estimates as highly suspect. There are two main sources of econometric difficulties.

First, the price data typically used in such estimations are list prices, or "charges." These prices are not the prices faced by the relevant decision-makers. To the extent consumers are the relevant decision-makers, they are insulated from prices by insurance, which often pays all or most of the costs of a hospital stay. To the extent that health insurance plans are the relevant decision-makers (through their choice of provider network), charges mismeasure the prices they face, since managed care plans typically negotiate substantial discounts from list charges, or negotiate reimbursement schemes with hospitals which are not directly based upon charges. At best, these two facts mean that there is substantial measurement error in the price variable, and (intuitively, at least) this tends to bias $\alpha$ toward zero. ${ }^{52}$ 
Second, standard discrete choice techniques encounter significant problems when there is substantial unmeasured quality, specifically if there is correlation across consumers in the idiosyncratic portion of consumers' evaluations of providers. If in addition to being unobserved to the analyst these variations in quality are (at least partially) observable to patients (e.g., through experience, the experience of friends, or the evaluations of their physicians), then there is good reason to believe that unmeasured (by the analyst) quality enters systematically into consumer decision-making. ${ }^{53}$ Since hospitals will take into account consumers' perceptions of quality in their price-setting behavior, hospitals' prices will be correlated with unmeasured quality [see Berry et al. (1995) for this argument developed fully]. Again, reasoning intuitively, one would expect high unobserved quality hospitals to be able to charge higher prices and to, nevertheless, receive "unexplainably" high demand. This is likely to lead to a negatively biased estimate of $\alpha$.

Both of these influences on $\alpha$ are in the same direction (assuming that $\alpha$ is positive); thus, we should expect conventional discrete choice techniques to underestimate the (absolute value of) elasticity of demand facing hospitals. In the hospital choice literature, measures of price $\alpha$ are frequently found to be negative or to have implausibly small positive values. Luft et al. (1991) estimated structural demand elasticities facing California hospital for Coronary Artery Bypass Graft surgery, using a hospital choice model like the one described above. They found own-price elasticities of demand for this service in the neighborhood of -1 . This estimated elasticity leads to very high predicted markups for hospital care for any standard equilibrium model of price-setting. Given the low level of accounting profits generated by hospitals, such markups seem implausible. ${ }^{54}$

The solution to both of these problems is instrumental variables estimation. The issue, as always, is finding suitable instruments. In the section 4.3 we develop a model of hospital price and quality setting. Identification of a hospital pricing equation based on the theoretical model is discussed in section 4.3.3.

\subsubsection{Managed care and market definition}

As mentioned in section 4.1, the impact of managed care on geographic markets has emerged as a critical issue in a number of hospital merger cases. The standard intuition has been that managed care will expand the size of hospital geographic markets as a result of their aggressively shopping on price. An alternative story is that since managed care plans compete for consumers based in part on their provider networks, competitive pressures will lead to their networks being more inclusive that imagined by the standard intuition. Thus there may be little or no impact of managed care on the size of the hospital geographic market. As was mentioned previously, research by Mobley and Frech (1997) that shows no significant impact of managed care coverage on observed consumer travel for hospital services in California is presumably consistent with this story.

Consider the following structure for examining this issue. Each insurer faces a demand for its services as a function of its price (the premium), benefits (coverages, cost-sharing, rationing mechanisms, etc.), provider network, and other factors that shift demand, such as the 
distribution of consumer distances to hospitals, other hospital characteristics, consumer risk aversion, etc. ${ }^{55}$ Their costs will depend on wages and other factor prices, the characteristics of the insurance product, and the prices they pay providers.

Insurers will choose premia, benefits, and hospitals for their networks to maximize profits. This will result in a derived demand for each hospital by each insurer which is a function of the number and characteristics of covered the lives of the insurer, the probability that the hospital is in the insurer's network, and the probability that various competing hospitals are in the insurer's network. This will yield a derived demand system for hospitals in a managed care environment.

Note that all insurers do not have to be managed care plans. An insurer's network can include all hospitals, as in conventional insurance. Assuming it is feasible to do so, estimating this system will provide own and cross-price elasticities of hospital demand, which can then be employed for the purposes of market definition as described in the preceding section. ${ }^{56}$ Examining the effect of managed care on hospital market definition would amount to simulating the effects that changes in managed care's market share will have on market boundaries.

This description is not intended as a blueprint for analysis in this area, it simply provides a starting point in terms of a framework for thinking about the issue. In particular, identification must be derived from a fully specified structural model of the insurance and hospital markets.

\subsection{Mergers, conversions, and ownership status}

In the next few sections we outline a general structure for thinking about hospital competition, ownership, mergers, and conversions. The structure is used to analyze parts of the hospital competition literature and its relevance to antitrust policy.

Hospitals sell products that are differentiated on a number of dimensions. Hospitals have their physical plant in distinct geographic locations, and consumers are known to value hospitals that are close to their homes. Hospitals have different religious affiliations. They are differentiated in the breadth of product line they offer, in the technological sophistication of their services, in the quality of the "hotel" services they offer, in their use and deployment of staffing, in their mortality rates, and probably in other dimensions as well. It seems reasonable, therefore, to model hospital competition and hospital mergers using models of differentiated oligopoly (see, for example, Hausman and Leonard, 1997, Werden, 1997, Anderson et al., 1992, Baker and Bresnahan, 1985).

An added complexity in the case of hospitals is that many hospitals are not-for-profit organizations. A literature has grown up around the idea that hospitals, unlike other firms, do not maximize profits, but rather some utility function, possibly reflecting the preferences of the board of trustees, the administrators, the employees more generally, or the physician staff (Newhouse, 1970, Pauly and Redisch, 1973, Lee, 1971, Sloan and Becker, 1982, Philipson and Lakdawalla, 1997). 
We present a simple theoretical model of hospital behavior in order to focus our discussion of hospital mergers. This model is not fully general, and one should keep this in mind in reading it. Each firm owns and operates a single hospital. Hospitals maximize a utility function, $U(\pi, Q, a)$. $\pi$ are the profits earned by the hospital, $Q$ is the quantity of output produced by the hospital, and $a$ are characteristics of the output produced by the hospital. We are intentionally vague about the interpretation of $a$. It may be quality, charity care, technological sophistication, educational activities, "status," or some other attribute of hospital services hospital administrators care about. ${ }^{57}$ To ease exposition, we will simply refer to $a$ as quality throughout, however. In pursuit of their goals, hospitals choose the quantity of their output and the characteristics of their product, taking into account that they are acting in a market in which other firms are present.

Hospitals are assumed to produce products differentiated (potentially) by $a$ and by location. Demand facing hospital $i$ is represented as $P^{i}=D^{i}\left(Q^{i}, a^{i}, \mathbf{Q}^{-i}, \mathbf{a}^{-i}\right)$. Using a characterization of the equilibrium of the game and solving out for other firms actions (see Baker and Bresnahan (1987), for example), we may write firm $i$ 's residual demand, $\bar{D}^{i}$, as

$$
P^{i}=\bar{D}^{i}\left(Q^{i}, a^{i}\right)=D^{i}\left(Q^{i}, a^{i}, \mathbf{Q}^{-i}\left(Q^{i}, a^{i}\right), \mathbf{a}^{-i}\left(Q^{i}, a^{i}\right)\right)
$$

The elasticity of residual demand is a function of demand elasticity, cross-demand elasticities, and the elasticities of the response functions of rivals, as perceived by the firm:

$$
\begin{aligned}
& \bar{D}_{1}^{i}=\frac{\partial D^{i}}{\partial Q^{i}}+\sum_{j \neq i} \frac{\partial D^{i}}{\partial Q^{j}} \frac{\partial Q^{j}}{\partial Q^{i}}+\sum_{j \neq i} \frac{\partial D^{i}}{\partial a^{j}} \frac{\partial a^{j}}{\partial Q^{i}} \\
& \bar{D}_{2}^{i}=\frac{\partial D^{i}}{\partial a^{i}}+\sum_{j \neq i} \frac{\partial D^{i}}{\partial Q^{j}} \frac{\partial Q^{j}}{\partial a^{i}}+\sum_{j \neq i} \frac{\partial D^{i}}{\partial a^{j}} \frac{\partial a^{j}}{\partial a^{i}}
\end{aligned}
$$

Following the conjectural variations empirical literature, is sometimes convenient to rewrite these as follows, so that $r_{Q}$ is the firm's "conjectural variation" arising from a quantity change and $r_{a}$ is the conjectural variation arising from a quality change ${ }^{58}$ :

$$
\begin{aligned}
& \bar{D}_{1}^{i}=\frac{\partial D^{i}}{\partial Q^{i}}\left(1+\sum_{j \neq i} \frac{\partial D^{i}}{\partial Q^{j}} \frac{\partial Q^{j}}{\partial Q^{i}} / \frac{\partial D^{i}}{\partial Q^{i}}+\sum_{j \neq i} \frac{\partial D^{i}}{\partial a^{j}} \frac{\partial a^{j}}{\partial Q^{i}} / \frac{\partial D^{i}}{\partial Q^{i}}\right)=\frac{\partial D^{i}}{\partial Q^{i}}\left(1+r_{Q}\right) \\
& \bar{D}_{2}^{i}=\frac{\partial D^{i}}{\partial a^{i}}\left(1+\sum_{j \neq i} \frac{\partial D^{i}}{\partial Q^{j}} \frac{\partial Q^{j}}{\partial a^{i}} / \frac{\partial D^{i}}{\partial a^{i}}+\sum_{j \neq i} \frac{\partial D^{i}}{\partial a^{j}} \frac{\partial a^{j}}{\partial a^{i}} / \frac{\partial D^{i}}{\partial a^{i}}\right)=\frac{\partial D^{i}}{\partial a^{i}}\left(1+r_{a}\right)
\end{aligned}
$$

Hospitals solve: 


$$
\begin{aligned}
& \max _{Q, a} U(\pi, Q, a) \\
& \pi=p Q-C(Q, a) \\
& \text { s.t. } \pi \geq \pi^{L}
\end{aligned}
$$

where we assume that $\pi^{L}$ is a lower bound on hospital profits and that the functions $U$ and $C$ are typical well behaved utility and cost functions.

The first-order conditions for a maximum can be easily manipulated to yield:

$$
\begin{aligned}
& P=C_{1}-\frac{U_{2}}{U_{1}+\lambda}-Q \bar{D}_{1} \\
& C_{2}=Q \bar{D}_{2}+\frac{U_{3}}{U_{1}+\lambda}
\end{aligned}
$$

Here the subscript on $C_{1}$ denotes a partial derivative with respect to its first argument, quantity. $\lambda$ is the LaGrange multiplier on profits. Assuming that $C_{22}$ is positive, we may rewrite these as:

$$
\begin{aligned}
& P=C_{1}-\frac{U_{2}}{U_{1}+\lambda}-Q \bar{D}_{1} \\
& a=f\left(Q \bar{D}_{2}+\frac{U_{3}}{U_{1}+\lambda}, Q\right),
\end{aligned}
$$

where $f$ is increasing in its first argument.

Economists typically have strong priors on the form of $U$ in for-profit firms. In particular, setting $U(\pi, Q, a)=\pi$ (and dropping the profit constraint) yields familiar first-order conditions:

$$
\begin{aligned}
& P=C_{1}-Q \bar{D}_{1} \\
& a=f\left(Q \bar{D}_{2}, Q\right)
\end{aligned}
$$

Notice that the difference between the NFP and FP first-order conditions for price is simply the term $-\frac{U_{2}}{U_{1}+\lambda}$. Assuming that $U_{2}$ is positive (NFPs derive positive utility from quantity), then we can think of NFPs as FPs with "lower costs," i.e., "NFP marginal costs" are $\hat{C}_{1}=C_{1}-\frac{U_{2}}{U_{1}+\lambda}$ 
(see Philipson and Lakdawalla (1997) for a fuller development). Thus, ignoring quality, we expect lower prices and higher quantities for NFPs than for FPs, due to the positive utility NFPs derive from quantity. We do, in fact, observe that NFP prices are lower on average than FP prices.

For the most part, we will drop the LaGrange multiplier on profits (assuming that the profit constraint does not bind). Furthermore, it will be convenient frequently to "linearize" the problem by imposing strong functional form assumptions. When convenient, we will treat the "slopes" of demand and residual demand curves, $Q \bar{D}_{1}, Q \bar{D}_{2}$, and the "conjectures" $r_{Q}, r_{a}$ as if they were parameters (possibly varying across firms and markets with covariates), rather than functions of firms' choice variables.

\subsubsection{Implications of the model: conversions}

Conversions are not directly relevant for antitrust purposes; however, we consider them since we believe that studying them can shed light on the alleged differences between for-profit and notfor-profit institutions and these differences can be relevant for antitrust purposes.

To understand the likely effects of conversion from not-for-profit to for-profit status, it is useful to look in detail at the components of the first-order conditions determining price and quality for not-for-profit (NFP) and for-profit (FP) firms:

(NFP)

$$
P=C_{1}^{N F P}-\frac{U_{2}}{U_{1}+\lambda}-Q D_{1}\left(1+r_{Q}^{N F P}\right)
$$

$$
\begin{aligned}
& a=f^{N F P}\left(Q D_{2}\left(1+r_{Q}^{N F P}\right)+\frac{U_{3}}{U_{1}+\lambda}, Q\right) \\
& P=C_{1}^{F P}-Q D_{1}\left(1+r_{Q}^{F P}\right) \\
& a=f^{F P}\left(Q D_{2}\left(1+r_{Q}^{F P}\right), Q\right)
\end{aligned}
$$$$
\text { (FP) }
$$

The change in price and quality caused by the conversion breaks out into several components. To keep the discussion simple, we approximate changes in price as below. We suppress discussion of quality, since it is similar.

$$
\Delta P \cong\left(C_{1}^{F P}-C_{1}^{N F P}\right)+\frac{U_{2}}{U_{1}}-Q D_{1}\left(r_{Q}^{F P}-r_{Q}^{N F P}\right)
$$


The price change resulting from the conversion has three components. The first component, $\left(C_{1}^{F P}-C_{1}^{N F P}\right)$, captures any efficiency gained in the conversion. If for-profit enterprises have lower (marginal) costs, say because of administrative scale economies related to large for-profit chains, economies related to "better" management, or to changes in the quality or quantity of service provided (i.e. decrease in $a$ or $Q$ ), then this effect will tend to reduce the price charged by the enterprise. The second component, $\frac{U_{2}}{U_{1}}$, reflects the differences in goals between the for-profit and not-for-profit enterprises. The for-profit values output only to the extent to which output increases profit; whereas the not-for-profit firm values output per se. Since the NFP values output per se, it has added incentive to lower price in order to increase output. The third component, $Q D_{1}\left(r_{Q}^{F P}-r_{Q}^{N F P}\right)$, captures any differences which may exist in the reactions of firms in the market to a for-profit or not-for-profit firm. If other firms in the market, for example, find it easier to collude with for-profit firms for whatever reason, this will be reflected in $r_{Q}^{F P}-r_{Q}^{N F P}>0$.

\subsubsection{Implications of the model: mergers}

As we discussed above, courts have often found that the not-for-profit status of hospitals involved in mergers weighs in favor of the merger, and some courts have given this factor very great weight (Grand Rapids, and the District Court in Augusta). In addition, scholarly commentators have put forward the proposition that mergers between not-for-profits should be treated differently [Kopit and McCann (1988), Lynk (1994), (1995a)] than those between forprofits.

We examine the effects of a merger between two hospitals in the same market using a residual demand curve approach. Key issues in this industry revolve around asymmetries in the behavior of FP and NFP firms and how these asymmetries affect the price and quality of product after the merger. Here, we assume that the two firms (each with its single hospital) merge but keep both hospitals open. They may realize cost savings, and they set prices and qualities cooperatively after merging.

Consider firms 1 and 2 and write their demand curves to emphasize their roles:

$$
\begin{aligned}
& P^{1}=D^{1}\left(Q^{1}, a^{1}, Q^{2}, a^{2}, \mathbf{Q}^{-1,2}, \mathbf{a}^{-1,2}\right) \\
& P^{2}=D^{2}\left(Q^{1}, a^{1}, Q^{2}, a^{2}, \mathbf{Q}^{-1,2}, \mathbf{a}^{-1,2}\right)
\end{aligned}
$$

As before, using whatever is the relevant solution concept for the market, solve out for all other firms' choices as a function of the choices of firms 1 and 2: 


$$
\begin{aligned}
& P^{1}=\hat{D}^{1}\left(Q^{1}, a^{1}, Q^{2}, a^{2}\right)=D^{1}\left(Q^{1}, a^{1}, Q^{2}, a^{2}, \mathbf{Q}^{-\mathbf{1 , 2}}\left(Q^{1}, a^{1}, Q^{2}, a^{2}\right), \mathbf{a}^{-\mathbf{1 , 2}}\left(Q^{1}, a^{1}, Q^{2}, a^{2}\right)\right) \\
& P^{2}=\hat{D}^{2}\left(Q^{1}, a^{1}, Q^{2}, a^{2}\right)=D^{2}\left(Q^{1}, a^{1}, Q^{2}, a^{2}, \mathbf{Q}^{-\mathbf{1 , 2}}\left(Q^{1}, a^{1}, Q^{2}, a^{2}\right), \mathbf{a}^{-\mathbf{1}, \mathbf{2}}\left(Q^{1}, a^{1}, Q^{2}, a^{2}\right)\right)
\end{aligned}
$$

The residual demand curves of the two firms are thus $\hat{D}^{1}\left(Q^{1}, a^{1}, Q^{2}, a^{2}\right)$ and $\hat{D}^{2}\left(Q^{1}, a^{1}, Q^{2}, a^{2}\right)$. Pre-merger prices are given by:

$$
\begin{aligned}
& P^{1}=C_{1}^{1}-\frac{U_{2}}{U_{1}}-Q^{1} \bar{D}_{1}^{1} \\
& P^{2}=C_{1}^{2}-\frac{U_{2}}{U_{1}}-Q^{2} \bar{D}_{3}^{2}
\end{aligned}
$$

Presumably the post-merger firm will also seek to maximize some objective function which contains variables other than profits. However, the theoretical literature of which we are aware provides little guidance as to how the merged entity should evaluate and trade off its objectives. In the sequel, we assume that the merged firm's utility function is identical to the separate firms', but that its arguments are the sum of the individual firm's arguments. ${ }^{59}$ This appears to be sensible for profits and quantity, but (given the vagueness with which it is interpreted) may or may not be sensible for $a{ }^{60}$ In addition, although we allow economies by permitting the merged firm's cost functions to differ from the separate firms', production in the two facilities is assumed to be non-joint. The new, post-merger firm maximizes:

$$
\begin{aligned}
& \max _{Q^{1}, Q^{2}, a^{1}, a^{2}} U\left(\pi^{1}+\pi^{2}, Q^{1}+Q^{2}, a^{1}+a^{2}\right) \\
& \pi^{1}+\pi^{2}=p^{1} Q^{1}+p^{2} Q^{2}-\tilde{C}^{1}\left(Q^{1}, a^{1}\right)-\tilde{C}^{2}\left(Q^{2}, a^{2}\right) \\
& \text { s.t. } \pi^{1}+\pi^{2} \geq \tilde{\pi}^{L}
\end{aligned}
$$

In the sequel, we will use $\tilde{U}$ to denote the utility function evaluated at the new, merged, profit, quantity, and quality. The post -merger cost function at hospital $i$ is denoted $\tilde{C}_{i}$. Post-merger prices and qualities are given by:

$$
\begin{aligned}
& P^{1}=\tilde{C}_{1}^{1}-\frac{\tilde{U}_{2}}{\tilde{U}_{1}}-Q^{1} \tilde{D}_{1}^{1}-Q^{2} \tilde{D}_{1}^{2} \\
& a^{1}=\tilde{f}\left(Q^{1} \tilde{D}_{2}^{1}+Q^{2} \tilde{D}_{2}^{2}+\frac{\tilde{U}_{3}}{\tilde{U}_{1}}, Q^{1}+Q^{2}\right)
\end{aligned}
$$




$$
\begin{aligned}
& P^{2}=\tilde{C}_{1}^{2}-\frac{\tilde{U}_{2}}{\widetilde{U}_{1}}-Q^{1} \tilde{D}_{3}^{1}-Q^{2} \tilde{D}_{3}^{2} \\
& a^{2}=\tilde{f}\left(Q^{1} \tilde{D}_{4}^{1}+Q^{2} \tilde{D}_{4}^{2}+\frac{\tilde{U}_{3}}{\tilde{U}_{1}}, Q^{1}+Q^{2}\right)
\end{aligned}
$$

For FPs, the same equations may be written, but with the terms involving utility functions omitted in both the pre- and post-merger price and quality equations.

The question of interest is whether one should expect NFPs to have substantially different post merger behavior than FPs regarding price and quality changes. Assuming that the degree of collusion among the other firms and the merging firms does not change with the merger, the price changes for FP and NFP hospitals are:

$$
\begin{aligned}
& \text { NFP } \\
& \Delta P^{1}=\tilde{C}_{1}^{1}-C_{1}^{1}-\frac{\tilde{U}_{2}}{\widetilde{U}_{1}}+\frac{U_{2}}{U_{1}}-Q^{1}\left(\tilde{D}_{1}^{1}-\bar{D}_{1}^{1}\right)-Q^{2} \tilde{D}_{1}^{2} \\
& \Delta P^{2}=\tilde{C}_{1}^{2}-C_{1}^{2}-\frac{\tilde{U}_{2}}{\widetilde{U}_{1}}+\frac{U_{2}}{U_{1}}-Q^{2}\left(\tilde{D}_{3}^{2}-\bar{D}_{3}^{2}\right)-Q^{1} \widetilde{D}_{3}^{1}
\end{aligned}
$$

$$
\begin{aligned}
& \text { FP } \\
& \Delta P^{1}=\tilde{C}_{1}^{1}-C_{1}^{1}-Q^{1}\left(\tilde{D}_{1}^{1}-\bar{D}_{1}^{1}\right)-Q^{2} \widetilde{D}_{1}^{2} \\
& \Delta P^{2}=\tilde{C}_{1}^{2}-C_{1}^{2}-Q^{2}\left(\tilde{D}_{3}^{2}-\bar{D}_{3}^{2}\right)-Q^{1} \widetilde{D}_{3}^{1}
\end{aligned}
$$

For FP hospitals, the price change for firm 1 consists of an "efficiency" component (potentially tending to reduce price), $\widetilde{C}_{1}^{1}-C_{1}^{1}$, reflecting any savings in marginal costs realized by the merger and a "competitive" component (tending to increase price), $-Q^{1}\left(\widetilde{D}_{1}^{1}-\bar{D}_{1}^{1}\right)-Q^{2} \widetilde{D}_{1}^{2}$, reflecting the fact that the merged firm internalizes the effects of each hospital's output decision on the output of the other hospital.

As in the case of conversions, if there is a difference in FP's and NFP's ability to realize reductions in marginal costs due to merger, then this generates differences in the price changes which mergers bring about. Setting this point aside, the principal difference in the price change terms is $\frac{U_{2}}{U_{1}}-\frac{\tilde{U}_{2}}{\widetilde{U}_{1}}$. To assess the impact of this term on the competitive impact of merger, we consider several cases. 
The simplest case is one in which the NFPs have linear utility functions:

$U(\pi, Q, a)=\alpha_{1} \pi+\alpha_{2} Q+\alpha_{3} a$. In this case, $\frac{U_{2}}{U_{1}}-\frac{\widetilde{U}_{2}}{\widetilde{U}_{1}}=0$ and the price increases one would expect

from FP merger and NFP merger are equal. So, the fact that hospitals place value on dimensions other than profit is not a compelling reason, in and of itself, for expecting FP and NFP pricing to react differently to merger.

What if the NFPs do not have linear utility functions? In this case, one should expect NFP firm 1's price increase to be higher (lower), than that for FPs if $\frac{U_{2}}{U_{1}}$ is lower (higher) at $\left(\pi^{1}+\pi^{2}, Q^{1}+Q^{2}, a^{1}+a^{2}\right)$ than it is at $\left(\pi^{1}, Q^{1}, a^{1}\right){ }^{61}$ This condition is, roughly, that the marginal utility of output should fall more slowly than the marginal utility of profits as the scale of output and profit rises. What precise shape a NFP's utility function has is obviously an empirical issue (which we address below), but, so long as profit constraints are not binding, a claim that there is a difference in price increases between a FP and NFP merger amounts to a claim about complicated curvature properties of the NFP's utility function and/or residual demand curve. The important issue, then, to be addressed when thinking about NFP mergers is whether or not NFPs' marginal utility of profit falls more sharply than do their marginal utility of quantity ${ }^{62}$ and the curvature properties of the demand curve. ${ }^{63}$

\subsubsection{Identifying the model}

From the previous sections we know that (ignoring any differences in FP and NFP production technology and in the responses of competitors to FP and NFP actions) the behavior of NFPs with respect to mergers will differ from the behavior of FPs only if the ratios $\frac{U_{2}}{U_{1}}, \frac{U_{3}}{U_{1}}$ are nonconstant. It is, therefore, of interest to ask whether one should expect these ratios and their variance with differing levels of price and quality to be identified.

The NFP's pricing and quality equations are:

$$
\begin{aligned}
& P=C_{1}^{N F P}-\frac{U_{2}}{U_{1}}-Q D_{1}\left(1+r_{Q}^{N F P}\right) \\
& a=f^{N F P}\left(Q D_{2}\left(1+r_{Q}^{N F P}\right)+\frac{U_{3}}{U_{1}}, Q\right)
\end{aligned}
$$

To facilitate discussion, we linearize $C_{1}^{N F P}$ and $\frac{U_{2}}{U_{1}}$ and drop the quality equation (take $a$ as exogenous): 


$$
\begin{aligned}
& C_{1}^{N F P}=\delta_{0}^{N F P}+\delta_{1}^{N F P} Q+\delta_{2}^{N F P} a+\delta_{3}^{N F P^{\prime}} W \\
& \frac{U_{2}}{U_{1}}=\mu_{0}+\mu_{1} \pi+\mu_{2} Q+\mu_{3} a
\end{aligned}
$$

where $\delta, \mu$ are parameter vectors and $W$ is a vector of input prices. Substituting into the pricing equation we get:

$$
\begin{aligned}
& P=\delta_{0}^{N F P}+\delta_{1}^{N F P} Q+\delta_{2}^{N F P} a+\delta_{3}^{N F P^{\prime}} W-\left(\mu_{0}+\mu_{1} \pi+\mu_{2} Q+\mu_{3} a\right)-Q D_{1}\left(1+r_{Q}^{N F P}\right) \\
& P=\left(\delta_{0}^{N F P}-\mu_{0}\right)+\left(\delta_{1}^{N F P}-\mu_{2}\right) Q+\left(\delta_{2}^{N F P}-\mu_{3}\right) a+\delta_{3}^{N F P^{\prime}} W-\mu_{1} \pi-Q D_{1}\left(1+r_{Q}^{N F P}\right)
\end{aligned}
$$

Let's assume that we have an estimated demand system (this would require $W$ to have at least two elements), so that we may view $D_{1}, D_{2}$ as data.

In the pricing equation, the separate identification of the scale effect $\left(\delta_{1}^{N F P}-\mu_{2}\right)$ and the market-power effect $\left(1+r_{Q}^{N F P}\right)$ has been treated elsewhere extensively (Bresnahan, 1989). This application introduces three new identification issues. First, firm profits appear in the pricing equation, second, quality appears in the pricing equation, and, third, the intercept and the slopes on $Q$ and $a$ are mixtures of cost function and utility function parameters.

Strategies for the identification of all of these will obviously depend upon data. There are fairly rich data sources available for hospitals, collected by both state and federal governments. These data sources permit the estimation of demand systems for hospital services (as discussed previously), cost functions for hospitals (see the discussion below under efficiencies), and (accounting) profit functions (Hoerger, 1991). Furthermore, as in many other industries, imperfect measures of price, based upon average revenue or "list" prices, can be constructed (see the discussion below in the structure-conduct-performance section). So, we proceed below as if demand, cost, price, and profit estimates are readily at hand. Depending upon how quality is interpreted in a particular application, it is either readily measured or measured with difficulty and noise (see the discussion on this issue in section 4.4.2.). Again, we proceed as if estimates are readily in hand.

We can speak in general about the identification of the pricing equation. Later, we will take up the separation of utility and cost function parameters. The constant and coefficients on $W$ are obviously identified. The coefficients on $Q$ and $D_{1} Q$ are identified as long as there is a shifter of demand and a (price) rotator of demand, (Bresnahan, 1989). Similarly, the coefficient on $a$ will be identified by a (quality) rotator.

The most problematic variable is $\pi$. Two difficulties exist here. First, as in other industries, measures of economic profits are rarely available, and the measures of accounting 
profits may be poor proxies (Fisher, 1983). Second, it is not immediately obvious that $\pi$ is identified separately from $Q$. Profit is determined by:

$$
\pi=P Q-C(Q, a)
$$

If the profit function meets the usual conditions for a neoclassical profit function, then absent arbitrary functional form restrictions, all shifters of $C$ (input prices, fixed factors) are also present in the marginal cost functions. Furthermore, $Q$ is already in the pricing equation and $P$ is affected by $Q$ and $a$, both already in the pricing equation. So, the coefficient on profits would seem not to be identified. There are a few possible strategies. Obviously, functional form restrictions are one. Another is to introduce fixed costs with (at least one) separate shifter into the cost function. A third possibility is to introduce an additional source of revenue, say returns from an invested endowment, into the profit function to provide exogenous variation in profit. The second and third possibilities are potentially viable strategies. Fixed costs are a very significant component of hospital costs. Likely candidates for separate fixed cost shifters are factors affecting the cost of capital, like interest rates, bond ratings, etc., construction costs, and certificate of need regulations. Data are available on all of these factors and have been used in health economics research, although not in this context. Again, these revenues are usually documented in hospital databases.

Second, we turn to the separation of cost and utility function parameters. It is of evident and obvious scholarly interest to separate these two effects, but it is not of evident and obvious regulatory interest to do so. If there is sufficient information in the pricing equation, as estimated, to simulate the effects of a merger, then there is little reason for a regulator interested primarily in the effects of the merger on price to take up the separation of cost and utility parameters. The question of whether NFP's reduce prices less because they have lesser scale diseconomies or because they have marginal utility of output which falls more slowly than their marginal utility of profit is irrelevant if price is the variable of interest to the regulator.

As is immediately apparent by inspecting the pricing equation, and as is definitionally true by the lack of separate identification, the separation of utility and cost function parameters is irrelevant to the question of pricing. To see this, consider two NFP firms, identical in all respects but that firm 1 has utility and cost parameters $\delta_{0}^{1}, \delta_{1}^{1}, \delta_{2}^{1}, \delta_{3}^{1}, \mu_{0}^{1}, \mu_{1}^{1}, \mu_{2}^{1}, \mu_{3}^{1}$ while firm 2 has utility and cost parameters $\left(\delta_{0}^{1}+\varepsilon_{0}\right),\left(\delta_{1}^{1}+\varepsilon_{1}\right),\left(\delta_{2}^{1}+\varepsilon_{2}\right), \delta_{3}^{1},\left(\mu_{0}^{1}+\varepsilon_{0}\right), \mu_{1}^{1},\left(\mu_{2}^{1}+\varepsilon_{1}\right),\left(\mu_{3}^{1}+\varepsilon_{2}\right)$. Obviously, these two firms will choose identical prices, pre and post merger. So, a regulator interested in price and quality alone would disregard the separate information even were it to be provided. ${ }^{64}$

However, there are several strategies for separate identification. The most apparent is to estimate the cost function along with the pricing equation. In this way, the cost function parameters would be identified by the cost function estimation and the utility function parameters by the pricing equation. The other apparent way would be to assume that the cost functions of FPs and NFPs are identical. Under this assumption, the cost function parameters would be identified by the pricing equations of the FPs (since the utility function parameters drop out), and 
the utility function parameters of the NFPs would be identified from differences in pricing behavior between FPs and NFPs.

\subsection{Empirical evidence on hospital competition and mergers}

There have been a large number of studies relevant to hospital merger analysis and hospital competition generally. There are excellent reviews elsewhere (Dranove and White, 1994, Frech, 1996). We present a selective summary of some relevant research findings.

In practice, researchers have sought to identify the pricing and quality equations using structure-conduct-performance (SCP) regressions. The idea in these studies is to use some measure of market structure, say the Herfindahl-Hirschmann index (HHI), as a proxy for some of the terms in the pricing equation, as:

$$
\begin{aligned}
& P=\left(\delta_{0}^{N F P}-\mu_{0}\right)+\left(\delta_{1}^{N F P}-\mu_{2}\right) Q+\left(\delta_{2}^{N F P}-\mu_{3}\right) a+\delta_{3}^{N F P}{ }^{\prime} W-\mu_{1} \pi-Q D_{1}\left(1+r_{Q}^{N F P}\right) \\
& D_{1} r_{Q}^{N F P}=D_{1} r_{Q}^{N F P}(H H I) \\
& \pi=\pi(H H I)
\end{aligned}
$$

In practice, reduced forms of these equations are usually estimated, and the price and quality equations are not usually estimated together. The equations usually have approximately the following appearance:

$$
\begin{aligned}
& P=\beta_{0}+\beta_{1} Q+\beta_{2} X_{D}+\beta_{3} W+\beta_{4} H H I \\
& a=\gamma_{0}+\gamma_{1} Q+\gamma_{2} X_{D}+\gamma_{3} W+\gamma_{4} H H I
\end{aligned}
$$

where $X_{D}$ represents demand shifters.

Sometimes there is an interaction between HHI and a dummy variable for ownership status. Presumably, this dummy represents differential effects of HHI on $r$ for FP and NFP hospitals, the fact that $\pi(H H I)$ appears in the NFP and not the FP equation, and the fact that the constant, $Q$-slope, and $a$-slopes are different.

Using HHI in this way is problematic. First, the use of $\mathrm{HHI}$ in a pricing equation is known to be justified in the homogenous-goods Cournot model of competition and other indicia are known to be appropriate in other models of conduct (Schmalensee, 1989 and citations therein). In the Cournot model, however, the coefficient on HHI provides information on the shape of the demand curve, not on the conduct of pricing (which is already assumed to be Cournot). Since the issue one is trying to address with a SCP regression is the relationship between structure and conduct, running a regression which prejudges conduct and provides information on demand properties conditional on that prejudgment is not ideal. Second, the HHI is endogenous to conduct, both because high prices attract entry and because differences in 
demand and cost conditions (often not fully accounted for in the pricing specification) affect both prices and the number of firms that will "fit" in a market (Evans et al., 1993). Third, the HHI is affected by the distribution of market share among firms. A firm with unusually low costs (thus, in many models high market share) will cause the HHI to be large and is likely to cause $P$ to be lower (Bresnahan, 1989, Schmalensee, 1989 and, relatedly, Demsetz, 1974 and Peltzman, 1977). Fourth, even a true relationship between HHI and price need not reflect differential conduct. If market average MC varies with HHI, then price could vary even as conduct remains the same. This relationship could arise in a number of ways. If bigger markets have more firms and these firms operate at different scales in bigger markets and there are scale economies, a relationship may exist between HHI and price which has nothing to do with conduct. If bigger markets have more firms (with more "draws" on the unobservable components of marginal cost) and low-cost firms have a disproportionate impact on prices, then price and HHI could be related without an HHI-conduct linkage (Bresnahan, 1989).

In short, the use of the Herfindahl index to assess the likely impact of mergers imposes implicit assumptions about the nature of the product, the nature of the competitors, the nature of conduct, and the nature of entry/exit decisions. When these assumptions are satisfied, of course, the technique potentially provides information about the effect of mergers on prices. When they are not, the technique does not. This is true of every technique, of course, so that it is not the imposition of assumptions which is troublesome, but the simultaneous implicitness and inflexibility of the assumptions which is problematic. In practice, since the assumptions are implicit, their applicability to the market at hand is not often discussed nor are they readily discussed. Furthermore, it is not apparent how to incorporate industry and market specific knowledge from outside the data or how to modify the approach when any particular implicit assumption is false.

The primary competing paradigm to SCP at present is that of the "New Empirical Industrial Organization." This technique differs in a number of ways from SCP (see discussion in Bresnahan, 1989). NEIO studies typically involve making explicit assumptions about production technologies, demand, and conduct. The assumptions typically leave enough parameters free so that the data identify such things as important cost function, demand function and conduct parameters. Furthermore, the assumptions differ from study to study and are tailored to the industry at hand. The strengths of the approach are, first, the explicitness of the economic assumptions, and, second, the ability to tailor assumptions to particular industries. This facilitates evaluation both of how relevant the analysis is to the chosen industry and how failure of the assumptions to hold is likely to affect the conclusions drawn.

A weakness of the approach is that conduct is typically measured holding industry structure constant (literally, not via covariates). This has two downside implications. First, evaluating the effect of a change in structure, say by a merger, typically requires additional assumptions. For example, Baker and Bresnahan (1985) evaluate the effect of mergers among brewers by assuming that the conduct of the non-merging parties is not affected by the merger, and only the two merging parties take account of the change in market structure. Werden (1997) evaluates the effect of mergers by assuming that his markets are characterized by differentiated product Bertrand competition. Second, it is difficult to integrate cross-sectional variation across 
markets in structure into the analysis. For some attempts to remediate this problem see Bresnahan and Reiss (1991), Sutton (1991), and Berry (1992). There are also rhetorical weaknesses of this family of techniques . First, explicit assumptions are more readily criticized, so that it may be in a researcher's private interest to avoid them. Second, estimation techniques are frequently complex, making their explication, especially to nonspecialists, more difficult.

\subsubsection{Structure-conduct-performance: price}

The first set of findings we present concerns hospital price-concentration studies. In this branch of the literature, some measure of price is regressed upon some measure of market concentration. The studies are differentiated in their operationalization of price (average revenue per discharge or per inpatient day is probably the mode), in their operationalization of concentration (some kind of Herfindahl or adjusted Herfindahl is probably the mode), in their study time period, in their study population, in their market definition, and in their control variables. However, it is not a completely misleading summary to say that the studies each regress price on a Herfindahl index, market covariates, hospital covariates including output, and dummy variables for ownership type.

Here, we present a tabular summary of the findings of a number of studies. In each of these studies, we used the results to analyze a "standard merger case" (SMC). In the SMC, there is a market consisting of five identical hospitals, each with a $20 \%$ market share, each not-forprofit. We consider a merger of two of the hospitals, and assume that in the new market configuration the new hospital will have a market share of $40 \%$, will have twice the output that it had before, and that the other three hospitals will continue to have market shares of $20 \%$. Thus it is straightforward to calculate the effect on the merging hospitals' prices, given a coefficient on the Herfindahl index and a coefficient on (log) output. For studies which use beds as a control variable, we consider two 218-bed hospitals merging and consider both the change in the Herfindahl and the change in bed size in the calculation (see Keeler et al., 1999). For many studies we have had to take some liberties in order to present the results in this standard format. For example, some studies use number of hospitals rather than HHI to operationalize structure: in those cases, we consider a decrease from five to four hospitals.

\section{[INSERT TABLE 3 ABOUT HERE]}

Several things are apparent from the table. First, the empirical basis for drawing inferences about hospital mergers from SCP studies is quite narrow. Five of the eight studies we examine use California data, and only one covers the entire United States. The other interesting pattern is that the estimated effect of the merger is increasing in the recency of the data. The correlation between the estimated effect size and the year of the data is 0.22 (it is 0.68 without the DL and LN studies). Finally, the California studies display stronger merger effects, in general, than do the non-California studies. Since California has had more rapid and complete penetration of managed care than have other states, one might wonder whether managed care penetration is associated with increases in the strength of the association between price and concentration. There is suggestive evidence in several papers that high HMO penetration tends 
to decrease prices and to increase the association between the HHI and price (Simon and Shin, 1993, Dranove et al., 1993, Melnick et al., 1992).

In addition to this work, there is a small body of work examining the association of concentration and price, differentiated by the ownership of the hospital. The theory has been advanced that not-for-profit organizations will not exercise any market power which they might come to posses, by dint of their different objectives [Kopit and McKann (1988), Lynk (1995a), (1994), FTC v. Butterworth (1996, 946 F.supp 1285), FTC v University Health (1991-1 Trade Cases $\llbracket[69,444)]$. As discussed previously, the courts have, in some cases, accepted this reasoning. There are five papers that we know of which specifically address this point. Again, with some loss of information in the interests of greater clarity, we present the results of these studies in tabular form. In this table, we consider the effects of the SMC, this time differentiating by ownership classification.

\section{[INSERT TABLE 4 ABOUT HERE.]}

All of these studies with the exception of LN use California data. There are a number of differences among these studies, however. The studies use different years of data. The Lynk and DL results are based upon 1989 data, while KMZ use several years (the results above are for 1994), SS use 1993, and LN use 1995 data. The studies also differ on market definition, the product markets examined, hospitals included in the analysis, and whether the LHS variable is logged. DL, SS, and KMZ provide discussions of their differences with Lynk. LN discuss differences between Lynk, DL, and KMZ. The message of these discussions is that each of the differences in technique and data accounts for some of the differences in measured effects. As we mentioned above, the absence of explicity assumptions mapping empirical technique, economic assumptions, and outside knowledge makes it quite difficult to evaluate the relative merits of the various empirical procedures.

\subsubsection{Structure-conduct-performance: non-price}

The empirical literature in the area of non-price competition is also largely of the SCP variety. This research falls into a number of categories, depending on what non-price attribute is measured and what normative spin is imparted to the results.

The medical arms racing (MAR) branch of the literature generally regresses some measure of input use or of costs on some measure of concentration. ${ }^{65}$ The idea is that less concentrated markets induce hospitals to compete more aggressively for patients, possibly via competition for physician affiliations or managed care network inclusion. This competition takes the form of actions by the hospital to increase the perceived attractiveness of their products, for example by adopting advanced medical technology, acquiring helicopters, employing more and/or more skilled nursing staff, etc. These actions are costly. The MAR is to be detected by looking for a correlation between concentration and the input use in question (regressing the presence of technology on HHI, regressing nurses per patient on HHI, etc.). A negative relationship is taken as evidence of (presumptively welfare reducing) non-price competition. Indexes of input use often used are the presence of particular technologies (Dranove et al., 1992, 
Luft et al., 1986, Robinson et al., 1987), length of stay (Robinson and Luft, 1985, Hersch, 1984), staffing levels and/or mixes (Robinson, 1988, Hersch, 1984), and reserve capacity (Joskow, 1980). A typical finding in this literature is that higher levels of concentration lead to lower levels of input use. So, for example, Dranove et al. (1992) find that more highly concentrated California hospital markets have less sophisticated medical equipment; Robinson and Luft (1985) find that length of stay is declining in concentration; Joskow (1980) finds that more concentrated hospital markets hold a lower reserve capacity of beds.

Another set of MAR papers models hospital costs as a function of concentration. Sometimes the studies estimate what are easily recognizable as neoclassical cost functions, but with Herfindahl index "dropped" in. In others, functional forms and right-hand-side variables are more ad hoc. The reasoning in these papers is roughly as follows. If non-price competition is more aggressive in less concentrated markets and if it is also cost-increasing, then one should expect to find lower costs in more concentrated markets. A number of papers in this stream of the literature do find that hospitals in more concentrated markets have lower costs (Robinson and Luft, 1985, Hersch, 1984, Zwanziger and Melnick, 1988). In addition, studies using more recent data in California (Melnick and Zwanziger, 1988, Zwanziger and Melnick, 1988) find that costs are increasing more quickly in high concentration markets, with the inference drawn that managed care caused hospitals to compete more on price than on quality.

Although most of the non-price competition literature falls into the above categories, there are papers outside of them. Shortell and Hughes (1988) examine the association between in-hospital mortality among Medicare patients in 1983 and concentration. There was no significant association between the two, and the point estimate of the impact of concentration upon mortality was small.

Another dimension which might be affected by competition is the provision of uncompensated care. Gruber (1994) studies the effect of competition on uncompensated care in California. He finds that an increase in Herfindahl by 0.12 leads to an increase in uncompensated care of $10 \%$ and an increase in the number of emergency rooms (disproportionately used by uninsured individuals) by $4 \%$.

More recently, Kessler and McClellan (1998) find a negative relationship between heart attack mortality and the Herfindahl index, suggesting that perhaps hospitals may take advantage of market power by skimping on quality. Hamilton and Ho (1998), however, find no impact of hospital mergers on heart attack mortality. Volpp and Waldfogel (1998) find that heart attack mortality in New Jersey increased following hospital rate deregulation, implying that more active price competition was accompanied by a decrease in quality competition.

\subsubsection{MAR, scale economies, and the efficiencies defense}

In antitrust cases generally, and in hospital merger cases in particular, firms often mount an "efficiencies defense." An efficiencies defense is a claim by the firms desiring to merge that the merger will create cost savings which will be passed along to consumers. These cost savings are claimed to be large enough to offset any anticompetitive effects of the merger. In the case of 
hospital mergers, two types of efficiencies are cited. First, economies of scale in the usual economic sense are often claimed. Indeed, in their merger guidelines, DOJ and FTC recognize that there may be substantial scale economies realized by mergers among hospitals with fewer than 100 beds. They have created a safety zone for such mergers in their statements of antitrust enforcement in health care (DOJ and FTC, 1996). In addition, hospitals, relying often on the MAR hypothesis, claim that merging will enable them to rationalize the production of hightechnology services, which they allege to have been wastefully duplicated due to the perverse effects of competition between hospitals. (See the discussion above under outcomes to date).

There is a large literature estimating hospital costs; however, it is fair to say that few firm conclusions can be drawn from it. To the extent that any consensus view of scale economies exists, it is that there are some scale economies for small hospitals, but that these economies are exhausted above about two hundred beds. Cowing et al. (1983) contains a review of the early literature on which that consensus is based. This early literature is, for the most part, based upon ad hoc regression specifications. Typically some measure of average costs is regressed upon beds and beds squared along with a variety of other control variables. The typical finding is a shallow U-shaped average cost curve with a minimum around 200 beds.

More recent contributions usually use specifications which are either neoclassical cost functions (using "flexible functional forms") or close relatives of neoclassical cost functions. These papers have produced mixed results, but our reading is that their results are roughly consistent with the earlier consensus. Vita (1990) and Granneman et al. (1986) find no scale economies for inpatient care for hospitals in their sample (in fact they find weak scale diseconomies at all levels of output). Fournier and Mitchell (1992) find substantial scale economies at point estimates; however, they are unable to reject constant returns to scale at conventional significance levels, since their parameters are imprecisely estimated. Cowing and Holtman (1983) find scale economies; however, Vita (1990) recalculates Cowing and Holtman's scale economy measures, shifting from Cowing and Holtman's short run cost function to a long run cost function, and finds none. Dor and Farley (1996) also find scale economies, but do not provide measures, confidence intervals, or hypothesis tests for them. Finally, Vitaliano (1987) finds scale economies; however, his output measure is beds, which is likely better thought of as a proxy for capital stock, so that it is unclear what to make of his estimates. Dranove (1998) estimates "cost functions" for cost centers (accounting sub-units of hospitals) within a sample of California hospitals and finds that scale economies are typically exhausted by hospitals as large as 200 beds.

Two related problems have prevented a firm consensus from emerging on either the proper methods for estimating hospital costs or on the facts of the extent and size of scale economies in production in the hospital industry. First, the "casemix" of the hospital, both in terms of which diseases are treated and in terms of the severity of illness has not been well controlled in studies to date. To the extent that large hospitals treat more complex (more costly) cases, measures of scale economies will be biased downward. Given the "primary", "secondary", "tertiary" and the "community" and "regional referral center" distinctions so common in the rhetoric of health planners and practitioners, it is at least plausible that this effect is large. 
Second, and similarly, output is invariably captured via very aggregate measures. "Discharges" or "patient-days" are frequently used aggregate output measures. In some studies, five outputs are used, but even this level of disaggregation is not common. Since there are over 400 DRGs (an output classification) for inpatient hospital care, and since even DRG's are aggregations of more fundamental output distinctions, there is face validity to this objection as well. Furthermore, larger hospitals usually have a broader range of services available and provide more specialized treatments (often costing more). Since this (badly measured) scope of output covaries positively with the scale of output and since the marginally added outputs are likely to be more costly than average, this effect works much like the casemix effect above to depress measurements of true scale economies for large hospitals.

Finally, there is a strain of this literature (Friedman and Pauly, 1981, Gaynor and Anderson, 1995) which demonstrates that consistent estimates of scale economies can not be obtained without explicitly modeling hospitals' problem of maintaining sufficient standby productive capacity in the face of uncertain demand. Lynk (1995b) argues that there may be substantial scale economies arising from this inventory management problem. To the extent that the hospital has a stochastic demand and relatively fixed capacity for various outputs, inventory models suggest that there can be substantial economies realized by consolidating the operations of several hospitals. Given the existence of these inventory related economies and given the already mentioned measurement problems, the argument goes, the findings of no scale economies in the cost function literature lack plausibility (Lynk, 1995b). These arguments depend upon hospital capacity being truly fixed in the short run, and any scale economies which would result from inventory effects would have to be balanced against any diseconomies from other operations.

\subsubsection{Event studies}

In addition to the SCP-type cross sectional work described above, there are several recent papers using a longitudinal approach to measuring the effects of mergers in hospital markets. Event studies of mergers attempt to infer the effects of mergers by examining movements in the prices of a firm's stock arising from information related to mergers. Since most hospitals are not-forprofit, the direct use of stock prices has not been particularly popular. Most of this literature, then, has used left-hand-side variables other than stock price, including output, output price, and cost to discern the effect of mergers.

However, one study does use stock price data of several for-profit, publicly traded hospital firms. Woolley (1989) examines the effects of mergers on the stock prices of "rival" hospital companies -- that is, hospital companies not involved in the merger. The idea is that, if a merger is anti-competitive and results in a higher price (and profits), these higher profits will be shared not only by the merging firms but by other market participants. Conversely, if the merger has no effect on price and only results in cost savings, the profits of rivals (hence the stock price of rivals) will not be affected by the merger. Woolley analyzed the movements in the prices of 9 for-profit hospital chains over the period 1969 to 1985 . For each merger or anti-merger occurring in this period, he examined the effect on the stock price of the firms uninvolved in the merger. For the most part, the mergers were positively associated with movements in the rivals' 
stock prices and the anti-mergers with negative movements. Woolley's interpretation that the results indicate the exercise of oligopoly power were criticized by Vita and Schumann (1991), reply Woolley (1991), who argue that: 1) Woolley's definition of the market is excessively broad, 2) that many of Woolly's mergers occurred in markets sufficiently unconcentrated that it is implausible that oligopoly power was increased by the merger, and 3) that the for-profit companies in Woolley's sample are so large, relative to the number of hospitals affected by each merger, that an effect could not be discernible in the company's aggregate profits, whence stock price. The question of which view is most convincing appears to turn on details of market definition and the relationship between structure and conduct, and these details are not presently known.

Two recent papers (Connor et al., 1997, Connor and Feldman, 1997) examine 122 hospital mergers which occurred between 1986 and 1994. The papers use a dataset in which the authors follow 3500 U.S. hospitals. Hospital mergers are identified from the AHA annual survey, and 122 are identified in this period. These papers use what is essentially a difference in differences approach to assess the effects of merger on the exercise of market power. In Connor et al. (1997), markets are divided into those in which a merger occurred (treatment) over the time period and those in which one did not (control). The difference in price (average revenue per admission) and costs are examined for hospitals in each type of market. The effect of mergers is the difference between the increase in prices (costs) by the merging firms in the merger markets and the difference in prices (costs) by firms in the non-merger markets. Overall, merging hospitals had lower growth in prices and costs than did hospitals in markets without mergers. However, mergers which occurred in markets which had a higher degree of concentration to start with generated slightly higher price increases than were seen in the control group, and generated smaller cost savings than did the mergers in the unconcentrated markets. Also, mergers that occurred among hospitals with higher capacity utilization, fewer duplicative services, and lower managed care penetration generated more anti-competitive effects. Connor et al. also found that the hospitals involved in mergers were different in several ways from the control hospitals in non-merger markets. They were bigger, more urban, more likely for-profit, more likely part of a system, more profitable, and had higher prices all before the merger occurred.

In Connor and Feldman (1997), the same data are used in a slightly different way to assess whether or not the mergers led to the exercise of oligopoly power. Using reasoning similar to Woolley's event study, the authors used the same difference in difference method to examine the difference between increases in price and costs in non-merging hospitals in merger markets (treatment) and the increase in price and costs between hospitals in non-merging markets (control). In this analysis, the authors find effects which are both very small in magnitude $(<1 \%)$ and not significant. These results were not changed in a substantive way by stratifying the markets by concentration or by stratifying the hospitals by capacity utilization. The authors conclude that there is not strong evidence that mergers create increases in oligopoly power by non-merging hospitals in the same market with merging hospitals.

Another recent paper is Alexander et al. (1996). This paper examines the effects of 92 mergers that occurred between 1982 and 1989 on a variety of operating characteristics of the merging hospitals. The authors examine changes in these characteristics from three years prior to 
the merger up to the merger and from the merger up to three years after the merger. These authors also use what amounts to a difference in differences estimator. For their comparison group, they draw 276 hospitals at random from the AHA survey. The authors seek to test, in essence, the efficiency-raising properties of mergers, so they look at costs and various correlates of cost, including staffing levels and beds. Overall, they find that in merging hospitals, the trend rate of growth of costs was lower for merging hospitals after the merger than it was before the merger, and that declines in occupancy continued at a slower rate after the merger. In addition, for the mergers that occurred after 1987, there were reductions in the trend rate of growth of costs and staffing levels and there was an increase in the trend rate of growth of occupancy rate postmerger. Like Connor et al., however, Alexander et al. find that there were substantial differences between merger and non-merger markets before the mergers occurred. Markets in which mergers occurred were declining in both admissions and beds faster than were non-merger. Their costs were increasing more slowly than were the non-merger markets, again before the merger occurred.

In a recent, unpublished dissertation, Krishnan (1998) uses a difference-in-differences technique to assess the effects of hospital mergers for a sample of Ohio hospitals. Her treatment group is lines of business (DRGs) for the merging hospitals in which the merging hospitals are likely to have gained market power (DRGs where market share increased by more than $20 \%$ because of the merger). Her control group is lines of business for the merging hospitals in which the merging hospitals are unlikely to have gained market power (change in market share less than $5 \%$ ). The average difference in these price changes (pre and post merger) was $4 \%$, so that, in lines of business where merging hospitals are likely to have gained market power, prices rose $4 \%$ more, post-merger, than in lines of business where merging hospitals are unlikely to have gained market power.

\subsubsection{Studies of Entry}

Two recent studies have employed the method developed by Bresnahan and Reiss (1991) for inferring the degree of competition in a market by observing entry behavior. Firms enter a market only if it is profitable to do so. For any given fixed cost of entry, the lower average variable profits are, the greater the market size required to break even is. Market size is assumed to be proportional to population. Since competition lowers average variable profits, this increases the population size required to support entry. Thus, if entry increases competition, more population should be required to support successive entrants. The population required to support successive entrants will stabilize when the prospective entrant's profit margin (i.e., competition) stabilizes.

The advantage of this approach is that it avoids any potential problems associated with using price or cost data, as discussed previously. There are a number of disadvantages, however. The approach relies on the population per firm required to support entry. This will be increasing as price competition reduces average variable profits. The problem is that a number of other factors can cause this to increase. Non-price competition can reduce average variable profits by increasing average variable costs without affecting price. Increases in fixed costs can also cause the population per firm required to support entry to increase. If later entrants get a lesser share of 
the market than do earlier ones then the population required to support entry can also be increasing in the number of firms.

Abraham, Gaynor, and Vogt (1998) use this approach to look at competition in local hospital markets. These are basically markets in rural areas of the U.S. They find that the incremental population needed to support additional hospitals increases with the number of hospitals in the market, at least through market structures of up to four firms. If the changing market size increments reflect only increased competition, then there are large increases in competition with additional firms, at least up through the fourth firm. While it is not possible to directly distinguish between price and non-price competition in this framework, they also find evidence that the presence of more HMOs reduces entry, consistent with HMOs increasing price competition.

Chernew et al. (1998) estimate hospital entry into "markets" for coronary artery bypass graft (CABG) surgery by payer type (Medicare, Medicaid, HMO, Fee-for-service, and Other). They find evidence that fee-for-service insurers are paying rates that allow for profitable entry. Medicare payment rates were generous in the mid 1980s, but allowed for zero profits by the mid 1990s. HMOs consistently paid rates that covered variable, but not, fixed costs. Medicaid rates are below variable costs.

\section{Monopsony and foreclosure}

\subsection{Introduction}

While a great deal of government antitrust enforcement in health care has addressed horizontal concerns (hospital mergers, physician boycotts, professional society advertising bans), there have also been important antitrust cases addressed to vertical issues. ${ }^{66}$ The two major vertical concerns that have arisen in health care markets are monopsony power and foreclosure. Concerns about monopsony power have been confined to the exercise of monopsony power by insurers against hospitals or physicians. Foreclosure concerns have arisen in the context of vertical integration, exclusive dealing, or most-favored nation (MFN) clauses between various combinations of insurers, hospitals, and physicians.

While these issues have for the most part not been viewed as anti-competitive by the courts in the past, they have received renewed attention in recent years. This is due to two factors: the recent growth to dominance of managed care in the U.S., and the evolution of economic and antitrust thinking on vertical restraints. As managed care firms have assumed large market shares in the insurance market, their bargaining power with hospitals and physicians has grown. This has led to allegations of the exercise of monopsony power by managed care firms. At the same time, the health care industry has undergone a great deal of reorganization, including mergers and acquisitions between insurers, hospitals, and physicians and a great variety of contractual arrangements between these entities, including exclusive contracts, long term contracts, and MFN contracts. These contractual or integrated arrangements between upstream and downstream firms have raised increased concerns about the possibility of these arrangements leading to foreclosure of competitors and thus increasing the market power of incumbents in 
these markets. The "Chicago School" thinking on vertical restraints, which overturned previous antitrust doctrine in this area, is that vertical restraints are pro-, rather than anti-, competitive. More recent developments in economic theory have led to the evolution of the "Post-Chicago School," which holds that vertical restraints have anti-competitive potential in certain circumstances. In what follows, we take up monopsony issues in section 5.2, bilateral market power in 5.3, and foreclosure in section 5.4.

\subsection{Monopsony power}

\subsubsection{Monopsony and antitrust enforcement}

The U.S. antitrust statutes can be interpreted as prohibiting monopsonistic as well as monopolistic practices (e.g., predatory pricing, price fixing, market division, bid rigging, refusal to deal, tying, merger for monopsony, price discrimination, etc. While there have been a number of cases in which the exercise of monopsony power was found to be an antitrust violation [see Blair and Harrison (1993, Chapter 2) for a review], for the most part the exercise of monopsony power has not been of major concern to enforcement authorities. In part this may be due to the view that monopsony is a rare phenomenon. While this may or may not be true in most markets in the U.S., questions about the exercise of monopsony power are definitely germane in health care markets, as we argue below. Another reason for this lack of concern may have to do with the specifics of antitrust law. U.S. antitrust law does not prohibit price setting by a seller that takes advantage of monopoly power. As an extension it would seem that the law would allow monopsonistic price setting as well. ${ }^{67}$ Most (but not all) of the cases that have been brought regarding monopsonistic price setting have been decided in favor of the defendant. Another reason has to do with the antitrust concept of "standing." Standing is roughly whether the party(ies) involved have the right to sue under the antitrust laws. The courts have often regarded sellers to an alleged monopsony as being without standing, since their complaint is that monopsony led to reduced prices. The view is that the sellers did not suffer any antitrust injury, since the antitrust laws are not intended to allow a seller to raise prices. In addition, the courts have regarded monopsony power as leading to reduced prices to consumers (although monopsony does not necessarily lead to reduced prices to consumers, as we discuss below). Since this is beneficial to consumers, they have been loath to consider it an antitrust violation, even if social welfare is reduced.

In health care most antitrust cases involving complaints about monopsony have involved complaints about unilateral price reductions by a monopsony buyer. In these cases this has been an insurer buying from a provider of health care services. As indicated previously, the courts have been reluctant for the most part to regard the unilateral exercise of market power as an antitrust violation and hence have mostly decided for the defendants in these cases. In the one case involving a complaint of collusion to obtain monopsony power the court found in favor of the plaintiffs. At present there have been no health care cases brought involving other sorts of potential monopsony violations. However, as consolidation continues in the insurance industry it is likely that cases will be brought concerning mergers between insurers. A possible source of complaint in those cases is merger for monopsony. We may also see cases alleging predatory 
pricing (in the case of monopsony this would involve paying high prices to sellers to deter entry), or collusion, especially as insurance markets become concentrated.

Table 5 contains a list of selected antitrust cases involving monopsony power in health care. ${ }^{68}$ In Kartell v. Blue Shield of Massachusetts, Ball Memorial Hospital v. Mutual Hospital Insurance, and Ocean State Physicians Health Plan v. Blue Cross and Blue Shield and many other cases, the courts have made it clear that a health insurance plan can bargain as hard as it wants to get lower prices from providers, providing it is not predatory (attempting to force prices below marginal cost or average variable cost would be judged predatory). The exception (St. Bernard Hospital v. Hospital Service Association) is a case where the insurer was controlled by nine participating providers and the monopsony power was thus judged to be illegally obtained via a combination.

\section{[INSERT TABLE 5 ABOUT HERE.]}

In what follows we provide a brief description of the effects of monopsony power in general, including how to estimate monopsony conduct. Section 5.2.2 contains a discussion of monopsony and welfare. In section 5.2.3 we describe a general approach to estimating monopsony conduct. We then turn to monopsony power in health care in section 5.2.4.

\subsubsection{Monopsony and welfare}

It is well known that monopsony power leads to a welfare loss for sellers of the product. The exercise of monopsony power in an input market implies that the quantity and price of the input sold will both be less than their competitive levels. Thus the owners of the input suffer a loss of surplus under monopsony. What is not commonly understood is the implication for consumer welfare. Since the monopsonist obtains a reduced price for the input it might seem that this will result in a lower marginal cost of production, which might be passed on to consumers.

Consider the following simple model, based in part on Blair and Harrison (1993), Chapter 3 , but adapted to represent the health care institutional setting. A health insurance firm produces output $(q)$, with two inputs: purchased hospital output $(x)$ and another input $(y)$, according to the following (well-behaved) production function,

$$
q=f(x, y)
$$

The hospital produces its output $(x)$ with costs described by the (continuous, twice differentiable) cost function $c(x)$. Assume, as is usual that $c_{x}>0$ and $c_{x x}>0$. Hospitals are price takers. Then hospitals' marginal cost curves are their supply curves and the insurer regards the hospital's marginal cost of production, $c_{x}$, as the unit price of hospital services. Since the insurer possesses monopsony power its marginal factor cost of hospital services is the derivative of the total factor $\operatorname{cost}\left(c_{x}(x) \cdot x\right)$. This is $c_{x}+c_{x x} \cdot x$. If the output market is competitive, the firm's profit function is 


$$
\pi=p \cdot f(x, y)-c_{x}(x) \cdot x-p_{y} \cdot y
$$

where $p$ is the output price and $p_{y}$ is the price of the other input. ${ }^{69}$ The profit maximizing amount of hospital output is where

$$
\frac{\partial \pi}{\partial x}=p \cdot f_{x}-c_{x}-c_{x x} \cdot x=0
$$

Clearly this implies that less hospital output is purchased under monopsony than in a competitive hospital market, the price of hospital output is lower (recall that $c_{x x}>0$ ), and hospitals are worse off.

It is also true, however, that marginal costs are higher under monopsony than with a competitive factor market. Let the insurance firm's total costs be

$$
T C=c_{x}(x) \cdot x+p_{y} \cdot y
$$

The cost minimizing demands for hospital output and for the other input will be $x=x\left(p_{y}, q\right)$ and $y=y\left(p_{y}, q\right)$, respectively, ${ }^{70}$ thus the cost function is

$$
C\left(q, p_{y}\right)=c_{x}\left(x\left(p_{y}, q\right)\right) \cdot x\left(p_{y}, q\right)+p_{y} \cdot y\left(p_{y}, q\right)
$$

Marginal cost is then

$$
\frac{\partial C}{\partial q}=c_{x x} \cdot x_{q} \cdot x+c_{x} \cdot x_{q}+p_{y} \cdot y_{q} .
$$

Note that the first term does not appear when the insurance firm is a competitive buyer in the hospital market. Since the first term is positive, the marginal cost of production is higher under monopsony. ${ }^{71}$ The general point can be established directly by noting that monopsony violates the conditions for efficient hiring of inputs, thus costs must be higher.

What are the implications of this for consumer welfare? Consider the following scenario. Assume that output is sold in a regional or national, competitive, market. The monopsonized factor, however, is purchased in local markets. Assume that this factor is immobile and that every firm is a monopsonist in its local factor market. ${ }^{72}$ The result is that every producer sells at the competitive market price, but operates at higher marginal costs. Thus, aggregate output is decreased relative to what would be produced if factor markets were competitive. This results in a welfare loss for consumers. If, however, only a small number of sellers possess monopsony power there will be (essentially) no loss for consumers. In a competitive market an individual seller is infinitesimal relative to the total, thus the above described output description only leads to a welfare loss in a competitive output market if a large number of sellers are also monopsonists. ${ }^{73}$ If a seller possesses monopoly power, then a monopsony distortion due to 
higher marginal costs exacerbates the output restriction due to monopoly. Consumers pay both higher prices and consume less output from a monopolist-monopsonist than from a monopolist.

\subsubsection{Detecting monopsony power}

In principle, detecting the exercise of monopsony power via econometric methods is not much different than is the same exercise for monopoly power. ${ }^{74,75}$ Let the question of interest be whether insurers possess monopsony power in the hospital market. Assume that the following are observable: the price and quantity of hospital output, the price or the quantity of insurance, factors that shift the marginal productivity of hospitals, and factors that shift the supply of hospital output.

Rearranging the equation above for the profit maximizing amount of hospital output yields the equation for hospital output price setting (or quantity of hospital output setting) by a monopsonist,

$$
p_{x}=c_{x}=p \cdot f_{x}-c_{x x} \cdot x
$$

where $p_{x}$ is the price of hospital output. Note that if the second term equals zero this corresponds to the wage setting condition in a perfectly competitive labor market. Following Bresnahan (1989), we can rewrite this to parameterize the extent of monopsony power,

$$
p_{x}=p \cdot f_{x}\left(x, y, M, \beta, \varepsilon_{f}\right)-c_{x x}\left(x, Z, \gamma, \varepsilon_{c}\right) \cdot x \cdot \theta_{M S}{ }^{76}
$$

where $M$ is a vector of insurer marginal productivity shifters, including perhaps management or technology, $\beta$ is a parameter vector, $\varepsilon_{f}$ and $\varepsilon_{c}$ are the econometric error terms for the marginal productivity and marginal supply functions, $Z$ are hospital supply shifters, $\gamma$ is a parameter vector, and $\theta_{M S}$ is a non-negative parameter indexing the degree of monopsony power. As $\theta_{M S}$ moves farther from zero the firm's conduct moves farther away from that of a perfectly competitive purchaser.

If observations on the quantity of insurance output are available a production function may be estimated jointly with the price setting equation. If not, however, the parameters $\beta$ can still be estimated by making an explicit assumption about the form of the function $f$.

If the output market is perfectly competitive, output price, $p$, can be taken as given. If the firm has market power in the output market then $p$ may be endogenous. In this case instruments for $p$ may be output demand shifters and marginal cost shifters. ${ }^{77}$

Estimation of the monopsony conduct parameter requires data on hospital transaction prices, marginal costs, and output. These data requirements are essentially the same as those described in section 4.4 for estimating the exercise of monopoly power. As indicated there, such data are commonly available in state hospital discharge databases. Analogous to the estimation 
of monopoly power by a seller, identification of the parameter $\theta_{M S}$ requires the presence of a supply rotator $^{78}$ (which changes the elasticity of supply) as an instrument for marginal supply. The basic idea is as follows. If the market is competitive, rotation of supply around the competitive equilibrium point will not change price or quantity. If the market if monopsonistic, however, the equilibrium price and quantity will change. Candidates for hospital supply rotators are factor prices in other industries (in the case of hospitals, prices paid by Medicare or Medicaid), non-operating income (e.g., from endowments or other sources, or, changes in the technology of producing hospital output. Changes in the technology of producing hospital services seem ideal for this task, although measuring them in a meaningful way may be difficult. Hospital non-operating income also seems a good candidate for a supply rotator, since not-forprofit hospitals' behavior may be subject to income effects. We are not aware of any studies of monopsony power in health care that utilize this approach. As indicated in the section that follows, existing studies have used a structure-conduct-performance approach to estimating monopsony power. As indicated previously in section 4.4, while such an approach can yield some interesting and useful correlations, it suffers from serious limitations. Applying more structural approaches to estimation may lead to significant advances in our understanding of the exercise of monopsony power in these markets.

\subsubsection{Studies of monopsony in health care markets}

There have been two areas in health care in which the question of monopsony power has arisen. These areas are insurers negotiating prices for health care services and the purchase of nursing labor by hospitals. We only discuss studies attempting to detect insurer exercise of monopsony power. See Sullivan (1989) for a state of the art test of monopsony power in the market for nurses and a survey of the literature in this area.

The question with regard to insurer negotiation of prices with providers is whether the insurer possesses monopsony power that allows them to artificially depress price and what the welfare impact of this exercise of monopsony power might be. This issue has been discussed in a number of articles [Feldman and Greenberg (1981), Adamache and Sloan (1983), Staten et al. (1987), Pauly (1987), Staten et al. (1987), Pauly (1988a, b, c), Frech (1988), Melnick et al. (1992), Foreman et al. (1996)] which have focussed on discounts obtained from providers by Blue Cross/Blue Shield plans. These studies have focused solely on the unilateral exercise of monopsony power.

While monopsony power is normally defined as the ability to price below marginal factor cost, it is clear that this ability is predicated on the purchaser's ability to buy elsewhere. If insurers have no power to control the providers from which their patients obtain care, they cannot possibly exercise monopsony power. Frech (1996) discusses how Blue Cross and Blue Shield plans were able to direct patients via their use of "participating provider" programs. ${ }^{79}$ Adamache and Sloan (1983), Feldman and Greenberg (1981), Frech (1988), and Foreman et al. (1996) find a positive relationship between Blue Cross market share (in the insurance market) and the size of hospital discounts from list prices (or simply lower hospital prices). Melnick et al. (1992) find a significant negative relationship between Blue Cross market share in the hospital and the hospital's negotiated prices. Foreman et al. find a significant negative relationship between Blue 
Cross market share in the insurance market and Blue Cross payments per beneficiary. Staten et al. (1987), however, find no significant relationship between the discounts Blue Cross receives from hospitals and Blue Cross market share in that hospital, although the point estimates are consistent with the earlier studies (Blue Cross market share positively related to hospital discounts). Frech (1988) finds a positive relationship between Blue Cross discount and per capita health expenditures. While not conclusive, this is consistent with monopsony power leading to higher marginal costs and higher output prices (if the monopsonist also possesses monopoly power in the output market). Overall, these findings indicate a negative relationship between insurer market share and hospital prices.

While these results are interesting, there are a number of methodological issues regarding whether one can infer monopsony power from these findings. First, strictly speaking, the monopsonistic structure of the market for hospital services is not necessarily related to the structure of the market for health insurance Pauly (1988b, 1998). As a consequence, Blue Cross market share (or any other measure of health insurance market structure) is not the conceptually appropriate measure of the structure of the market for selling hospital services. It is, however, likely that an insurer with monopsony power in a hospital market will also possess monopoly power in the health insurance market, especially if the geographic markets for both products are very similar.

Neither is Blue Cross share of a specific hospital's revenues an appropriate measure of monopsonistic structure. Monopsony concentration is how concentrated sales are among buyers. Thus, for example, a monopsony Herfindahl index would use buyer's market shares of output purchased for the entire market, not the share of a particular buyer for a particular seller.

The second point is that even if this is the case, it does not follow that an insurer with monopoly power will possess monopsony power. A monopoly health insurer may face a perfectly elastic supply of hospital services. Even though it is a single buyer, it will pay the competitive price for hospital services and purchase the competitive quantity. Third, it is not clear that regressions of price or price differentials against market share identify tests of hypotheses concerning market power. The negative relationship between premiums and market share may simply reflect movement along a demand curve, as opposed to identifying the exercise of market power.

Fourth, although the Feldman-Greenberg, Adamache-Sloan, and Foreman et al. studies treat Blue Cross market share as endogenous, it is not clear that there is sufficient power in their data to identify causal effects. ${ }^{80}$ Melnick et al. recognize the endogeneity of their Blue Cross share measure, but do not address it.

Fifth, as Pauly (1987) points out, the difference in Blue Cross and commercial insurer hospital payments isn't necessarily a measure of monopsony power. Monopsony power is properly measured by the price paid for the input or the quantity chosen of the input deviating from their competitive levels. Differential hospital prices for different insurers may reflect price discrimination by hospitals (i.e., hospital monopoly power) as opposed to insurer monopsony power. $^{81}$ 
Sixth, the variables used by these studies do not properly measure transactions prices. Staten et al. use the difference between total payments for Blue Cross and commercial insurers, while Foreman et al. use total Blue Cross payments per Blue Cross beneficiary. This undoubtedly includes quantity differences, thus it is difficult to know whether the estimated effects measure price differences or quantity differences due to differences in benefits or differences in enrollee characteristics between Blue Cross and other plans. Similarly, payments per member also include quantity effects. Feldman-Greenberg and Adamache-Sloan use (one minus) the ratio of the fraction of hospital charges paid by Blue Cross to the fraction of hospital charges paid by commercial insurers. This undoubtedly includes bad debts and payment refusals for uncovered services, as opposed to actual transaction prices. The best measure is that of Melnick et al., who have an index of prices actually paid to a hospital by the California Blue Cross PPO relative to the average of this index across all hospitals in the PPO network.

In the context of managed care, Pauly (1998) has noted that lower prices in hospital markets could result either due to increased buyer sensitivity to price (i.e., increased competition), or due to the exercise of monopsony power. Hence he concludes that merely observing lower prices in hospital markets doesn't provide sufficient information to identify the exercise of monopsony power. Pauly suggests that observing quantity will provide that information. The idea is that quantity will expand with lower prices under competition, while quantity will decrease with lower prices under monopsony. Pauly, however, assumes that managed care results in the elimination of moral hazard effects ex ante. However, if managed care does not eliminate moral hazard ex ante, competition can result in both a lower price and a reduction in quantity. A benevolent, omniscient, insurer will ration care ex post and thereby improve consumers' welfare. A lower price will lead to more rationing, hence under managed care competition can be associated with a reduction in quantity [see Gaynor et al. (1998)]. The consequence is that simple reduced form estimation does not suffice to identify the exercise of monopsony power.

One important difference between health care markets and most other markets is that health insurers do not directly choose the quantity of the intermediate good purchased (hospital services). Since consumers choose the quantity of hospital services, insurers do not perfectly control the quantity of the intermediate good, even if they "manage" care. Further, since consumers bear only part of the cost of hospital services they consume, they will demand more hospital services than will an insurer. ${ }^{82}$ Consumers' demand will depend on the price of hospital care, the health insurance premium, and the coinsurance rate. In the "normal" case of monopsony, the buyer chooses a quantity that is off its "demand" curve (strictly speaking a buyer's demand curve doesn't exist in monopsony, just as a supply curve doesn't exist in monopoly), but on the seller's supply curve. In this case, however, consumers will demand more than the quantity the insurer wants to buy and the hospitals want to sell at the monopsony price, due to moral hazard. However, an insurer will still have an expected quantity of hospital services that consumers will choose at each hospital price, premium, and coinsurance rate. The task of the insurer is then to choose the hospital price, insurance premium, and coinsurance rate to maximize profit, subject to the constraint that consumers' demand equals supply. If there is not a profit maximizing coinsurance rate that balances consumer demand with supply at the 
monopsony price, then the insurer will not fully exercise its monopsony power. It is possible that there will be no exercise of monopsony power in this situation at all. Pauly (1988b) is the only paper of which we are aware that recognizes this issue, although Pauly does not impose the constraint that demand must equal supply. Formal modeling of the optimal choice of hospital price and insurance policy by an insurer possessing monopsony power remains to be done. The normative consequence is that if an insurer doesn't fully exercise its monopsony power the usual welfare consequences of monopsony may not be present in health care markets.

Overall, while the bulk of the empirical work in this area has been consistent with the exercise of monopsony power by health insurers, existing studies have not directly tested the monopsony power hypothesis. An agenda for future empirical research is to employ structural methods, as reviewed in section 5.2.3, to identify this conduct.

As stated at the outset of this section, the courts have uniformly rejected attempts to prosecute the unilateral exercise of monopsony power. Nonetheless, as insurance and health care markets continue to evolve it is very likely that cases will arise that involve allegations of merger for monopsony or practices intended to create or extend monopsony power. Advancing economic research in this area will provide the basis for the economics analysis that will be necessary to support good legal decisions.

\subsection{Bilateral market power}

\subsubsection{Identifying bilateral market power}

While the discussions in the preceding two sections have focused on monopoly power and monopsony power in isolation, it is reasonable to suppose that there are health care markets in which both are present. While bilateral monopoly is a classic textbook example, it is rarely considered explicitly in most studies of organized markets. Health care may be a case, however, in which bilateral possession of market power is relevant [Pauly (1998)]. Markets for hospital services are frequently characterized by both a small number of hospitals and a small number of insurers (buyers). Recent consolidation among insurers, hospitals, and physicians has increased the number of markets where this is likely to be true.

Identification of market conduct becomes difficult in this case. In particular, neither movements in prices nor quantities serve to identify monopoly or monopsony power when either is possible. To illustrate, consider an observed price decrease and corresponding quantity increase for a hospital. Such a change could be caused by an increase in the price elasticity of demand facing a hospital, i.e., a decrease in monopoly power. However it could just as well be caused by an increase in the elasticity of hospital supply (marginal cost) facing a monopsony insurer. This situation requires separate identification of monopoly and monopsony power effects.

Consider the following framework. Suppose that the price for hospital services $\left(p_{x}\right)$ is determined as a weighted average of the monopoly price and the monopsony price. We remain agnostic about the process by which this occurs, although one possibility is that this is the Nash 
bargaining outcome, in which case the weights represent relative bargaining power. ${ }^{83}$ Price can then be represented by the following equation,

$$
\begin{aligned}
p_{x} & =\omega\left[c_{x}-p_{x}^{\prime} \cdot x \cdot \omega \cdot \theta_{M P}\right]+(1-\omega)\left[c_{x}+c_{x x} \cdot x \cdot \theta_{M S}\right] \\
& =c_{x}-p_{x}^{\prime} \cdot x \cdot \omega \cdot \theta_{M P}+c_{x x} \cdot x \cdot(1-\omega) \cdot \theta_{M S}
\end{aligned}
$$

where $\omega$ is the weight on monopoly versus monopsony, $c$ is the cost of production for $x, p_{x}^{\prime}$ is the first derivative of inverse demand with respect to $x, \theta_{M P}$ is the monopoly conduct parameter, and $\theta_{M S}$ is the monopsony conduct parameter. The first terms in square brackets represent the monopoly outcome and the second set of terms in brackets represent the monopsony outcome. While it may not be possible to identify $\omega$ separately from $\theta_{M P}$ and $\theta_{M S}$, it will be possible to identify $\omega \theta_{M P}$ separately from $(1-\omega) \theta_{M S}$ by the use of a demand rotator and a supply/marginal cost rotator as instruments, respectively. Separate identification of $\omega$ may be possible via functional form assumptions (i.e., nonlinearities) or by the use of instruments that affect relative bargaining strength, but not demand, marginal cost, or marginal factor cost. ${ }^{84}$ Regulations, such as those which govern selective contracting by insurers, are potential candidates.

One thing this analysis points out is that estimates of monopoly or monopsony conduct which assume the absence of one will underestimate the true value of the conduct parameter, since what is identified is monopoly relative to monopsony power, not the absolute values of either. Consider for the moment monopoly power (the same points will also hold for monopsony). If it is assumed that there is no monopsony power when there actually is, then the degree of monopoly power will be underestimated. The parameter recovered from the data will be an estimate of $\omega \theta_{M P}$, not of $\theta_{M P}$. This issue has been ignored in most NEIO studies of market power. The reason may be that it appears to be reasonable to assume no monopsony power in most other markets studied by industrial organization economists, such as automobiles, steel, railroads, etc. This may not be the case, however, as a number of studies have found a negative impact of buyer concentration on seller price-cost margins. ${ }^{85}$ In health care, however, bilateral market power is definitely an issue which should not be ignored.

\subsubsection{Welfare implications}

The presence of market power on both sides of a market changes welfare analysis from the case where there is market power only on one side (monopoly or monopsony only). The theory of the second-best applies, and if one market distortion is fixed, adding another may improve welfare. For example, if we take monopoly power as given, an increase in monopsony power can be welfare improving. This will not, however, be true in general. First, whether monopsony results in increased or decreased quantity depends on the relative elasticities of supply and demand. If supply is more elastic than demand, then the monopsony output will be greater than the monopoly output, and monopsony is welfare improving. The reverse is true when supply is more elastic than demand. In this case the distortion from monopsony is worse than the monopoly distortion. Thus, while monopsony in the face of monopoly (or vice versa) may be used for a "countervailing market power defense" [Blair and Harrison (1993)], any resulting efficiencies are 
not automatic and hence the efficiency of the countervailing power must be established. ${ }^{86}$ The one case in which monopsony is definitely welfare improving is when supply is perfectly elastic. $^{87}$ In that case marginal factor cost is identical with marginal cost and the monopsony outcome is the same as the perfectly competitive outcome, so the result of monopsony power is to completely offset monopoly power and restore the competitive equilibrium outcome.

While it is possible for bilateral monopoly to improve welfare over simple monopoly or monopsony, it is never preferable to perfect competition. For example, consider a hospital merger which would lead to a substantial increase in monopoly power in a market dominated by a single insurer. While the merger could be allowed on the efficiency grounds previously described, a superior policy would be to maintain competition in the hospital market and remove constraints to competition in the insurance market.

Pure bilateral monopoly will rarely, if ever, be observed in practice. The most likely situation is that of bilateral oligopoly. Since there are no general results on the welfare effects of oligopoly, we cannot say in general what the welfare impacts of countervailing power might be when there is oligopoly (oligopsony) power on both sides of the market.

\subsubsection{Studies of relative bargaining power}

Empirical work on this issue has been rare. There are, however, two studies which have addressed themselves to this issue. Melnick et al. (1992) examine the impact of Blue Cross' share of a hospital's inpatient days, a hospital's share of Blue Cross' total hospital days, and the Herfindahl index in the hospital's market on the hospital prices paid by the California Blue Cross PPO. They find that Blue Cross' share of the hospital's days has a negative impact on price, a hospital's share of Blue Cross' days has a positive impact on price, concentration in the hospital market is positively related to price, and the positive impact hospital share of Blue Cross days on price is greater in more concentrated hospital markets. These results demonstrate very interesting associations, but as Melnick et al. emphasize, they should not be regarded as definitive. As mentioned in the preceding section, there are issues with endogeneity, market definition, and measurement of market share. In addition, the Blue Cross PPO had at most an $8.9 \%$ share of patient days in California hospitals, while the mean was 2.6\%. As such, the results seem somewhat strong for such small shares of hospitals' output.

Brooks et al. (1997) specify and estimate a Nash bargaining model of hospital-insurer bargaining over prices. The paper represents a significant advance over other work by writing down a carefully specified theoretical model of bargaining. The model, however, is one of bilateral monopoly, while most real world situations are likely to involve bilateral oligopoly. Brooks et al. estimate the relative bargaining power parameter using measures of actual transactions prices for a specific condition, appendectomy. The focus on a specific condition eliminates concerns about proper comparisons between aggregate payments or price indexes across hospitals. The choice of appendectomy is particularly felicitous, since this is a condition for which treatment is likely to be relatively homogeneous compared to many others. Further, they could control for severity or complication differences by differences in diagnosis. 
The estimating equation which is derived directly from the structural model is

$$
P-P_{L}=\gamma\left(P_{T}-P_{L}\right)+\varepsilon
$$

where $P$ is the transaction price, $P_{L}$ is the hospital's reservation price, $P_{T}$ is the insurer's reservation price, $\gamma$ is the bargaining power parameter, and $\varepsilon$ is an error term. In order to explore whether relative bargaining power is influenced by characteristics such as market structure, Brooks et al. also estimate

$$
P-P_{L}=(\alpha+\beta Z)\left(P_{T}-P_{L}\right)+\varepsilon
$$

where $Z$ is a vector of exogenous influences of bargaining power. Brooks et al. report a point estimate of 0.686 for $\gamma$. This indicates that hospitals have relatively more bargaining power than insurers, which is not consistent with insurers possessing monopsony power. They find that hospitals in more concentrated markets for appendectomies have greater bargaining power. They did not include any measures of concentration in the insurance market, although the proportion of the population enrolled in HMOs is estimated to have a positive impact on hospital bargaining power. This may proxy for concentration in the market for buyers of hospital services.

Estimation of the bargaining power parameter requires knowledge of each party's disagreement, or threat, points. In this case the threat points are the reservation prices for the hospital and for the insurer. The reservation price for the insurer is assumed to be the hospital's list price. Brooks et al. did not have actual list prices, so they used a regression model to estimate a predicted list charge. The reservation price is then assumed to be the greater of the predicted list charge or actual price. The reservation price for the hospital is assumed to be either the cost of a unit of output or the next best price paid by an alternative seller. Again, these are not observed, so Brooks et al. use an involved procedure to estimate this. $P_{L}$ is taken to be the minimum of an estimate of what Medicare reimbursement would be, the predicted list charge, or the actual price. There are some potential problems with this approach. First, it isn't obvious that a list price represents a buyer's reservation price when buyers have alternative sellers from which to choose. If buyers choose sellers to negotiate with based at least in part on list prices, then list prices will likely be set below a buyer's reservation price. Analogously, it is not clear that alternative sellers' prices represent the reservation price. Second, there is the question of correcting for sampling error in the reservation price estimates, and separately, about whether these are endogenous. Third, if the predicted Medicare price and predicted list price are both greater than the transaction price, then the estimates of the hospital's and the insurer's reservation prices are both equal to the transaction price, and hence there is no gain from bargaining.

The factors $Z$ affecting relative bargaining power are assumed to be represented by a Herfindahl index calculated for appendectomies, the number of hospitals, the proportion of the population enrolled in HMOs, state dummy variables, and a number of hospital characteristics. As discussed above, the results seem reasonable, although this regression resembles a priceconcentration regression typical of the studies of hospital competition discussed in section 4.4. As such, it shares their virtues and limitations. 


\section{4. $\quad$ Foreclosure 88}

The other major form of vertical behavior that has been of concern in health care antitrust have been vertical restraints that tend to reduce competition in the of the markets involved. These include vertical integration, exclusive dealing, and most-favored-nations contracts. ${ }^{89} \mathrm{~A}$ commonly used term for this effect is "foreclosure." The reason for concern is obvious. Consider a situation with a health insurance duopoly and a hospital monopoly. If one of the insurers integrates with the hospital or engages it in an exclusive contract, it will have the ability to foreclose the other insurer from the market, thereby gaining monopoly power. This is, however, an unsettled area, both in economics and in antitrust. As the Chicago School pointed out, in situations like that in the preceding example, foreclosure will not necessarily occur, since it requires that foreclosure is profitable both for the insurer and for the hospital. Further, there are potential efficiency gains associated with vertical restraints. The Post-Chicago School acknowledges this and analyzes the circumstances under which foreclosure can occur as an equilibrium phenomenon. Since vertical restraints both involve potential anti-competitive effects and efficiencies, antitrust cases involving (non-price) ${ }^{90}$ vertical restraints are judged on a rule of reason basis. This makes economic analysis of effects on competition and efficiencies essential in such cases.

Table 6 contains a listing of some of these cases. ${ }^{91}$ These cases have concerned vertical integration, exclusive dealing, and most-favored-nation contracts. The courts for the most part have found for the defendants, finding insufficient evidence of anti-competitive effects. As indicated previously, the vast bulk of exclusive dealing cases or vertical integration cases have been rejected by the courts impacts (e.g., Hyde, Vicksburg, Marshfield). The Oltz case represents an exception. In this case a group of anesthesiologists obtained an exclusive contract from a hospital after threatening to leave if a nurse anesthetist was not fired. The anesthesiologists' annual incomes increased by over 40 percent after the nurse anesthetist was fired, from which the court concluded that the exclusive deal had an anti-competitive effect [Frech and Danger (1998)]. In some recent cases involving vertical integration (Marshfield, Vicksburg) the courts did consider the possibility of anti-competitive effects of vertical integration, although they concluded that such effects were not present in those situations. The courts have also been unsympathetic to claims of anti-competitive effects from most-favorednation (MFN) contracts (e.g., Marshfield, Ocean State). In a recent case breaking with this precedent (Delta Dental), the court found for the plaintiff, banning the use of most-favorednation clauses in a consent decree. The court also found for the plaintiff in the Reazin case.

\section{[INSERT TABLE 6 ABOUT HERE.]}

There has not been a great deal of research in health economics on these issues, although there has been some recent increase in research in this area. We expect that this will increase as these issues increase in importance with the spread of managed care and these forms of vertical restraint [see Gaynor and Haas-Wilson (1998)]. In what follows we first review the general literature on vertical restraints, discussing its relevance to health care, and then turn to the health economics literature. 


\subsubsection{Efficiencies}

One line of investigation in the economics literature has been concerned with understanding the potential efficiencies associated with vertical integration and vertical restraints, such as exclusive dealing agreements. Both vertical integration and vertical restraints can be efficiency enhancing by leading to more efficient input pricing, lowering transactions costs, assuring supply of an input, improving coordination between the firms, and improving monitoring [Coase (1937), Spengler (1950), Klein et al. (1978), Williamson (1975, 1989), Carlton and Perloff (1994), Riordan and Salop (1995)]. There is some empirical evidence indicating efficiency gains from vertical restraints [LaFontaine (1992), Masten (1984), Spiller(1985), Crocker and Reynolds (1993), Lieberman (1991)].

\subsubsection{Anti-competitive concerns}

The economics literature on the anti-competitive impacts of vertical restraints has been extremely unsettled. Early court decisions were extremely restrictive in their treatment of vertical restraints due to concern that these restraints could lead to market foreclosure and consequently be harmful to competition. ${ }^{92}$ Strong criticism of case law by the Chicago School led to a new perspective in which vertical restraints were viewed as competitively neutral or procompetitive [Bork (1978)]. Current thinking on vertical restraints builds upon the Chicago School critique by applying modern industrial organization theory to the analysis of more realistic market structures and conduct. This "Post-Chicago School" literature [Riordan and Salop (1995)] identifies situations in which vertical restraints can raise concerns about competition. ${ }^{93}$ In what follows we discuss the literature on vertical integration and exclusive dealing together, since they are analytically similar, and then discuss the literature on most-favored-nations (MFN) contracts.

\subsection{2.i. Vertical integration and exclusive dealing}

The Chicago School critique of antitrust policy toward vertical integration and exclusive dealing consists of three main points. First, vertical integration or exclusive dealing between a downstream firm and an upstream supplier does not necessarily imply that the net supply of inputs to rival downstream firms is reduced. ${ }^{94}$ For example, with multiple upstream firms, rival downstream firms may now have access to other suppliers previously utilized by the firm involved in the merger or the exclusive deal. Just because access to one supplier is foreclosed does not mean that the net supply of inputs has been foreclosed. In addition, entry can occur in the upstream market, either by independent entrants, or by the excluded downstream firms themselves. So even if there is an upstream monopoly, vertical integration or exclusive dealing does not necessarily imply foreclosure. Second, the Chicago School claims that a monopolist cannot enhance its monopoly power by the use of exclusive dealing or other vertical restraints. There is a "single monopoly profit," regardless of the nature of vertical relations [Bork (1978, p.229)]. In the case of the upstream monopolist above, the upstream firm has nothing to gain from such a merger, since it is already maximizing its profits by selling to the entire downstream industry as a monopolist. Third, the Chicago School criticizes the case law on forward integration on the grounds that upstream firms could not induce downstream firms to accept 
exclusionary contracts if such contracts actually hurt the downstream firms [Director and Levi (1956)]. In the case with multiple upstream firms above, if the unintegrated upstream firms gain market power as a result of the vertical merger, the upstream firm approached by the downstream firm has an incentive to remain unintegrated. The downstream firm must compensate an upstream partner for lost profits, potentially rendering the deal unprofitable. Posner (1976, p. 212) and Bork (1978, p. 309) conclude that exclusionary contracts cannot cause any harm and therefore ought to be disregarded by antitrust law. The Chicago School conclusion is that since there are no anti-competitive impacts of vertical integration or exclusive dealing, these vertical restraints will only exist where they result in efficiencies, hence they must be beneficial.

The Chicago School view is based on economic models that employ strong assumptions. In particular, the result of a single monopoly profit depends critically on the assumptions of a fixed proportions technology, perfect competition in the upstream or input market, and monopoly in the downstream or output market with prohibitive barriers to entry. ${ }^{95}$ The results are critically sensitive to these assumptions [Riordan and Salop (1995), Westfield (1981), Vernon and Graham (1971)]. These assumptions do not hold in most markets and certainly do not hold in health care markets.

The Post-Chicago School literature argues that vertical restraints can enhance efficiency, but also that vertical restraints can be anti-competitive under certain conditions. The anticompetitive impacts of vertical restraints come from: 1) the potential for a vertically related firm to raise rivals' costs and/or foreclose rivals' access to a necessary market and 2) the potential for vertical relations to confer market power by facilitating horizontal coordination or collusion.

A number of papers [Salinger (1988), Ordover et al. (1990), Hart and Tirole (1990), Bolton and Whinston (1993), Riordan (1998), Choi and Yi (1996)] demonstrate that vertical integration sometimes can lead to foreclosure in equilibrium, concluding that vertical integration may be anti-competitive. ${ }^{96}$

Another concern with vertical restraints is that they may act as facilitating devices, leading to horizontal collusion. For example, if a downstream firm is integrated with an upstream input supplier but continues to buy inputs from other upstream firms then it will receive price quotes and other information from these firms. It can also transmit information from the integrated upstream firm to the other upstream firms. This information can be used to facilitate collusive practices in the upstream market [Riordan and Salop (1995)]. In addition, an increase in the market power of a firm through a vertical agreement may provide it with sufficient power to initiate or enforce collusive horizontal behavior.

The concern over exclusive dealing agreements is the same as that with vertical integration: can they can lead to market foreclosure or facilitate horizontal collusion Whether there is foreclosure critically depends on whether an exclusive deal reduces the net supply of inputs to rival firms in the downstream market. If access is reduced, then exclusive dealing agreements will raise the cost of doing business to rival firms [Krattenmaker and Salop (1986a, 1986b), Salop and Scheffman $(1983,1987)]$. This will put rival downstream firms at a cost disadvantage, increase the market power and the profits of the downstream firm with the 
exclusive deal, and reduce social welfare [Katz (1989), Comanor and Frech (1985), Mathewson and Winter (1987), Schwartz (1987)]. Not only can this deter entry into the downstream market or increase the unilateral market power of the downstream firm with exclusive contracts, it can make collusive agreements among downstream firms more likely. An increase in the market power of the firm with exclusive contracts can provide it with the necessary power to implement and enforce collusive agreements [Riordan and Salop (1995)]. A number of papers show that an exclusionary equilibrium can exist if it is not possible for the upstream firms to coordinate with each other [Aghion and Bolton (1987), Katz (1989), Rasmusen et al. (1991)].

While the vast bulk of the literature on the anti-competitive impacts of vertical integration or exclusive dealing is theoretical, there have been some attempts to empirically test whether there are strategic motives for vertical integration. Lieberman (1991) and Spiller (1985) attempt to distinguish between efficiencies and anti-competitive explanations for vertical mergers. Neither study finds any support for the anti-competitive hypothesis.

\subsection{2.ii. Most favored nation clauses}

Most-favored-nation (MFN) clauses, also called most-favored-customer clauses, are vertical contractual agreements in which the seller (for example, a hospital or physician group/network) agrees not to charge the buyer (for example, an insurer) more than the lowest price it charges any other buyer. If the seller offers another buyer a lower price, then the seller must offer the same lower price to the buyer with the MFN clause. MFN clauses have appeared in contracts between health care providers and HMOs, Blue Cross and Blue Shield plans, managed dental plans, pharmacy networks, and vision care insurers. ${ }^{97}$

Recent work on MFN contracts also shows that such contracts can have anti-competitive effects in some situations; however, Chicago School analysts have interpreted MFN clauses as simply representing efforts by firms to obtain low prices and therefore as promoting competition [Posner (1995)]. Indeed, the fact that firms are willing to sign such contracts is interpreted as evidence that such contracts must not be harmful.

Modern theoretical analyses find, however, both that MFN clauses have the potential to be anti-competitive [Salop (1986), Cooper (1986), Png and Hirshleifer (1987), Baker (1996)] and efficiency enhancing [Butz (1990), Png (1991), Cooper and Fries (1995)]. ${ }^{98}$

MFN clauses may impair horizontal competition in at least two ways. First, MFN clauses may facilitate tacit coordination [Salop (1986)]. In the case of health care, MFN clauses may decrease competition among health care providers by reducing providers' incentives to offer lower prices to insurers. Since any discount the provider grants to another insurer means granting the discount to its partner in the MFN contract, the provider must grant the discount on all the inframarginal units it sells to its partner. This makes price reductions very costly and may be a way to signal a commitment to collusive pricing. Further, MFN clauses may reduce insurers' incentives to bargain with providers for lower prices, since rival insurers with MFN clauses would reap the benefits of the lower prices too. If MFN clauses facilitate coordination among providers and discourage selective discounting, then MFN clauses will lead to higher 
prices for health care services and/or lower quality health care services. The limiting factor on this behavior is the ease of entry or expansion into the market. If potential competitors or existing rivals can enter or expand easily, then the anti-competitive impacts of MFN contracts will be limited.

Second, MFN clauses may increase rival insurers' costs and thereby deter entry. When an insurer with a large market share signs a contract including a MFN clause with a large hospital or physician group, that insurer has effectively increased its own costs and the costs of rival insurers and potential rivals in the insurance market. The MFN clause assures that the hospital or physician group will not offer to provide services at lower fees to rival insurers or potential entrants. Thus, a large insurer getting most-favored-customer treatment may be able to charge prices above the competitive level or lower quality below the competitive level.

There has been very little empirical research on the impacts of MFN clauses. One study is by Crocker and Lyon (1994), who study the use of MFN clauses in natural gas contracts. They conclude that the impact is to improve efficiency, not decrease competition.

\subsubsection{Health economics research on vertical restraints}

There has not been very extensive research in health economics on vertical restraints. Three recent papers consider the impacts of exclusive dealing between insurers and providers on competition in the insurance market. Gaynor and Ma (1996) consider differentiated health care providers and homogeneous insurers. Thus providers possess some market power, but the insurance market is perfectly competitive. Individuals, however, do not know which provider they will prefer should they fall ill and they are risk neutral with regard to this uncertainty, so, in essence, health care providers are homogeneous ex ante. Since exclusive dealing means that both the insurer and the provider must be chosen ex ante, this effectively eliminates the differentiation between the providers. There is no anti-competitive effect in equilibrium, since the insurance market is perfectly competitive. Further, there is no ability to commit. The result is that exclusive dealing cannot create market power where there was none. Gal-Or (1996) considers the same problem, but with differentiated insurers. With differentiated insurers foreclosure can occur in equilibrium. In this case, a provider who agrees to an exclusive deal with an insurer will likely accept a lower payment rate in return for a larger volume of patients. If both insurers sign exclusive deals with different providers, this benefits insurers by reducing the outside options of the providers and thus reducing their payment rates. Encinosa (1996) considers exclusive deals between HMOs and physician groups. There is an incumbent HMO which has a cost advantage over a rival, but must invest in order to serve the entire market. When the incumbent HMO is risk averse, it may engage in an exclusive deal with the single provider. This will result in foreclosure and is socially inefficient. At present, however, exclusive contracts per se appear to be relatively rare between insurers and health care providers. Long term services contracts are common, and may confer a degree of exclusivity on an insurer who is a large buyer.

Exclusive contracts between hospitals and physicians are common [Frech and Danger (1998)]. In antitrust cases in this area, plaintiffs have argued that the exclusive contract(s) 
between a hospital and a group of physicians amounts to tying, since consumers who wish to buy from the hospital must also buy from the particular physician group. The counterargument is that tying does not increase hospital profits [Lynk (1984)]. It has additionally been contended that exclusive deals between hospitals and physicians are harmful to physician competition. If hospitals are controlled to a significant degree by their physician staffs, they may agree to an exclusive deal that reduces competition in the physician market and increases the staff's profits, even if it harms hospital profits [Frech and Danger (1998)]. Alternatively, exclusive dealing between a hospital and a physician group may increase quality or efficiency [Blackstone and Fuhr (1984), Lynk and Morrisey (1987)].

Lynk and Morrisey (1987) empirically examine the impact of hospital market power on the probability of an exclusive contract between a hospital and physicians. Lynk and Morrisey use county level hospital market share and Herfindahl index as measures of market structure. They find a negative relationship between hospital market share and the probability of an exclusive contract, which they interpret an rejecting the hypothesis of exclusive contracts being anti-competitive. Danger and Frech (1998), however, point out that Lynk and Morrisey erred in calculating the total effect of market share, taking into account the effect on the Herfindahl index. Their corrected estimates indicate a positive impact of hospital market share on the probability of an exclusive contract. Neither of these efforts, however, directly test the main hypothesis of an anti-competitive effect of exclusive dealing between hospitals and physicians: that it will reduce competition and increase price in the physician services market. Hospital market power seems to be a necessary, but not sufficient condition for this effect.

Some recent studies have considered possible gains from vertical integration between hospitals, physicians, and insurers [Conrad and Shortell (1996), Walston,Kimberley, and Burns (1996)]. These studies have found very little evidence of increased efficiency or quality due to integration. We are not aware of any empirical attempts to test whether such integration affects competition.

While the use of MFN clauses has been fairly common in health care through Blue Cross reimbursement contracting with physicians, we are aware of no studies that directly examine this issue. Scott Morton (1997) is a recent study of the impact of the adoption by the Medicaid program of an MFN clause in purchasing pharmaceuticals. Scott Morton finds that prices of brand name drugs facing competition from generics increased about 4 percent after the Medicaid MFN policy took effect. She finds no impact on the prices of patented drugs. In addition, the prices of generic drugs rose more in concentrated markets following the introduction of the policy. These results suggest that the MFN clause may have softened price competition.

\section{Conclusions}

In this chapter we have reviewed the relevant research issues on the economics of competition and antitrust in health care markets. We have attempted to summarize the current literature, indicating what we know and what we don't know on the basis of these research findings. Where appropriate we have attempted to suggest methodological approaches for some of the 
major research issues in this area: in particular hospital competition and insurer monopsony or bilateral market power between insurers and hospitals.

Although there has been a significant amount of research in health economics on the competitive workings of health care markets, in some sense research in this area is still in its infancy. Since only relatively recently has vigorous competition emerged in health care markets, concomitant with the vigorous application of antitrust, much remains to be understood about competition and antitrust in health care. In addition, the rich set of behaviors and data from health care markets may be of use to industrial organization economists and antitrust analysts wishing to understand the impacts of some facilitating practices generally. 
${ }^{1}$ While many health care systems outside the U.S. do not depend to the same degree on markets, competition is nonetheless important. In particular, where there is competitive bidding or any system that uses cross firm comparisons for contracting, competition will be important to ensure efficiency. We do not discuss such issues in this chapter. See the chapter by Chalkley and Malcomson on government purchasing of health services.

${ }^{2}$ See also the chapter in this Handbook by David Dranove and Mark Satterthwaite on the industrial organization of health care.

${ }^{3}$ See the chapter in this Handbook by Thomas McGuire on physicians, Gaynor (1994), or Frech (1996) for a review of issues concerning physician markets.

${ }^{4}$ See the chapter in this Handbook on pharmaceuticals by F.M. Scherer.

${ }^{5}$ For a fuller description see Miles (1998), Chapter 1.

${ }^{6}$ Note that competition policy issues have emerged in a number of countries as reforms have attempted to create market incentives in the health system.

${ }^{7}$ See Chapter 1, "General Background” in Miles (1998).

${ }^{8}$ For example, American Medical Ass'n., 94 F.T.C. 701 (1980), enforced, 638 F.2d 443 (2d Cir. 1980), aff; d by equally divided court, 455 U.S. 6765 (1982).

${ }^{9}$ Goldfarb v. Virgina State Bar, op. cit., Arizona v. Maricopa County Medical Soc'y, 457 U.S. 332 (1982).

${ }^{10}$ American Medical Association v. United States, op. cit., American Soc'y of Anesthesiologists, 93 F.T.C. 101 (1979) (consent order).

${ }^{11}$ Wilk v. American Medical Ass'n, 671 F. Supp. 1465 (N.D. Ill. 1987), aff'd, 895 F.2d 352 ( $7^{\text {th }}$ Cir.) cert. denied, 496 U.S. 927 (1990).

${ }^{12}$ A government regulator or purchaser may still want competition among providers in order to provide incentives for efficiency and quality.

${ }^{13}$ Strictly speaking, this is true of tangible products as well. Steel of a certain grade produced at the same foundry varies between runs. No two cars are identical, even if they are produced on the same assembly line by the same 
workers. Even simple tap water varies in its composition. This is simply the nature of the physical world. Regardless, it is commonly agreed that services are inherently more heterogeneous than manufactured or mined goods.

${ }^{14}$ It would probably be more accurate to say that it is preference heterogeneity which is critical, since this should call forth heterogeneity in production by producers. This is especially likely to be true for services, since the cost of altering the product to suit the customer (e.g., a barber chatting more with his garrulous customers and less with his laconic ones) is likely to be low.

15 Over 88 percent of all physicians were located in metropolitan areas in 1989 [Roback et al., 1990].

${ }^{16}$ Even if physicians are very similar, information problems can cause patients to value physicians they know about (in terms of quality or characteristics they value) more highly. This can bestow market power on physicians and lead to a monopolistically competitive market structure even if physicians are essentially homogeneous. Information is discussed in the next section.

${ }^{17}$ More definite results can be derived in specific models. For example, Deneckere and Rothschild (1992) show for a class of models that competition is approximately optimal when firms' fixed costs go to zero relative to the size of the market.

${ }^{18}$ In an intriguing paper, Berry and Waldfogel (1997) present empirical evidence indicating that there is excessive entry in radio broadcasting. To our knowledge, this is the only empirical evidence on this issue.

${ }^{19}$ It is not clear that the results for a price regulated industry apply directly to health care. Since price is controlled by health care firms it is not clear that the results would carry through in a carefully specified model.

${ }^{20}$ United States v. Carilion Health System (892 F 2d 1042).

${ }^{21}$ Suspending for a moment the question of whether such strategies are rational or successful.

${ }^{22}$ This is essentially the intuition in Crew (1969). Gaynor et al. (1998) show this formally.

${ }^{23} \mathrm{He}$ assumes a homogeneous product. It is not clear what impact introducing product heterogeneity might have on the results. The papers which consider patient search with a heterogeneous product, e.g., Dranove and Satterthwaite (1992), do not consider the effects of insurance.

${ }^{24}$ Monopoly does have the advantage that the insurer knows the total quantity of a consumer's insurance purchases. Rothschild-Stiglitz assume that this is known in a competitive market, but it may be difficult for such a market to set 
up this exchange of information [see Jaynes (1978) and Hellwig (1988)]. If information cannot be exchanged by firms in the competitive market then competition results in a $3^{\text {rd }}$ best, and is thus inferior to monopoly.

${ }^{25}$ Hubbard (1997) investigates the functioning of the market for automobile repairs. He finds evidence inconsistent with significant agency problems in this market.

${ }^{26}$ See e.g., Darby and Karni (1972), Milgrom (1981), Wolinsky (1993), Plott and Wilde (1980), Crawford and Sobel (1980), Pitchik and Schotter (1987), Green and Stokey (1981), Nitzan and Tsur (1991) generally, and Pauly (1980), Dranove (1988), and Glazer and McGuire (1991) for discussions of this in health care.

${ }^{27}$ A recent paper by Ma et al. (1994) analyzes the case where the accuracy of the diagnosis is increasing in physician effort. Physician effort is noncontractible, and this noncontractability causes physicians to shirk and undersupply effort. ${ }^{28}$ See, however, Emons (1997) for a result in which no inducement occurs in equilibrium, even though sellers have the ability to induce.

${ }^{29}$ If marginal inducement costs are increasing, the results are indeterminate, because entry decreases the marginal revenue from inducement but also reduces marginal cost.

${ }^{30}$ See the chapter on regulation in this Handbook by David Salkever for more extensive discussion.

${ }^{31}$ Federal Trade Commission v. Butterworth Health Corporation and Blodgett Memorial Medical Center (1996, 2 Trade Cases 71,571); 1996 QL 570479 (W.D. Mich. September 26, 1996).

32 The DOJ/FTC Joint Merger Guidelines (U.S. Department of Justice and Federal Trade Commission, 1997) describe it as a five step process. The organization is somewhat different, but consists of essentially the same factors.

${ }^{33}$ These include the potential for entry and any likely impact, potential for efficiency gains, and the potential that one of the merging firms will fail without the merger.

${ }^{34}$ The HHI is defined as the sum of squared market shares for all firms in the market. The antitrust authorities use percentage of the market (as opposed to proportion) for market share, thus the maximum value for the $\mathrm{HHI}$ is 10,000 and the minimum is $n \cdot\left(\frac{100}{n}\right)^{2}=\frac{10,000}{n}$, where $n$ is the number of firms. 
35 Citations for the decisions are as follows: Poplar Bluff (FTC v. Tenet Healthcare (1998 ,US Dist Lexis 11849), Long Island (U.S. v. Long Island Jewish Medical Center, (1997-2 Trade Cases I771,960), Grand Rapids (FTC v. Butterworth Health Corporation (1996, 946 F.Supp. 1285), Dubuque (902 F.Supp. 968, 1995), Joplin (FTC v. Freeman Hospital (1995, 911 F.Supp. 1213), Ukiah (Adventist Health System/West (1994, 117 FTC 223), Augusta (District Court: FTC v. University Health, 1991-1 Trade Cases \$[69,444 Circuit Court: FTC v. University Health (11 ${ }^{\text {th }}$ Circuit, 1991, 938 F.2d 1206), Rockford (U.S. v. Rockford Memorial Corporation (1989, 717 F.Supp. 1251), Roanoke (U.S. v. Carilion Health System (707 F.Supp. 840)), Chattanooga (Hospital Corporation of America (1985, 106 FTC 361), San Luis Obispo (American Medical International (1984, 104 FTC 1)

${ }^{36}$ In fact, the court rarely accepts the government's (or the hospitals') case in its entirety, but for the government to prevail, the court must accept, in large measure, each of the government's points.

${ }^{37}$ Distance is an extremely important observed determinant of patient choice of hospital. Demand for a managed care plan's product depends on the hospitals in its network. Therefore a managed care plan has a derived demand for hospitals for its network based in part on hospitals' distances from consumers. Managed care demand also depends on price, which in turn is affected by hospitals' prices. Which of these two positions is correct depends on the tradeoff between price and distance consumers make when choosing insurance.

${ }^{38}$ While how far consumers are willing to travel for hospital care is not a settled matter, some empirical evidence indicates that managed care has almost no impact on the observed distance consumers travel for hospital services (Mobley and Frech, 1998).

39 All relative to prior decisions in other industries and to the Horizontal Merger Guidelines (U.S. Department of Justice and Federal Trade Commission, 1997). The Guidelines state that a market with an HHI below 1,000 is considered unconcentrated, a market with an HHI between 1,000 and 1,800 is considered moderately concentrated, and a market with an HHI above 1,800 is considered highly concentrated. Mergers in moderately concentrated markets that result in an $\mathrm{HHI}$ increase of 100 points or more are considered to potentially raise significant competitive concerns. In highly concentrated markets mergers that raise the HHI by more than 50 points but less than 100 points are considered to potentially raise significant competitive concerns. Mergers in highly concentrated 
markets that increase the HHI by 100 points or more are presumed likely to create, enhance, or facilitate the exercise of market power.

${ }^{40}$ The 1997 Guidelines for horizontal mergers are a revision of the 1992 Guidelines with regard to efficiencies. They are unchanged with regard to market definition. They do differ on market definition from the Guidelines previously issued by the DOJ in 1984 and the FTC in 1982.

${ }^{41}$ Actually, the guidelines say "small but significant and nontransitory" price increase and later go on to say that, most often, this means $5 \%$ for the period of at least one year.

${ }^{42}$ We note that the 1997 Guidelines specify market definition in terms of a price increase, holding the prices of all other goods constant. The 1984 DOJ Guidelines do not specify that all other prices are held constant. This difference gives rise to different implementation methods, as we discuss below.

${ }^{43}$ For general discussion of market definition, see Scherer and Ross (1990), pp. 176-184, Geroski (1998).

${ }^{44}$ Courts have not usually recognized this substitution as important, however. They appear to rely on the testimony of physicians that many inpatients could not easily substitute to outpatient care. This reasoning appears to be faulty, since the fact that some people are not price sensitive at current prices is irrelevant, unless hospitals somehow may price discriminate among patients who are and are not sensitive.

${ }^{45}$ Fixed proportions are not supported empirically. See Farley and Hogan (1990).

${ }^{46}$ Morrisey et al. (1988) advocate the use of this method for hospitals and illustrate its application.

47 Actually, the guidelines only use the Bertrand assumption to assess the profitable price rise after the hypothetical merger or cartelization.

${ }^{48}$ This basic method is due to Scheffman and Spiller (1987). They, however, propose using estimates of residual demand. This method takes, e.g., firm 3's reaction to firm 1 and 2's actions into account and substitutes this reaction function out, so the resulting demand is only in terms of the actions of firm 1 and firm 2. Using residual demand, rather than structural demand, as we propose, has the advantage of allowing for other firms' reactions to those of the "cartel" firms. There are two disadvantages, however. First, the 1997 (and 1992) Guidelines explicitly state that market definition takes all other firms' prices as given. This cannot be done using residual demand. Second, since residual demand is only in terms of the actions of the firms in the hypothetical cartel, separate residual demands must 
be estimated for every possible combination of firms. This may be an onerous or impossible task in markets with anything other than a small number of firms.

${ }^{49}$ The cellophane fallacy refers to a case in which the court concluded that cellophane was in the same product market as other flexible wrapping materials, based on a high cross-price elasticity of demand (U.S. v. E.I. duPont de Nemours and Co., 351 U.S. 377 (1956). A rational monopolist, however, will set its price so that its product is a substitute for alternatives. The reverse cellophane fallacy is drawing the false conclusion that a firm with a low cross-price elasticity of demand enjoys market power. The problem with respect to market definition is that the estimated price increase will be based on demand elasticities estimated at prevailing prices. If elasticity is not constant and there is not sufficient variation to estimate it over the range relevant for the simulated merger then a low elasticity may lead one to falsely conclude two firms are in the same market when in fact they are not.

${ }^{50}$ This example is from Berry (1994).

${ }^{51}$ Notice that our use of $\delta_{j}$ is slightly non-standard in this literature in that we break price out separately.

52 If the coinsurance rate and/or discount is equal across decision-makers, no bias in the elasticity of demand would arise; however, we do not believe that this is the case.

53 There is a widespread belief among researchers in health economics that there is substantial variation in quality among hospitals and that variation is difficult for third party analysts to measure. Indeed, there is a very large literature in health services research whose stated purpose is to develop measures of hospital quality. Since this literature has not met with great success and since there are so many different quality measures, there is a paucity of easily available evaluations of the relative quality of different hospitals; although, in recent years several states have released evaluations of hospital mortality and, for a time, the U.S. Health Care Financing Administration did the same. As a consequence, the issues raised here with respect to unobservable quality are relevant, although future developments in quality measurement may reduce the scope for these sorts of problems.

54 Of course, these facts can be rationalized by extreme scale economies or extreme errors arising from the distinction between accounting and economic profits.

${ }^{55}$ We ignore strategic interactions with other insurers for purposes of simplicity in exposition. This clearly would have to be part of a complete analysis. 
${ }^{56}$ We have ignored consumer choice of hospital conditional on insurance plan. While this is important in the insurer's decision, since they must take into account expected hospital utilization, consumer choice will not be affected by hospital prices since they are fully insured under managed care.

${ }^{57}$ We proceed as if $a$ is a scalar quantity. Making it a vector changes the analysis very little.

${ }^{58}$ Although conjectural variations are a convenient way to think about market power, firms' expectations are not measured empirically by $r$. what is measured empirically is the behavior of firms, so that firms behave "as if" their C.V. was $r$. See Breshnahan (1989) on this point. (If preferred, one can think of $1+r$ as a conduct parameter, as in Breshanan (1989)).

${ }^{59}$ Note that we have assumed identical preferences for both firms. If that were not the case, some method for aggregating the firms' preferences would have to be assumed.

${ }^{60}$ If $a$ represents charity care, this seems a reasonable procedure. If it represents an index of technological sophistication, it may also be a reasonable procedure. It seems least reasonable when $a$ is interpreted as "process" quality (Donabedian, 1980). In this case, perhaps "average" $a$ in some sense should be used instead.

${ }^{61}$ Note that in this analysis, we are implicitly assuming that the hospitals' residual demand curve has the functional form $p=\beta_{0}+\beta_{1} \ln Q+f(a)$. This simplifying assumption allows us to ignore the effect of changing the point at which demand is evaluated on marginal revenue, much as the linearity assumption on utility allowed us to ignore the effect of point of evaluation on the "marginal cost" attributable to the utility component. Relaxing the demand assumption also introduces additional complexity. In the case of linear utility functions as described in the text, a constant-elasticity demand will yield smaller price increases for NFPs, while with constant-slope demand, NFPs will have larger price increases. We are grateful to Tom Philipson for explaining the importance of the shape of the demand curve to us here.

${ }^{62}$ It is worth pointing out here that a NFP with a constant marginal utility of output, a zero marginal utility of profit (hence a binding profit constraint), acts like a NFP with a more sharply declining marginal utility of profit than marginal utility of output -- post-merger, the shadow price of profit will likely fall, since profit is more easily gotten, so that $\frac{U_{2}}{U_{1}+\lambda}\left(=\frac{U_{2}}{\lambda}\right)$ will fall post-merger. 
${ }^{63}$ For a related discussion, see Froeb et al. (forthcoming).

${ }^{64}$ A separate and interesting question is whether a regulator should be interested in only the price and (observable) quality effects of mergers. Presumably, the NFP form has evolved to predominate in the hospital industry for some reason, possibly related to information asymmetry [c.f. Frank and Salkever (1994)], and, in this case, the fact that NFPs have different objectives may mitigate the extent to which they exploit these asymmetries. Discovering that NFPs have different objectives from FPs might lead a regulator to adopt different attitudes towards them for reasons we do not model.

65 Again, for a more comprehensive review, see Dranove and White (1994) or the chapter in the Handbook by Dranove and Satterthwaite on Industrial Organization.

${ }^{66}$ The most numerous kind of antitrust suits in health care are vertical cases. These are private suits brought by physicians denied hospital staff privileges, which are invariably rejected by the courts. We do not discuss these since they have clearly been judged not to be relevant to competition.

${ }^{67}$ For example, Ball Memorial Hospital, Inc. v. Mutual Hospital Insurance, Inc. ( $7^{\text {th }}$ Circuit, 1986, 784 F.2d 1325) and Kartell v. Blue Shield of Massachusetts, Inc., (1 ${ }^{\text {st }}$ Circuit, 1984, 749 F.2d 922) cert. Denied, (1985, 471 U.S. 1029).

${ }^{68}$ See Miles (1998), Chapter 15, Section 22 for a complete listing of cases.

${ }^{69}$ See Scherer and Ross (1990, Chapter 14) for an exposition of the case where the buyer possesses monopoly power in the market for its output. The case when the buyer is a monopoly seller of its output is not qualitatively different from the case when it sells in a competitive market. Since the latter is simpler expositionally, we present that here. Nonetheless, it is straightforward to adapt this analysis to reflect selling market power on the part of the buyer.

${ }^{70}$ Note that since the price of hospital output, $c_{x}$, is a function of an endogenous variable, $x$, the factor demands are functions of the only two exogenous variables, $p_{y}$ and $q$.

${ }^{71}$ See also Pauly (1998) on this point.

${ }^{72}$ Lumber markets are like this. Trees are immobile and logs are heavy and difficult to transport. Boards, however, are much easier to transport. Hence markets for logs are usually local and often dominated by a single buyer or a small number of buyers, while markets for lumber are national, with many sellers. 
${ }^{73}$ Strictly speaking, if the market is perfectly competitive, any seller who can price below others will capture the entire market (i.e., Bertrand equilibrium). It is not clear in such a case that an equilibrium exists with monopsony power being exercised.

${ }^{74}$ For a somewhat different (but related) approach see Just and Chern (1980), who examine oligopsony power in the market for tomatoes. Sullivan (1989) examines monopsony power in the market for nurses using a very similar approach to what we describe here.

75 The exercise of market definition for monopsony can in principle be followed using the Merger Guidelines, as described in section 4.2.2, with the exercise calculating whether buyers acting as a cartel could decrease price by more than $5 \%$.

${ }^{76}$ Notice that this can be re-expressed as $p_{x}-p \cdot f_{x} / p_{x}=\left(-c_{x x} \cdot x / p_{x}\right) \cdot \theta_{M S}=\theta_{M S} / \eta_{s}$, where $\eta_{s}$ is the elasticity of hospital supply. Thus the percentage gap between the factor price and the value of the marginal product is a function of the degree of monopsony power and the inverse elasticity of supply.

${ }^{77}$ Presumably output price is correlated with the error in the marginal productivity function. The marginal cost of production will fluctuate with marginal productivity, causing fluctuations in price to be correlated with the marginal productivity error.

${ }^{78}$ It is a demand rotator that is required in the case of monopoly power.

${ }^{79}$ Participating providers agree to accept an insurer's fee as payment in full and not bill patients covered by that insurer for the difference between their price and the payment. Participating providers are identified as such by the insurer.

${ }^{80}$ Feldman and Greenberg and Adamache and Sloan both have 60+ observations corresponding to individual Blue Cross plan areas. Foreman et al. have quarterly observations on 47 Blue Cross/Blue Shield plans for two years.

${ }^{81}$ For more detailed criticism of the Staten (1987) paper, see Pauly (1987). See also Staten et al. (1988) response and Pauly's further response (1988a).

${ }^{82}$ Moral hazard will lead consumers to demand more than would an insurer who maximizes social welfare. This will be true even for an insurer with market power, since it will wish to restrict output even further below the socially optimal level. 
${ }^{83}$ This is intended as an heuristic, rather than a formal model. An important task for any future research in this area is to derive such a pricing function directly from a well defined theoretical model. See Brooks et al. (1997) for a model of price determination as a Nash bargaining game between a hospital and an insurer. They do not, however, model competition. Their model is a model of bilateral monopoly, while we are suggesting what is needed is a model of price determination in bilateral oligopoly.

${ }^{84}$ Further work is necessary to determine if such nonlinearities flow from (reasonable) assumptions about the structure of the model. If not, identification via functional form would be strictly ad hoc and hard to defend. Svejnar (1986) uses structural functional form assumptions in a model of bilateral monopoly to identify the bargaining power parameter along with other parameters of the model via nonlinearities in the econometric model.

${ }^{85}$ See Scherer and Ross (1990, pp. 533-535) for a survey of these results.

${ }^{86}$ There have been attempts at such countervailing market power defense in hospital antitrust cases. This argument has also been advanced to allow physician "unions" to collectively set prices for independent physician firms without threat of antitrust prosecution.

${ }^{87}$ Consider the monopsony condition for a factor $x, p \cdot f_{l}=w+\partial w / \partial l \cdot l$. This can be transformed to $p \cdot f_{l}=w \cdot\left(1+1 / \varepsilon_{S}\right)$, where $\varepsilon_{s}$ is the elasticity of supply. Clearly this condition goes toward the competitive condition (value of marginal product of labor equals its wage) as the supply curve of labor becomes perfectly elastic. ${ }^{88}$ This section draws in part on joint work with Deborah Haas-Wilson and with Albert Ma, some of which appears in Gaynor and Haas-Wilson (1998) and Gaynor and Ma (1996).

${ }^{89}$ We only list the forms of vertical restraints that are relevant to health care markets. For example, we do not list resale price maintenance, although this has been a major issue in the literature on vertical restraints, since it is not possible to resell a physician visit or an appendectomy.

${ }^{90}$ Vertical restraints involving price, i.e., resale price maintenance, is per se illegal.

${ }^{91}$ Vertical cases are by far and away the most numerous type of antitrust case brought in health care. However, the vast bulk of these are private antitrust suits brought by physicians denied hospital privileges (these often take the form of challenges to exclusive contracts). The courts have invariably rejected such claims. As a consequence we 
only list a selected subset of cases involving exclusive dealing. Cases involving vertical integration or most-favorednations clauses have been far less numerous. See Miles (1998) for a comprehensive listing.

${ }^{92}$ For example' U.S. v. Aluminum Co. of America (2 ${ }^{\text {nd }}$ Circuit, 1945, 148 F.2d 416); Lorain Journal v. U.S., (1951, 342 U.S. 143), United Shoe Machinery Corp. v. U.S. (1922, 258 U.S. 451, 458) for exclusionary practices and Brown Shoe Co., Inc. v. U.S. (1962, 370 U.S. 294), A.G. Spalding \& Bros., Inc. (1960, 56 F.T.C. 1125), Kennecott Copper Corp. v. U.S. (1965, 381 U.S. 414), Ford Motor Co., v. U.S. (1965, 381 U.S. 414), Ford Motor Co. v. U.S. (1972, 405 U.S. 562) for vertical integration.

${ }^{93}$ This literature has been criticized in turn for only demonstrating the possible existence of anticompetitive effects, but not considering efficiency enhancing impacts [see Klass and Salinger (1995)].

${ }^{94}$ This applies similarly to the consideration of upstream firms' access to a buyer if an upstream firm merges or engages in an exclusive deal with a downstream firm.

${ }^{95}$ Note that the single monopoly profit result, and its criticisms, apply as well to the case of forward integration in which there is a monopoly in the input market and perfect competition in the output market.

96. The results can be somewhat fragile. For example, the results of Ordover et al. (1990) depend critically upon an assumption that the integrated firm can commit to sell to the unintegrated downstream firm at a higher price than the internal transfer price within the integrated firm [Reiffen (1992)]. Some more recent papers are less sensitive to assumptions [Riordan (1998), Choi and Yi (1996)].

${ }^{97}$ As Frech (1996) points out, the traditional Blue Cross physician reimbursement policy of paying usual, customary, and reasonable fees contains, in essence an MFN clause due to the usual stipulation. Many Blue Cross plans, however, do not enforce the usual clause.

98 Corts (1996), however, finds that MFN clauses can be competitive and welfare enhancing. 


\section{References}

Adamache, K.W. and F.A. Sloan (1983), "Competition between non-profit and for-profit health insurers," Journal of Health Economics, 2: 225-243.

Alexander, J.A., M.T. Halpern, and S.D. Lee (1996), "The short-term effects of merger on hospital operations," Health Services Research, 30(6): 827-47.

Anderson, S.P., A. DePalma, and J.F. Thisse (1992), Discrete Choice Theory of Product Differentiation, Cambridge, MA: MIT Press.

Arrow, K.J. (1963), "Uncertainty and the welfare economics of medical care," American Economic Review, December, 53: 941-973.

Baker, J.B. (1988), "The antitrust analysis of hospital mergers and the transformation of the hospital industry," Law and Contemporary Problems, 51(2):96-164.

Baker, J.B. (1996), "Vertical restraints with horizontal consequences: competitive effects of 'most-favored-customer' clauses," Antitrust Law Journal, 64: 517-534.

Baker, J.B. (1997), "Unilateral competitive effects theories in merger analysis," Antitrust, Spring.

Baker, J.B. and T.F. Bresnahan (1985), "The gains from merger on collusion in productdifferentiated industries," Journal of Industrial Economics, 33:427-44.

Baker, J.B. and T.F. Bresnahan (1988), "Estimating the Residual Demand Curve Facing a Single Firm," International Journal of Industrial Organization, 6(3):283-300.

Becker, E.R. and F.A. Sloan (1982), "Hospital ownership and performance," Economic Inquiry, 23(1):21-36.

Berry, S. (1992) "Estimation of a model of entry in the airline industry," Econometrica, 60: 889917.

Berry, S. (1994) "Estimating discrete-choice models of product differentiation," Rand Journal of Economics, 25: 242-262.

Berry, S., Levinsohn, J., and A. Pakes (1995) "Automobile prices in market equilibrium," Econometrica, 63: 841-890.

Berry, S. and J. Waldfogel (1997), "Free entry and social inefficiency in radio broadcasting," unpublished manuscript, University of Pennsylvania.

Blair, R.D. and J.L. Harrison (1993), Monopsony: Antitrust Law and Economics, Princeton, NJ: Princeton University Press. 
Blackstone, E.A. and J.P. Fuhr (1984), "Antitrust and exclusive agreements: the case of hospitalbased physicians," The Antitrust Bulletin, 29: 739-758.

Bresnahan, T.F. (1989), "Empirical studies of industries with market power," in R. Schmalensee and R.D. Willig, eds., Handbook of Industrial Organization, Volume 2, Amsterdam: NorthHolland, 1011-1057.

Bresnahan, T.F. and P. Reiss, (1991), "Entry and competition in concentrated markets", Journal of Political Economy, 99: 977-1009.

Brooks, J.M., A. Dor, and H.S. Wong (1997), "Hospital-insurer bargaining: an empirical investigation of appendectomy pricing," Journal of Health Economics, 16: 417-434.

Burns, L.R. and D.R. Wholey (1992), "The impact of physician characteristics in conditional choice models for hospital care," Journal of Health Economics, 11:43-62.

Butz, D.A. (1990), “Durable good monopoly and best-price provisions," American Economic Review, 80: 1062-1076.

Cave, J.A.K. (1986) "Subsidy equilibrium and multiple-option insurance markets," in R. Scheffler and L. Rossiter, eds., Advances in Health Economics and Health Services Research, 6: 27-35, Greenwich, CT and London: JAI Press.

Coase, R. (1937), "The nature of the firm," Economica, 4: 386-405.

Comanor, W.S. and H.E. Frech III (1985), "The competitive effects of vertical agreements," American Economic Review, 75: 539-546.

Connor, R.A. and R.D. Feldman (1997), "Horizontal hospital mergers and their effects on nonmerging hospitals in the same market area," American Enterprise Institute Conference Paper from the conference: Managed Care and Changing Health Care Markets, April 10, 1997.

Connor, R.A., R.D. Feldman, B.E. Dowd, and T.A. Radcliff (1997), "Which types of horizontal hospital mergers produce savings and which do not?" unpublished manuscript, University of Minnesota.

Conrad, D. and S. Shortell (1996) "Integrated health systems: promise and performance," Frontiers of Health Services Management, 13(1): 3-40.

Cowing, T.G., A.G. Holtman and S. Powers (1983), "Hospital cost analysis: a survey and evaluation of recent studies," Advances in Health Economics and Health Services Research, 4:257-303. 
Cowing, T.G. and A.G. Holtman (1983), "Multiproduct Short-Run Hospital Cost Functions: Empirical Evidence and Policy Implications from Cross-Section Data," 49(3):637-53.

Crew, M. (1969), "Coinsurance and the welfare economics of medical care," American Economic Review, 59(5): 906-908.

Crocker, K.J. and T.P. Lyon (1994), "What do 'facilitating practices' facilitate? An empirical examination of most-favored nation clauses in natural gas contracts," Journal of Law and Economics, 37: 297-322.

Crocker, K.J. and K.J.Reynolds (1993), "The efficiency of incomplete contracts: an empirical analysis of Air Force engine procurement," RAND Journal of Economics, 24:126-146.

Dixit, A. and J.E. Stiglitz (1977) "Monopolistic competition and optimum product diversity,"American Economic Review, 67: 297-308.

Federal Trade Commission (1996) Revised Federal Trade Commission, Department of Justice Policy Statements on Health Care Antitrust Enforcement, US Department of Justice, Washington, DC.

Donabedian, A. (1980), The Definition of Quality and Approaches to its Assessment, Ann Arbor, MI: Health Administration Press.

Dor, A. and D.E. Farley (1996), "Payment source and the cost of hospital care: evidence from a multiproduct cost function with multiple payers," Journal of Health Economics, 15:1-21.

Dranove, D. (1988), "Demand inducement and the physician/patient relationship," Economic Inquiry, 26:281-298.

Dranove, D. and M.A. Satterthwaite (1992), "Monopolistic competition when price and quality are imperfectly observable," Rand Journal of Economics, 23:518-534.

Dranove, D. and M. Shanley (1989), "A note on the relational aspects of hospital market definition," Journal of Health Economics, 8:473-8.

Dranove, D., M. Shanley and C.J. Simon (1992), "Is hospital competition wasteful?," Rand Journal of Economics, 23: 247-262.

Dranove, D., M. Shanley and W.D. White (1993), "Price and concentration in local hospital markets: the switch from patient-driven to payer-driven competition," Journal of Law and Economics, 36: 179-204.

Dranove, D. and W.D. White (1994), "Recent theory and evidence on competition in hospital markets," Journal of Economics and Management Strategy, 3(1): 169-209. 
Dranove, D. and R. Ludwick (1999) "Competition and pricing by nonprofit hospitals: a reassessment of Lynk's analysis," Journal of Health Economics 18: 87-98.

Elzinga, K.G. and T.F. Hogarty (1973), "The problem of geographic market definition in antimerger suits," Antitrust Bulletin, 18: 45-81.

Elzinga, K.G. and T.F. Hogarty (1978), “The problem of geographic market definition revisited: the case of coal," Antitrust Bulletin, 23: 1-18.

Emons, W. (1997), “Credence goods and fraudulent experts," Rand Journal of Economics, Spring, 28(1): 107-119.

Encinosa, W.E. (1996), "Exclusive contracting in health care markets," unpublished manuscript, University of Michigan.

Farley, D.E. and C. Hogan (1990), "Case-mix specialization in the market for hospital services," Health Services Research, 25(5):757-783.

Feldman, R. and W. Greenberg (1981), "The relation between the Blue Cross share and the Blue Cross 'discount' on hospital charges," Journal of Risk and Insurance, 48: 235-246.

Foreman, S.E., J.A. Wilson, and R.M. Scheffler (1996), "Monopoly, monopsony, and contestability in health insurance: a study of Blue Cross plans," Economic Inquiry, 34: 662-677.

Fournier, G.M. and J.M. Mitchell (1992), "Hospital costs and competition for services, a multiproduct analysis," Review of Economics and Statistics, 74(4):627-34.

Frank, R.G. and D.S. Salkever (1994), "Nonprofit organizations in the health sector," Journal of Economic Perspectives, 8(4): 129-144.

Frech, H.E. III (1988), "Monopoly in health insurance: the economics of Kartell v. Blue Shield of Massachusetts," in H.E. Frech III, ed., Health Care in America: The Political Economy of Hospitals and Health Insurance, San Francisco: Pacific Research Institute for Public Policy, 353372.

Frech, H.E. (1996), Competition and Monopoly in Medical Care, Washington, DC: AEI Press.

Frech, H.E., III and K.L. Danger (1998), "Exclusive contracts between hospitals and physicians: the antitrust issues," Health Economics, 7:175-178.

Friedman, B. and M.V. Pauly (1981), ) "Cost functions for a service firm with variable quality and stochastic demand," Review of Economics and Statistics, 63:620-624.

Froeb, L.M. and G.J. Werden (1992), "The Reverse Cellophane Fallacy in Market Delineation," Review of Industrial Organizations, 7(2):241-47. 
Froeb, L., S. Tschantz, P. Crooke, and G. Werden (forthcoming) "The effects of assumed demand form on simulated post merger equilibria, "Review of Industrial Organization.

Gal-Or, Esther (1996), "Exclusionary equilibria in health care markets," Journal of Economics and Management Strategy, 6(1): 5-43.

Garnick, D.W., E. Lichtenberg, C.S. Phibbs, H.S. Luft, D.J. Peltzman, and S.J. McPhee (1989), "The sensitivity of conditional choice models for hospital care to estimation technique," Journal Health Economics, 8:377-97.

Gaynor, M. (1994), "Issues in the industrial organization of the market for physician services," Journal of Economics and Management Strategy, 3: 211-255.

Gaynor, M. and G.F. Anderson (1995), "Uncertain demand, the structure of hospital costs, and the cost of empty hospital beds," Journal of Health Economics, 14(3):291-317.

Gaynor, M. and D. Haas-Wilson (1998), "Vertical relations in health care markets," in M. Morrisey, ed., Managed Care and Changing Health Care Markets, Washington, DC: American Enterprise Institute Press.

Gaynor, M., D. Haas-Wilson, and W.B. Vogt (1997), “Are invisible hands good hands? Moral hazard, competition, and the 2nd best in health care markets," unpublished manuscript, Carnegie Mellon University.

Gaynor, M. and C.A. Ma (1996), "Insurance, vertical restraints, and competition," unpublished manuscript, Carnegie Mellon University.

Granneman, T.W., R.S. Brown, and M. Pauly (1986), "Estimating hospital costs, a multiple output analysis," Journal of Health Economics, 5:107-27.

Gruber, J. (1994), "The effect of price shopping in medical markets: hospital responses to PPOs in California," Journal of Health Economics, 38: 183-212.

Hamilton, B. and V. Ho (1998), "Hospital mergers and acquisitions: does market consolidation harm patients?" unpublished manuscript, Washington University.

Hersch, P.L. (1984), "Competition and the performance of hospital markets," Review of Industrial Organization, 1(4):324-40.

Hoerger, T.J. (1991), "Profit variability in for-profit and not-for-profit hospitals," Journal of Health Economics, 10:259-89.

Hurdle, S. and G.C. Pope (1989), "Physician productivity: trends and determinants," Inquiry, 26: 100-115. 
Just, R. and W. Chern (1980), “Tomatoes, technology, and oligopsony,” Bell Journal of Economics, 11: 584-602.

Katz, M.L. (1989), "Vertical contractual relations," in R. Schmalensee and R.D. Willig, eds., Handbook of Industrial Organization, Amsterdam: North-Holland, 655-721.

Keeler, E.B., G. Melnick, and J. Zwanziger, (1999) "The changing effects of competition on nonprofit and for-profit hospital pricing behavior," Journal of Health Economics 18: 69-86.

Kessler, D. and M. McClellan (1998), "Is hospital competition socially wasteful?" unpublished manuscript, Stanford University.

Klein, B., R.G. Crawford, and A.A. Alchian (1978), "Vertical integration, appropriable rents, and the competitive contracting process," Journal of Law and Economics, 21: 297-326.

Kopit, W.G. and R.W. McCann (1988), "Toward a definitive antitrust standard for nonprofit hospital mergers," Journal of Health Politics Policy and Law, 13(4): 635-662.

Krattenmaker, T.G. and S.C. Salope (1986a), "Competition and cooperation in the market for exclusionary rights," American Economic Review, Papers and Proceedings, 76:109-113.

Krattenmaker, T.G. and S.C. Salope (1986b), "Anticompetitive exclusion: raising rivals' costs to achieve power over price," Yale Law Journal, 96:209-293.

Krishnan, R. (1998), "Market restructuring and pricing in the hospital industry," unpublished doctoral dissertation, Katz Graduate School of Business, University of Pittsburgh.

Lafontaine, F. (1992), "Agency theory and franchising: some empirical results," Rand Journal of Economics, 23: 263-283.

Lee, M.L. (1971), "A Conspicuous Production Theory of Hospital Behavior," Southern Economic Journal, 38(1):48-58.

Lee, R.H. and T.A. Mroz (1991), "Family structure and physicians' hours in large, multispecialty groups," Inquiry, 28: 366-374.

Lieberman, M.B. (1991), "Determinants of vertical integration: an empirical test," Journal of Industrial Economics, 39: 451-466.

Luft, H.S., D.W. Garnick, C.S. Phibbs, D.J. Peltzman, E. Lichtenberg, and S.J. McPhee, (1991), "Modeling the effect of hospital charges and quality on choice," Journal of Health Care Marketing, 11(3):2-11. 
Luft, H.S., C.S. Phibbs, D.W. Garnick, and J.C. Robinson (1988), "Rejoinder to Dranove and Shanley," Journal of Health Economics, 8:479-83.

Luft, Harold, J.C. Robinson, D. Garnick, S. Maerki, and S. McPhee (1986), "The role of specialized clinical services in competition among hospitals," Inquiry, 23: 83-94.

Lynk, W.J. (1984), “Tying and exclusive dealing: Jefferson Parish Hospital v. Hyde,” in The Antitrust Revolution: The Role of Economics, J.E. Kwoka and L.J. White, eds., New York: HarperCollings Publishers.

Lynk, W.J. (1994), "Property rights and the presumptions of merger analysis," Antitrust Bulletin, 39(2):363-83.

Lynk, W.J. (1995a), "Nonprofit hospital mergers and the exercise of market power," Journal of Law and Economics, 38:437-61.

Lynk, W.J. (1995b) , "The creation of economic efficiencies in hospital mergers," Journal of Health Economics, 14:507-30.

Lynk, W.J. and L.R. Neumann (1999), "Price and profit," Journal of Health Economics, 18: 99105.

Lynk, W.J. and M.A. Morrisey (1987), “The economic basis of Hyde: are market power and exclusive contracts related?" Journal of Law and Economics, 30(2): 399-421.

Madrian, B. (1994) "Employment-based health insurance and job mobility: Is there evidence of job-lock?" Quarterly Journal of Economics, 109: 27-54.

Masten, S.E. (1984), "The organization of production: evidence from the aerospace industry," Journal of Law and Economics, 27: 403-417.

McGuire, T.G. and M.V. Pauly (1991), "Physician response to fee changes with multiple payers," Journal of Health Economics, 10:385-410.

Melnick, G.A. and J. Zwanziger (1988), "Hospital behavior under competition and cost containment policies, the California experience, 1980-1985," Journal of the American Medical Association, 260(18):2669-2675.

Melnick, G.A., J. Zwanziger, A. Bamezai, and R. Pattison (1992), "The effect of market structure and bargaining position on hospital prices," Journal of Health Economics, 11: 217-233.

Miles, J.J. (1998), Health Care and Antitrust Law, St. Paul, MN: West Group.

Miyazaki, H. (1977) "The rat race and internal labor markets," Bell Journal of Economics, 8: 394-418. 
Mobley, L.R. and H.E. Frech III (1997), "Managed care, distance traveled and hospital market definition: an exploratory analysis," unpublished paper, University of California, Santa Barbara.

Morrisey, M.A., F.A. Sloan, and J. Valvona (1988), "Defining geographic markets for hospital care," Law and Contemporary Problems, 51: 165-194.

Neipp, J. and R.Zeckhauser (1986) "Persistence in the choice of health plans," in R.Scheffler and L. Rossiter, eds., Advances in Health Economics and Health Services Research, 6: 47-72, Greenwich, CT and London: JAI Press.

Newhouse, J.P. (1970), "Toward a theory of nonprofit institutions: an economic model of a hospital," American Economics Review, 60(1):64-74.

Newhouse, J.P. (1978), "The structure of health insurance and the erosion of the medical marketplace," in Competition in the Health Care Sector: Past, Present, and Future, Warren Greenberg, ed., Germantown, MD: Aspen Publishers.

Newhouse, J.P. (1996), "Reimbursing health plans and providers: selection versus efficiency in production," Journal of Economic Literature, 34(3): 1236-1263.

Noether, M. (1988), "Competition among hospitals," Journal of Health Economics, 7:259-84.

Ordover, J.A., G. Saloner and S.C. Salop (1990), "Equilibrium vertical foreclosure," American Economic Review 80: 127-142.

Pauly, M.V. (1968), "The economics of moral hazard: comment," American Economic Review, 58:531-537.

Pauly, M.V. (1978), "Is medical care different?" in Competition in the Health Care Sector: Past, Present, and Future, L. Goldberg and W. Greenberg, eds., Washington, D.C.: Federal Trade Commission.

Pauly, M.V. (1980), Doctors and Their Workshops, Chicago: University of Chicago Press.

Pauly, M.V.(1986), "Taxation, health insurance, and market failure," Journal of Economic Literature, 24: 629-675.

Pauly, M.V. (1987), "Monopsony power in health insurance: thinking straight while standing on your head," Journal of Health Economics, 6: 73-81.

Pauly, M.V. (1988a), “Reply,” Journal of Health Economics, 7: 85-87.

Pauly, M.V. (1988b), "Market power, monopsony, and health insurance markets," Journal of Health Economics, 7: 111-128. 
Pauly, M.V. (1988c), "Competition in health insurance markets," Law and Contemporary Problems, 51: 237-271.

Pauly, M.V. (1998), "Managed care, markets, and monopsony," unpublished manuscript, University of Pennsylvania.

Pauly, M.V. and M. Redisch (1973), "The not-for-profit hospistal as a physicians' cooperative," American Economic Review, 63(1):87-99.

Phibbs, C.S. and J.C. Robinson (1993), "A variable-radius measure of local hospital market structure," Health Services Research, 28(3):313-324.

Png, I.P.L. (1991), "Most favored customer protection versus price discrimination when customer demand is uncertain," Journal of Political Economy, 99: 1010-1028.

Png, I.P.L. and D. Hirshleifer (1987), "Price discrimination through offers to match price," Journal of Business, 60: 365-383.

Riley, J.G. (1979) "Informational Equilibrium," Econometrica, 47: 331-59.

Riordan, M.H. (1998) "Anticompetitive vertical integration by a dominant firm," American Economic Review, 88: 1232-1248.

Riordan, M.H. and S.C. Salop (1995), "Evaluating vertical mergers: a post-chicago approach," Antitrust Law Journal, 63:513-568.

Rizzo, J.A. and D. Blumenthal (1994), "Physician labor supply: do income effects matter?" Journal of Health Economics, 14(4): 433-453.

Robinson, J.C. (1988), "Market structure, employment, and skill mix in the hospital industry," Southern Economic Journal, 55(2): 315-25.

Robinson, J.C., D.W. Garnick, and S.J. McPhee (1987), "Market and regulatory influences on the availability of coronary angioplasty and bypass surgery in US hospitals," New England Journal of Medicine, 317(2):85-90.

Robinson, J.C. and H. Luft (1985), "The impact of hospital market structure on patient volume, average length of stay, and the cost of care," Journal of Health Economics, 4: 333-356.

Romeo, A.A., J.L. Wagner, and R.H. Lee (1984), "Prospective reimbursement and the diffusion of new technologies in hospitals," Journal of Health Economics, 3:1-24.

Rothschild, M. and J.E. Stiglitz (1976) "Equilibrium in competitive insurance markets: an essay on the economics of imperfect information," Quarterly Journal of Economics, 90: 629-650. 
Royalty, A.B. and N. Solomon (1997) "Health plan choice: price elasticities in a managed competition setting," unpublished manuscript, May, Stanford, CA: Stanford University.

Salop, S.C. (1979) "Monopolistic competition with outside goods," Bell Journal of Economics, 10: 141-156.

Salop, S.C. and D.T. Scheffman (1983), "Raising rivals' costs," American Economic Review, Papers and Proceedings, May, 73(2): 267-271.

Salop, S.C. and D.T. Scheffman (1987), "Cost-raising strategies," Journal of Industrial Economics 36:19-34.

Salop, S.C. (1986), "Practices that (credibly) facilitate oligopoly coordination," in J. Stiglitz and G.F. Mathewson, eds., New Developments in the Analysis of Market Structure, Cambridge, MA: The MIT Press.

Satterthwaite, Mark A. (1979) "Consumer information, equilibrium industry price, and the number of sellers," Bell Journal of Economics, 10: 483-502.

Satterthwaite, Mark A. (1985) "Competition and equilibrium as a driving force in the health services sector," in Managing the Service Economy, Robert Inman, ed., Cambridge: Cambridge University Press.

Scheffman, D.T. and P.T. Spiller (1987), "Geographic market definition under the U.S. Department of Justice merger guidelines," Journal of Law and Economics, 30:123-47.

Scherer, F.M. and D. Ross (1990), Industrial Market Structure and Economic Performance, 3rd Edition, Boston: Houghton Mifflin Company.

Scott Morton, F.M. (1997), "The strategic response by pharmaceutical firms to the Medicaid most-favored-customer rules," Rand Journal of Economics, 28: 269-290.

Shortell, S.M. and E.F.X. Hughes (1988), "The effects of regulation, competition, and ownership on mortality rates among hospital inpatients," New England Journal of Medicine, 318:1100-7.

Simpson, J. and R. Shin (1997), "Do non-profit hospitals exercise market power?" unpublished paper, Federal Trade Commission.

Sloan, F.A. (1975), "Physician supply behavior in the short run," Industrial and Labor Relations Review, 28: 549-569.

Spence, A.M. (1976) "Product selection, fixed costs, and monopolistic competition," Review of Economic Studies, 43: 217-235. 
Spence, A.M. (1978), "Product differentiation and performance in insurance markets," Journal of Public Economics, 10: 427-447.

Spiller, P.T. (1985), “On vertical merger,” Journal of Law, Economics, and Organization, 1: 285-312.

Stano, M. (1987), "A further analysis of the physician inducement controversy," Journal of Health Economics, 6(3): 227-238.

Staten, M., W. Dunkelberg, and J. Umbeck (1987), "Market share and the Illusion of power: can Blue Cross force hospitals to discount?" Journal of Health Economics, 6:43-58.

Staten, M., J. Umbeck, and W. Dunkelberg (1988), "Market share/market power revisited, a new test for an old theory," Journal of Health Economics, 7:73-83.

Stiglitz, J.E. (1977), "Monopoly, non-linear pricing and imperfect information: the insurance market," Review of Economic Studies, 44:407-430.

Sullivan, D. (1989), "Monopsony power in the market for nurses," Journal of Law and Economics, 32: S135-S178.

Sutton, J.(1991) Sunk Costs and Market Structure: Price Competition, Advertising, and the Evolution of Concentration, Cambridge, MA: MIT Press.

Svejnar, J. (1986), "Bargaining power, fear of disagreement, and wage settlements: theory and evidence from U.S. industry," Econometrica, 54: 1055-1078.

U.S. Department of Justice (1984) Merger Guidelines, Washington, D.C.: U.S. Department of Justice.

U.S. Department of Justice and Federal Trade Commission (1997) Horizontal Merger Guidelines, Issued April 2, 1992, Revised April 8, 1997, Washington, D.C.: U.S. Department of Justice, Federal Trade Commission.

Vita, M.G. (1990), "Exploring hospital production relationships with flexible functional forms," Journal of Health Economics, 9:1-21.

Vita, M.G. and L. Schumann (1991), "The competitive effects of horizontal mergers in the hospital industry: a closer look," Journal of Health Economics, 10:359-72.

Vitaliano, D.F. (1987), "On the estimation of hospital cost functions," Journal of Health Economics, 6:305-18. 
Volpp, K. and J. Waldfogel (1998), “Competition and the quality of hospital care: heart attack mortality after the onset of price competition in New Jersey," unpublished manuscript, University of Pennsylvania.

Walston, S.L., Kimberley, J.R., and L.R. Burns (1996) "Owned vertical integration and health care: promise and performance," Health Care Management Review, 21(1): 83-92.

Werden, G.J. (1981), "On the use and misuse of shipments data in defining geographic markets," Antitrust Bulletin, 26:719-737.

Werden, G.J. (1990), "The limited relevance of patient migration data in market delineation for hospital merger cases," Journal of Health Economics, 8:363-76.

Werden, G.J. (1997), "Simulating unilateral competitive effects from differentiated products mergers," Antitrust, Spring.

Werden, G.J. and L.M. Froeb (1994), "The effect of mergers in differentiated products industries: logit demand and merger policy," Journal of Law, Economics and Organization, 10(2):407-426.

Westfield, F.M. (1981), "Vertical integration: does product price rise or fall?" American Economic Review, 71(3):334-346.

Williamson, O.E. (1975), Markets and Hierarchies: Analysis and Antitrust Implications, New York: Free Press.

Williamson, O.E. (1989), "Transaction Cost Economics," in Richard Schmalensee and Robert Willig, eds., Handbook of Industrial Organization, Amsterdam: North-Holland.

Wilson, C. (1977) "A model of insurance markets with incomplete information," Journal of Economic Theory, 16: 167-207.

Woolley, J.M. (1989), "The competitive effects of horizontal mergers in the hospital industry," Journal of Health Economics, 8:271-91.

Woolley, J.M. (1991), "The competitive effects of horizontal mergers in the hospital industry: an even closer look," Journal of Health Economics, 10:373-8.

Zwanziger, J. and G. Melnick (1988), "The effects of hospital competition and the Medicare PPS program on hospital cost behavior in California," Journal of Health Economics, 7:301-20. 


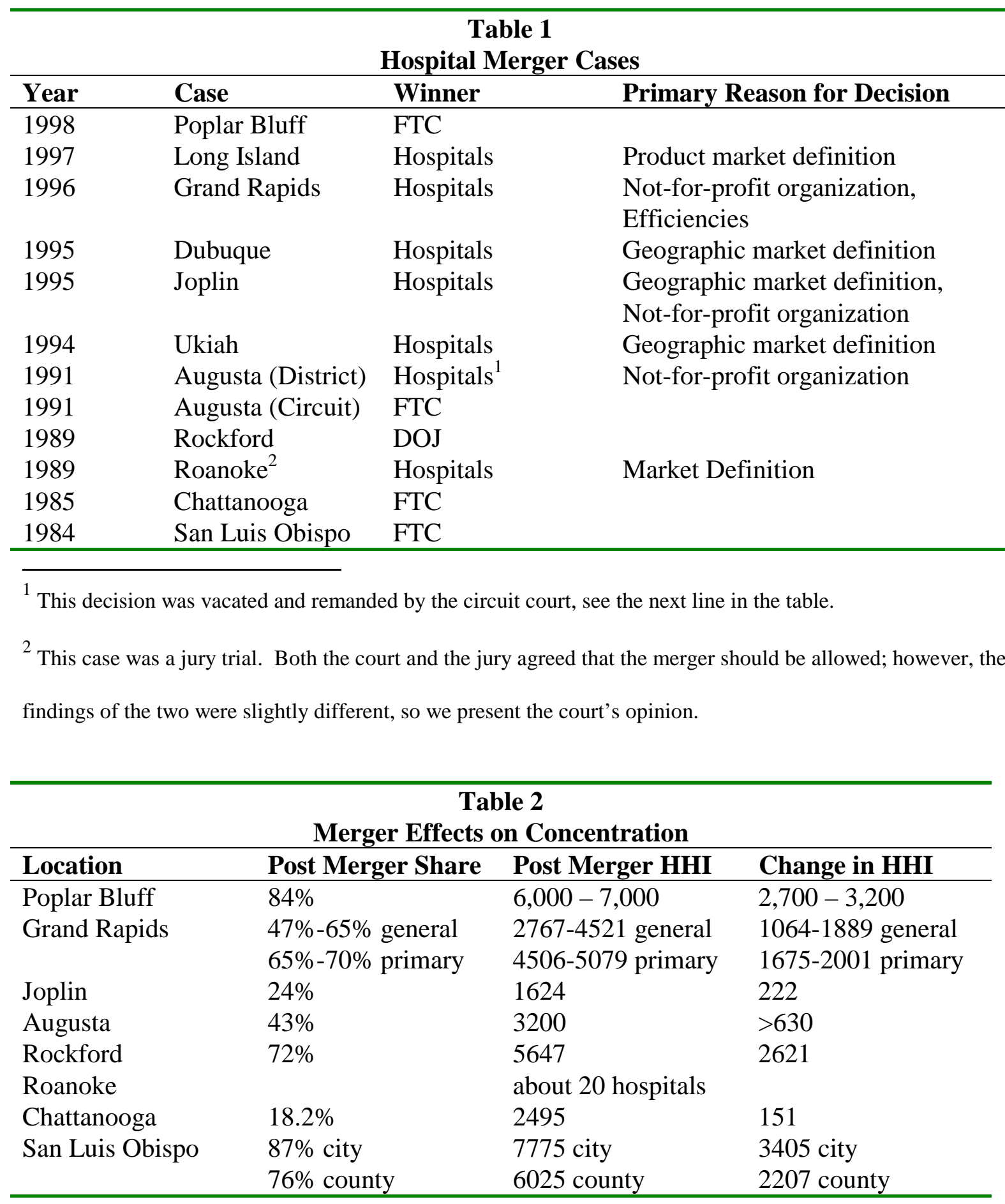




\begin{tabular}{llll}
\hline \multicolumn{4}{c}{ Table 3 } \\
Effects of Standard Merger on Price from Price-Concentration Studies \\
\hline Study & \multicolumn{1}{c}{ Price Effect } & \multicolumn{1}{c}{ Data - Year } & Data - Place \\
\hline DSW & $+5 \%{ }^{2}$ & 1988 & CA \\
MZBP & $+2 \%$ & 1987 & CA \\
Lynk & $-1 \%$ & 1989 & CA \\
LN & $-3 \%$ & 1995 & MI \\
KMZ & $+6 \%$ & 1994 & CA \\
SS & $+10 \%$ & 1993 & CA \\
DL & $+17 \%$ & 1989 & CA \\
BDW & $+2 \%$ & $1988-92$ & US \\
SUD & $+2 \%$ & 1983 & IN \\
Noether & $-1 \%$ & 1977,8 & US \\
\hline
\end{tabular}

${ }^{1}$ The abbreviations are: DSW-Dranove, Shanley, and White (1993) MZBP-Melnick, Zwanziger, Bamezai, and Pattison (1992) Lynk-Lynk (1995) LN-Lynk and Neumann (1999) KMZ-Keeler, Melnick, and Zwanziger (1999) SS-Simpson and Shin (1997) DL-Dranove and Ludwick (1999) BDW-Brooks, Dor, and Wong (1997) SUDStaten, Umbeck, and Dunkelberg (1987), Noether-Noether (1988).

${ }^{2}$ The authors use a dummy variable to capture scale effects. The dummy variable big equals 1 if the hospital in question is large enough. Here (to capture the effect of merger on output) we assume that the authors' dummy variable BIG goes from 0 to 1 but that the dummy variable HIGH TECH does not change.

\section{Table 4}

Effects of Standard Merger on Price, by Ownership Form

\begin{tabular}{llll}
\hline Study & FP & NFP & Government \\
\hline Lynk & $+17 \%$ & $-1 \%$ & $+7 \%$ \\
LN & NA & $-3 \%$ & NA \\
KMZ & $+16 \%$ & $+6 \%$ & $+9 \%$ \\
SS & $+9 \%$ & $+10 \%$ & $8-9 \%$ \\
DL & NA & $+17 \%$ & NA \\
\hline
\end{tabular}




\begin{tabular}{|c|c|c|c|}
\hline \multicolumn{4}{|c|}{$\begin{array}{c}\text { Table } 5 \\
\text { Selected Health Care Monopsony Cases }\end{array}$} \\
\hline Year Decided & Case (Parties) & Winner & Primary Reason \\
\hline 1985 & $\begin{array}{l}\text { Kartell (Physicians } \\
\text { vs. Insurer) }\end{array}$ & Insurer & $\begin{array}{l}\text { Not illegal to } \\
\text { exercise market } \\
\text { power to obtain } \\
\text { lower prices (via } \\
\text { balance billing ban). }\end{array}$ \\
\hline 1986 & $\begin{array}{l}\text { Ball Memorial } \\
\text { (Hospital vs. } \\
\text { Insurer) }^{2}\end{array}$ & Insurer & $\begin{array}{l}\text { Not illegal to } \\
\text { exercise market } \\
\text { power to obtain } \\
\text { lower prices (via a } \\
\text { PPO). }\end{array}$ \\
\hline 1990 & $\begin{array}{l}\text { Ocean State } \\
\text { (Physicians vs. } \\
\text { Insurer) }\end{array}$ & Insurer & $\begin{array}{l}\text { Not illegal to } \\
\text { exercise market } \\
\text { power to obtain } \\
\text { lower prices (via } \\
\text { MFN clause). }\end{array}$ \\
\hline 1982 & $\begin{array}{l}\text { St. Bernard Hospital } \\
\text { (Hospital vs. } \\
\text { Insurer) }\end{array}$ & Hospital & $\begin{array}{l}\text { Price fixing by } \\
\text { collusive } \\
\text { monopsony is } \\
\text { illegal. Insurer was } \\
\text { controlled by } \\
\text { participating } \\
\text { hospitals, therefore } \\
\text { constituted illegal } \\
\text { combination. }\end{array}$ \\
\hline
\end{tabular}

${ }^{1}$ Kartell v. Blue Shield of Massachusetts ( $1^{\text {st }}$ Circuit, 1984, 749 F.2d 922) cert. Denied (1985, 471 U.S. 1029).

2 Ball Memorial Hospital, Inc. v. Mutual Hospital Insurance, Inc. ( $7^{\text {th }}$ Circuit, 1986, 784 F.2d 1327).

${ }^{3}$ Ocean State Physicians Health Plan, Inc., et al. v. Blue Cross and Blue Shield of Rhode Island (1 ${ }^{\text {st }}$ Circuit, 1989, $883^{\text {F.2d 1101) }}$ cert. Denied (1990, 494 U.S. 1027).

${ }^{4}$ St. Bernard Hospital v. Hospital Service Association of New Orleans $\left(5^{\text {th }}\right.$ Circuit, 1982, 712 F.2d 978). 


\section{Table 6}

Selected Health Care Vertical Restraints Cases

\begin{tabular}{|c|c|c|c|c|}
\hline Year Decided & Case & Vertical Restraint & Winner & Primary Reason \\
\hline 1996 & $\begin{array}{l}\text { Vicksburg (Hospital vs. } \\
\text { Hospital-Physician Group } \\
\text { merger) }\end{array}$ & Vertical Integration & $\begin{array}{l}\text { Merged } \\
\text { hospital- } \\
\text { physician } \\
\text { group }\end{array}$ & $\begin{array}{l}\text { Barriers to entry to } \\
\text { physician market low, } \\
\text { therefore no } \\
\text { foreclosure. }\end{array}$ \\
\hline 1995 & $\begin{array}{l}\text { Marshfield (Insurer vs. HMO- } \\
\text { Physician Group) }^{2}\end{array}$ & $\begin{array}{l}\text { Vertical Integration, Most- } \\
\text { Favored-Nations Clause }\end{array}$ & $\begin{array}{l}\text { HMO- } \\
\text { Physician } \\
\text { Group }\end{array}$ & $\begin{array}{l}\text { HMO-Physician } \\
\text { group did not have } \\
\text { market power in } \\
\text { physician market, } \\
\text { therefore foreclosure } \\
\text { impossible. MFN } \\
\text { clauses simply lower } \\
\text { prices, therefore } \\
\text { procompetitive. }\end{array}$ \\
\hline 1982 & Hyde (Physician vs. Hospital) ${ }^{3}$ & $\begin{array}{l}\text { Exclusive Dealing (between } \\
\text { hospital and physician group) }\end{array}$ & Hospital & $\begin{array}{l}\text { Exclusive dealing } \\
\text { promotes efficiency } \\
\text { and quality. } \\
\text { Competition not } \\
\text { harmed by exclusion } \\
\text { of one physician. }\end{array}$ \\
\hline 1988 & $\begin{array}{l}\text { Oltz (Nurse Anesthetist v. } \\
\text { Hospital) }\end{array}$ & $\begin{array}{l}\text { Exclusive Dealing (hospital } \\
\text { and anesthesiologist group) }\end{array}$ & Nurse & $\begin{array}{l}\text { Exclusive deal } \\
\text { shielded } \\
\text { anesthesiologists } \\
\text { from competition. }\end{array}$ \\
\hline 1990 & $\begin{array}{l}\text { Ocean State (Physicians vs. } \\
\text { Insurer) }\end{array}$ & Most-Favored-Nations Clause & Insurer & $\begin{array}{l}\text { MFN clause did not } \\
\text { reduce physician } \\
\text { competition. }\end{array}$ \\
\hline 1990 & Reazin (Hospital v. Insurer) ${ }^{6}$ & Most-Favored-Nations Clause & Hospital & $\begin{array}{l}\text { Blue Cross } \\
\text { monopolized } \\
\text { insurance market, in } \\
\text { part through use of } \\
\text { MFN clause, which } \\
\text { prevented provider } \\
\text { discounts to other } \\
\text { payers. }\end{array}$ \\
\hline 1996 & $\begin{array}{l}\text { Delta Dental (FTC vs. } \\
\text { Insurer) }\end{array}$ & Most-Favored-Nations Clause & Government & $\begin{array}{l}\text { MFN clause reduced } \\
\text { dentist competition; } \\
\text { made dental } \\
\text { insurance market } \\
\text { entry difficult. }\end{array}$ \\
\hline
\end{tabular}


${ }^{1}$ HTI Health Services, Inc. vs. Quorum Health Group, Inc., River Regional Medical Corporation, and Vicksburg Clinic, P.A. U.S. District Court for the Southern District of Mississippi, Western Division (Civil Action No. 5:96CV-108Br(S)).

${ }^{2}$ Blue Cross/Blue Shield United of Wisconsin and Compcare Health Services Insurance Corporation v. Marshfield Clinic and Security Health Plan of Wisconsin in the U.S. Court of Appeals for the Seventh Circuit (Nos. 95-1965, 952140).

3 Jefferson Parish Hospital Dist. No. 2 v. Hyde (466 U.S. 2, 1984, O'Connor, Burger, Powell \& Rehnquist, JJ., concurring)

${ }^{4}$ Oltz v. St. Peter's Community Hospital (9 ${ }^{\text {th }}$ Circuit, 1988, 861 F.2d 1440).

${ }^{5}$ Ocean State Physicians Health Plan, Inc., et al. v. Blue Cross and Blue Shield of Rhode Island (1 ${ }^{\text {st }}$ Circuit, 1989, $883^{\text {F.2d 1101 }}$ ) cert. Denied (1990, 494 U.S. 1027).

${ }^{6}$ Reazin v. Blue Cross \& Blue Shield of Kan., Inc., 663 F. Supp. 1360, 1418 (D. Kan. 1987), aff'd, 899 F.2d 951

(10th Cir.), cert. denied, 497 U.S. 1005 (1990).

${ }^{7}$ U.S. v. Delta Dental of Rhode Island, 96-113/P, 1996 WL 570397 (D.R.I. Oct. 2, 1996). 